\title{
POWER QUALITY ANALYSIS OF A THREE-PHASE CYCLOCONVERTER UNDER VARIABLE OPERATING CONDITIONS
}

\author{
A Thesis \\ presented to \\ the Faculty of California Polytechnic State University, \\ San Luis Obispo
}

\author{
In Partial Fulfillment \\ of the Requirements for the Degree \\ Master of Science in Electrical Engineering
}

by

Kevin Palani

June 2010 
(C) 2010

Kevin Palani

ALL RIGHTS RESERVED 


\section{COMMITTEE MEMBERSHIP}

TITLE:

AUTHOR:

DATE SUBMITTED:

COMMITTEE CHAIR:

COMMITTEE MEMBER:

COMMITTEE MEMBER:
Power Quality Analysis of a Three-Phase

Cycloconverter under Variable Operating Conditions

Kevin Palani

June 2010

Dr. Taufik, Professor

Dr. Ahmad Nafisi, Professor

Dr. Ali O. Shaban, Professor 


\author{
ABSTRACT \\ Power Quality Analysis of a Three-Phase Cycloconverter \\ under Variable Operating Conditions
}

\title{
Kevin Palani
}

June 2010

The objective of this study is to observe the correlations between variable operating conditions and power quality parameters for a three-phase to single-phase cycloconverter. The cycloconverter is examined in its most straightforward form without additional output filters or elaborate control methods. Variable operating conditions include input frequency, output frequency, and resistive load size. The power quality parameters of interest are power factor, input current total harmonic distortion (THD), output voltage THD, and efficiency. The scope of the project includes analytical calculations, PSpice simulations, as well as a hardware implementation. The results show that output frequency has minimal effect on power quality. High input frequencies tend to yield less efficiency and larger loads yield higher efficiency. Total harmonic distortion undesirably peaks at a combination of low input frequency and high output frequency. Extrapolations can be made for the cycloconverter operating at different frequencies and loads based on the trends observed within the test matrix.

Keywords: three phase cycloconverter, power quality 


\section{ACKNOWLEDGEMENTS}

It is an honor for me to thank the people who made this thesis possible. First, I would like to thank Dr. Taufik for his continued guidance and support during the course of this thesis as well as during my career at Cal Poly. Dr. Taufik shows great dedication to his students as a professor, thesis advisor, and friend. I would also like to thank other faculty members as well as fellow students, who provided assistance and kept me on track when I encountered obstacles.

I would not have been able to finish this project without the help of J.T. Matherly at Enerpro, Inc. A large portion of the cycloconverter hardware including two firing boards, six SCR modules, and heatsink were loaned to me by Enerpro. Without this, I would not have been able to make the hardware measurements. Thank you J.T. for arranging all of this as well as for always answering any question I had.

Last but not least, I would like to thank my family. They have continued to support my thesis and career at Cal Poly. Their optimism and encouragement have allowed me to overcome any obstacle that I face. I would not be here today without their undivided support. 


\section{TABLE OF CONTENTS}

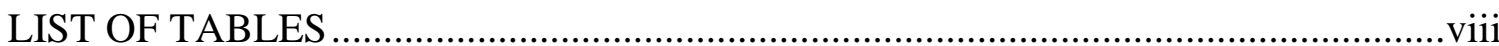

LIST OF FIGURES …………………………………......................................... ix

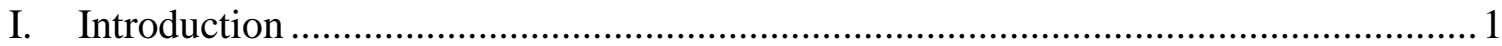

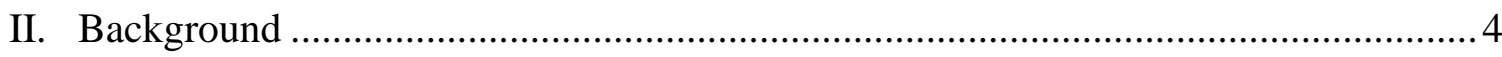

2.1. Ideal Single-Phase/Single-Phase Cycloconverter ................................................ 6

2.2. Ideal Three-Phase/Single-Phase Cycloconverter............................................... 9

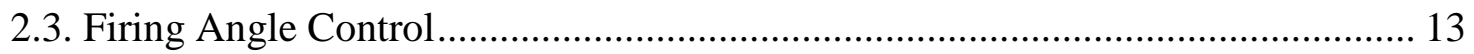

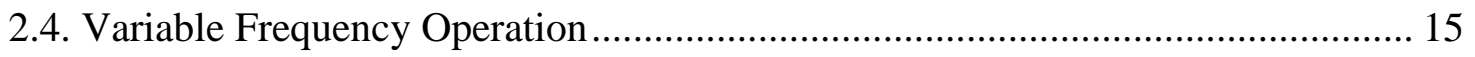

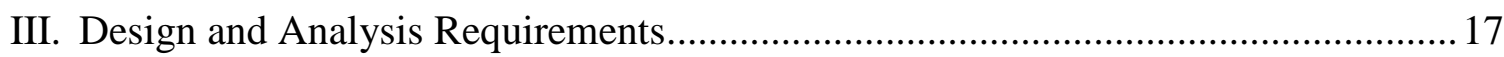

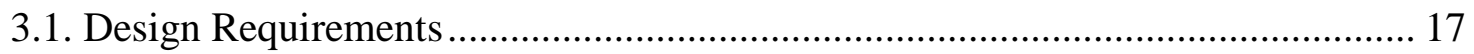

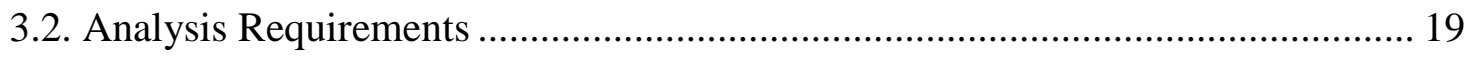

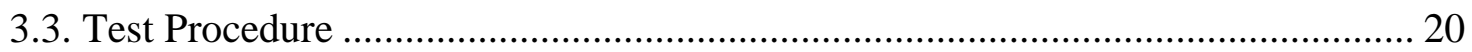

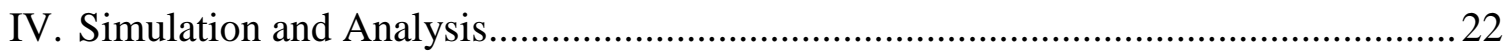

4.1. Preliminary Switching Loss Analysis .............................................................. 22

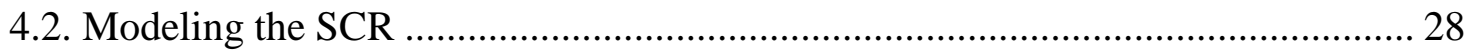

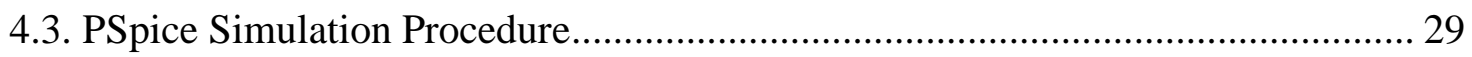

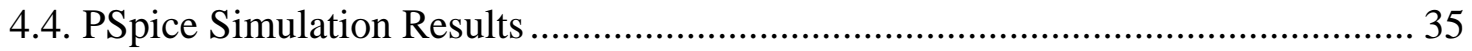

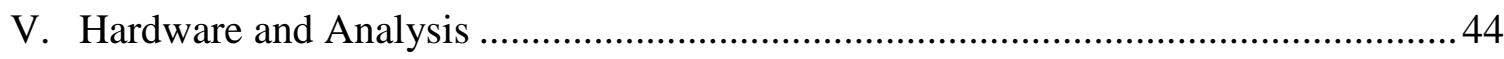

5.1. Hardware Components ................................................................................. 44

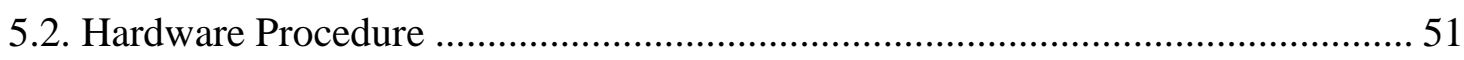

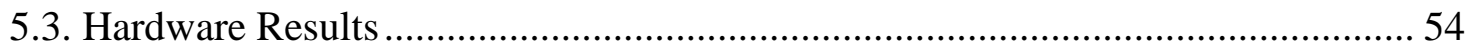

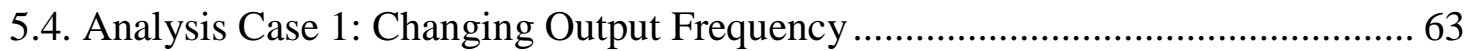




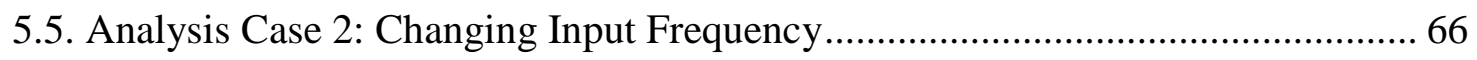

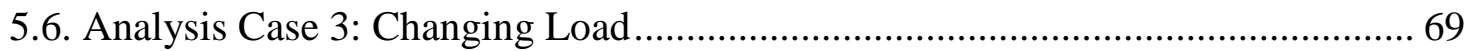

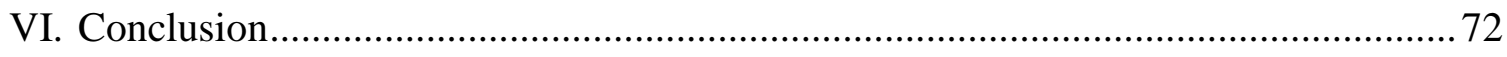

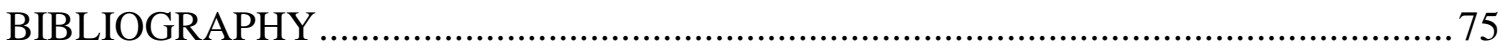




\section{LIST OF TABLES}

Table 2-1. Switch Conduction for Single-Phase/Single-Phase Cycloconverter ................ 7

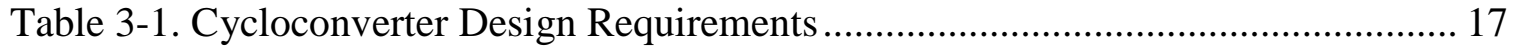

Table 3-2. Cycloconverter Power Quality Analysis Requirements ................................ 19

Table 4-1. Estimated Parameters for Modeling Switching Loss ................................... 24

Table 4-2. Calculated Switching Loss and Efficiency Values...................................... 27 


\section{LIST OF FIGURES}

Figure 1-1. Power electronics block diagram ........................................................... 1

Figure 2-1. Single-phase/single-phase cycloconverter diagram ........................................ 6

Figure 2-2. Theoretical single-phase/single-phase cycloconverter waveforms .................. 8

Figure 2-3. Three-phase/single-phase cycloconverter diagram ........................................ 9

Figure 2-4. Three-phase/single-phase cycloconverter waveforms .................................. 10

Figure 2-5. Three-phase/single-phase cycloconverter waveforms, continued.................. 11

Figure 2-6: Theoretical cycloconverter frequency spectra ………………………....... 12

Figure 2-7. Three-phase/single-phase cycloconverter waveforms, CWC method ........... 14

Figure 2-8. Theoretical cycloconverter frequency spectrum, CWC method .................... 15

Figure 3-1. Simplified cycloconverter block diagram .................................................. 20

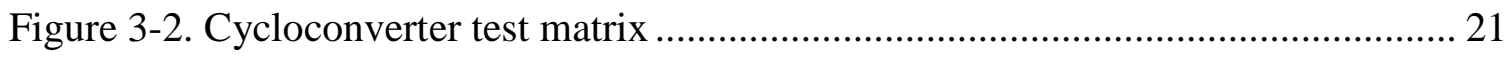

Figure 4-1. Thyristor: (a) symbol and (b) current-voltage characteristics ....................... 23

Figure 4-2. Theoretical switching waveforms for one input period ................................ 26

Figure 4-3. Theoretical efficiency of a three-phase input cycloconverter ........................ 27

Figure 4-4. Simple SCR model for PSpice simulation ................................................. 29

Figure 4-5. Simulated 200W, 180Hz:30Hz cycloconverter waveforms .......................... 31

Figure 4-6. Simulated 200W, 400Hz:30Hz cycloconverter waveforms ......................... 33

Figure 4-7. Simulated 200W, 400Hz:30Hz cycloconverter frequency spectra ................ 34

Figure 4-8. Simulated input power factor at 122V/100W load ....................................... 35

Figure 4-9. Simulated input power factor at 122V/200W load ...................................... 36

Figure 4-10. Simulated input power factor at 122V/300W load ...................................... 36

Figure 4-11. Simulated input total harmonic distortion at 122V/100W load ................... 38 
Figure 4-12. Simulated input total harmonic distortion at 122V/200W load 38

Figure 4-13. Simulated input total harmonic distortion at 122V/300W load 39

Figure 4-14. Simulated output total harmonic distortion at 122V/100W load 40

Figure 4-15. Simulated output total harmonic distortion at 122V/200W load 40

Figure 4-16. Simulated output total harmonic distortion at 122V/300W load 41

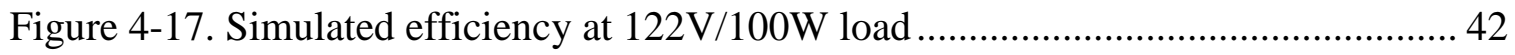

Figure 4-18. Simulated efficiency at 122V/200W load ............................................ 42

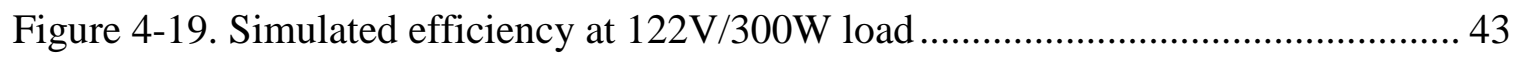

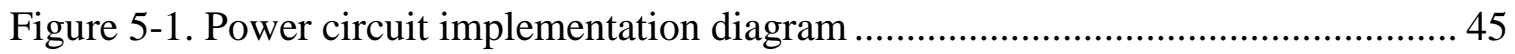

Figure 5-2. Photo of hardware power circuit ....................................................... 45

Figure 5-3. Enerpro FCOVF6100 firing board schematic ........................................... 47

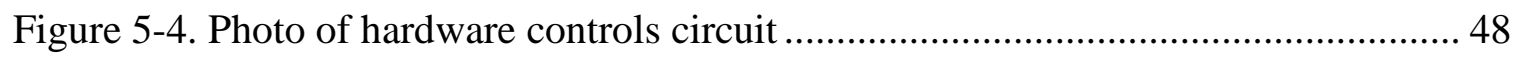

Figure 5-5. Photo of hardware test bench setup................................................ 51

Figure 5-6. Oscilloscope captures of SCR gating signals ........................................ 53

Figure 5-7. Oscilloscope captures of input voltage and current waveforms.................... 54

Figure 5-8. Oscilloscope captures of output voltage and current waveforms.................. 55

Figure 5-9. Experimental 200W, 400Hz:30Hz cycloconverter frequency spectra .......... 55

Figure 5-10. Experimental input power factor at 122V/100W load .............................. 56

Figure 5-11. Experimental input power factor at 122V/200W load ............................ 57

Figure 5-12. Experimental input power factor at 122V/300W load ............................. 57

Figure 5-13. Experimental input total harmonic distortion at 122V/100W load............. 58

Figure 5-14. Experimental input total harmonic distortion at 122V/200W load............. 58

Figure 5-15. Experimental input total harmonic distortion at 122V/300W load ............. 59 
Figure 5-16. Experimental output total harmonic distortion at 122V/100W load........... 60

Figure 5-17. Experimental output total harmonic distortion at 122V/200W load........... 60

Figure 5-18. Experimental output total harmonic distortion at 122V/300W load........... 61

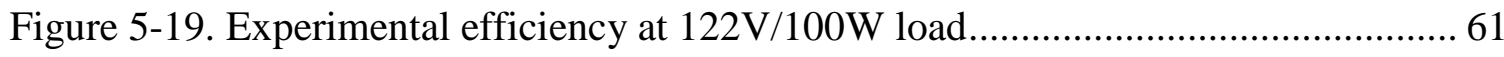

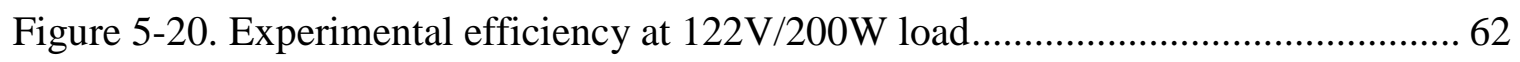

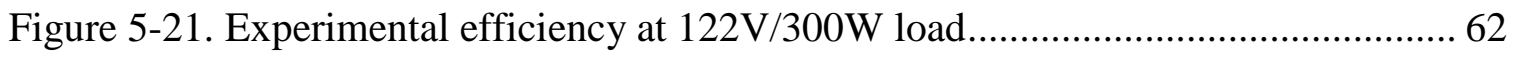

Figure 5-22. Input power factor comparison at 200W load, interval output frequency ... 63

Figure 5-23. Input THD comparison at 200W load, interval output frequency ............... 64

Figure 5-24. Output THD comparison at 200W load, interval output frequency ............. 65

Figure 5-25. Efficiency comparison at 200W load, interval output frequency ............... 65

Figure 5-26. Input power factor comparison at 200W load, interval input frequency ..... 66

Figure 5-27. Input THD comparison at 200W load, interval input frequency ................ 67

Figure 5-28. Output THD comparison at 200W load, interval input frequency.............. 67

Figure 5-29. Efficiency comparison at 200W load, interval input frequency .................. 68

Figure 5-30. Input power factor comparison at $60 \mathrm{~Hz}$ output, interval loads .................. 69

Figure 5-31. Input THD comparison at $60 \mathrm{~Hz}$ output, interval loads ........................... 70

Figure 5-32. Output THD comparison at $60 \mathrm{~Hz}$ output, interval loads ......................... 70

Figure 5-33. Efficiency comparison at $60 \mathrm{~Hz}$ output, interval loads ............................ 71 


\section{Introduction}

The vast majority of today's industrial and commercial electronic systems use electrical energy. In order for these systems to function, power must be delivered from a source to a load. The main problem is that there is not a single universal form of power. First and foremost, there are the two standards of direct current (DC) and alternating current (AC). In addition, there can be variable amplitudes, as well as variable frequencies and multiple phases for AC. In most cases the form of the input source is different from the load requirements. An example is a high voltage transmission system interfacing with a lower voltage distribution system. This brings about the need for conversion between these different forms of electrical power via power electronics.

Power electronics refer to the conversion of electrical power using a power circuit and a control circuit. The basic block diagram of a conversion system is shown in Figure 1-1.

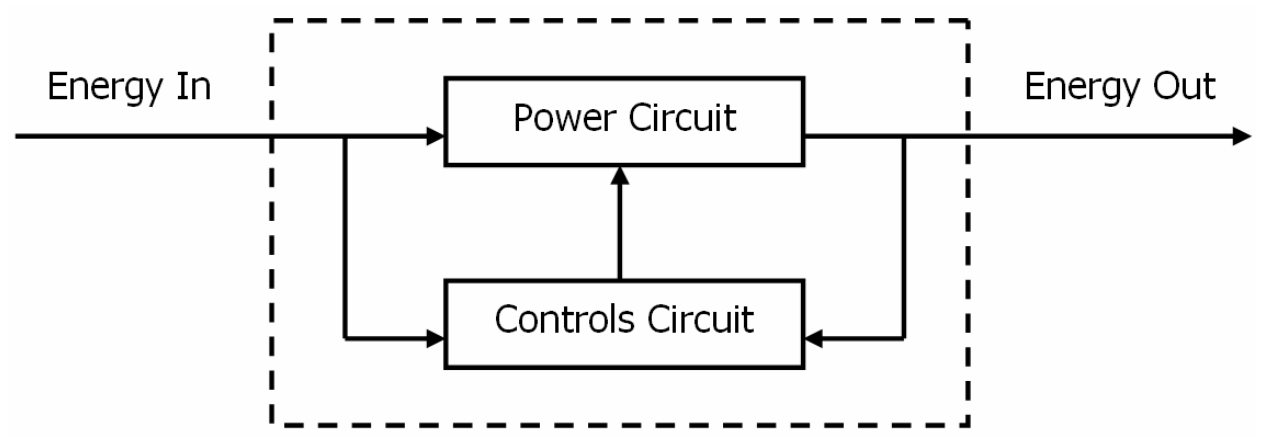

Figure 1-1. Power electronics block diagram

The power circuit contains the necessary solid-state switches and circuitry to process the electrical power from one form to another. The controls circuit drives the solid-state devices with the necessary logic. There is also feed-forward from the input or feedback from the output to create a closed loop system. This is important for example to achieve 
line or load regulation. In addition to the circuit elements above, there may also be input and output filters to reduce unwanted high frequency noise. This high frequency noise comes mostly from switching action that creates harmonics to the voltage or current waveforms. This occurs at both the input and output of the circuit. If ignored, these harmonics can interfere with performance and proper operation of equipment connected at either the source or the load.

Power electronics encompasses four main power conversions. The first is from AC to DC, commonly known as rectification. This supplies power from an AC source to a DC load. A major use of rectifiers is in consumer electronics power supplies. The next conversion is from DC to AC, also known as inversion. The concept is the opposite of a rectifier. Major uses of inverters are for grid-connected solar panels and high-voltage direct current (HVDC) transmission lines. The third conversion is from DC to DC. This is a growing field of power conversion today, especially with its applications in consumer electronics and battery-powered devices. The final conversion is from AC to AC. This is generally used in high power applications, such as transferring power between power grids as well as driving variable frequency loads such as induction motors and synchronous motors.

Under AC to AC conversion, there are one-stage and two-stage approaches. In the two-stage approach, AC normally at a fixed frequency is first rectified to DC, and then inverted back to AC typically at various frequencies. This method is commonly found in motor drive applications such as the adjustable speed drives (ASD) to control the speed of induction motors. The one-stage method is also known as the direct method. Here the AC input is switched directly to another AC at varying RMS amplitude and/or 
frequency. One common application is the light dimmer. At high power levels, one application that makes use of the one stage method is the cycloconverter. In a cycloconverter, input may be single or multiphase and the output may be single or multiphase. The output is usually lower in frequency than the input. This thesis focuses on the study of cycloconverter performance. 


\section{Background}

A large percentage of electricity infrastructure in the world is based on AC. Generation, transmission, and distribution networks using $\mathrm{AC}$ have dated back to the 1800s. As such, AC to AC conversion is not a new topic. The conversion takes a given $\mathrm{AC}$ source and delivers $\mathrm{AC}$ power with different amplitude, frequency, or number of phases. For example, high voltage transmission can be converted to low voltage distribution via a step-down transformer. This is a simple way for a magnitude change. However, electricity networks and variable-speed motor drives show that magnitude conversion is not sufficient by itself.

As previously mentioned, there are two main approaches to AC-AC power conversion. The first one is the two-stage process called a DC-link converter. The concept is to first use a rectifier to change the input AC to a DC waveform. This DC stage will have capacitors and inductors to store energy from the input. This DC stage will then pass through and serve as the input to an inverter to produce the AC output waveform. Benefits of this system are the flexibility in output amplitude, frequency, and phase. However, with intermediate filters on the DC bus as well as output filters, the system is larger and more complex.

The second approach to AC-AC conversion is the one-stage method such as the cycloconverter. This avoids the intermediate DC bus and switches directly from the input $\mathrm{AC}$ waveform to create the output $\mathrm{AC}$ waveform. The benefits of this system are less filtering complexity and large power capability. However, there is an upper limit to the output frequency which is proportional to the input frequency. One of the first

commercially used cycloconverters was developed in 1930. German locomotive engines 
required a low frequency of $16.6 \mathrm{~Hz}$ in order to generate large amounts of torque. However, the electrical line frequency was $50 \mathrm{~Hz}$. A combination of a transformer and large tube thyristors allowed for obtaining the desired output amplitude and frequency. With advances in thyristor technology, cycloconverters are a very efficient and straightforward platform for very high power AC-AC conversion, typically in excess of $100 \mathrm{~kW}$.

A cycloconverter can be simplified as two converter bridges. One bridge, called the positive converter, supplies AC power to the load during the positive half cycle of the output. The second bridge, called the negative converter, supplies power to the load during the negative half cycle of the output. There are two possible modes of operation: circulating current mode and non-circulating current mode. Circulating current mode maintains simultaneous conduction of both bridges by placing reactors between the bridges. Circulating current maintains current flow across the converter bridges and prevents the output current from becoming discontinuous as a result of switching. The more popular mode is the non-circulating current mode. In this case, only one bridge is active at any given time. While one bridge is on, the other is off and vice-versa. This reduces the complexity of the circuit by removing the large and heavy reactors. Efficiency is also improved, since the circulating current mode exhibits power loss from circulating current through the reactors and idle converters. This thesis will cover the non-circulating current operation of a cycloconverter. 


\subsection{Ideal Single-Phase/Single-Phase Cycloconverter}

The most straightforward cycloconverter is a single-phase/single-phase cycloconverter. This takes a single-phase input and converts it to a single-phase output with different magnitude and frequency. Figure 2-1 shows a schematic of the singlephase to single-phase cycloconverter.

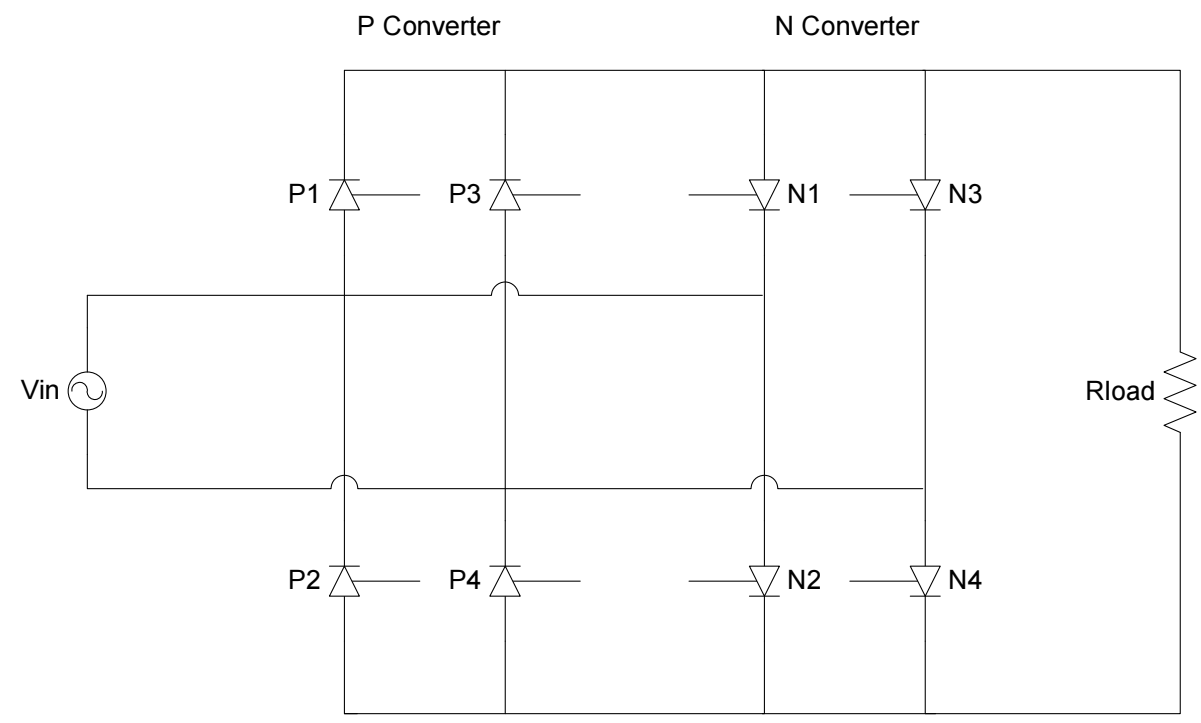

Figure 2-1. Single-phase/single-phase cycloconverter diagram

Assume the input voltage has arbitrary magnitude, $V_{m}$, and frequency, $\mathrm{f}_{\mathrm{i}}$. The phase angle, $\varphi$, will be zero for this case. The mathematical representation is shown below.

$$
V_{\text {in }}(t)=\sqrt{2} V_{L N} \sin \left(2 \pi f_{i} t+\phi\right)=V_{m} \sin \left(2 \pi f_{i} t\right)=V_{m} \sin (\theta)
$$

In order to find the voltage at the load, the diode conduction rule is used. The rule states that the most positive anode conducts while the most negative cathode conducts. This means that for every positive half cycle of $\mathrm{V}_{\text {in }}$, switches $\mathrm{P} 1$ and P4 will be conducting for the positive converter. Switches N3 and N2 will be conducting for the negative converter. Similarly, for every negative half cycle of $\mathrm{V}_{\text {in }}$, switches P3 and P2 will be conducting for the positive converter and switches N1 and N4 will be conducting for the 
negative converter. A summary of switch conduction is shown in Table 2-1 with $\theta=2 \pi f_{i} t$

Table 2-1. Switch Conduction for Single-Phase/Single-Phase Cycloconverter

\begin{tabular}{|c|c|c|c|c|c|c|c|c|}
\hline Vin & \multicolumn{3}{|c|}{ N Converter } & \multicolumn{4}{c|}{ P Converter } \\
\hline Range of $\boldsymbol{\theta}$ & N1 & N2 & N3 & N4 & P1 & P2 & P3 & P4 \\
\hline $\mathbf{0}<\boldsymbol{\theta}<\boldsymbol{\pi}$ & OFF & ON & ON & OFF & ON & OFF & OFF & ON \\
\hline $\boldsymbol{\pi}<\boldsymbol{\theta}<\mathbf{2} \boldsymbol{\pi}$ & ON & OFF & OFF & ON & OFF & ON & ON & OFF \\
\hline
\end{tabular}

The aspect of adjustable output frequency relates to the duration of time the converter bridges are on. Only one converter bridge can be on at a given time to avoid cross-firing the switches and creating a short circuit across the source. Given a particular output frequency, the necessary conduction period of each converter can be calculated using the following Equation 2-2.

$$
T_{P-o n}=T_{N-o n}=\frac{1}{2 f_{o}}
$$

It is important for $\mathrm{T}_{\mathrm{P} \text {-on }}$ to equal $\mathrm{T}_{\mathrm{N} \text {-on }}$ in order to have a net $\mathrm{DC}$ voltage across both converters equal to zero. This means that only AC voltage will be transferred to the load.

In order to control the magnitude of the output voltage, the firing angle is adjusted. The firing angle is defined as the delay angle before which the switch turns on at each conduction interval. In order for this to be achieved, the switch control voltage must be phase-locked onto the input voltage. The firing angle is defined to be zero at local maxima of the input voltage. This gives a possible range of 0 degrees to 180 degrees of firing angle location. At the firing angle location, the switch starts conducting. Since the switches for cycloconverters are generally thyristors, they will turn off when the anode-cathode voltage is less than zero. This will be later discussed in detail in the section on switching analysis. The switching functionality can be seen in Figure 2-2 for a 
typical single-phase/single-phase cycloconverter with output frequency equal to a fourth of the input frequency.

(a)

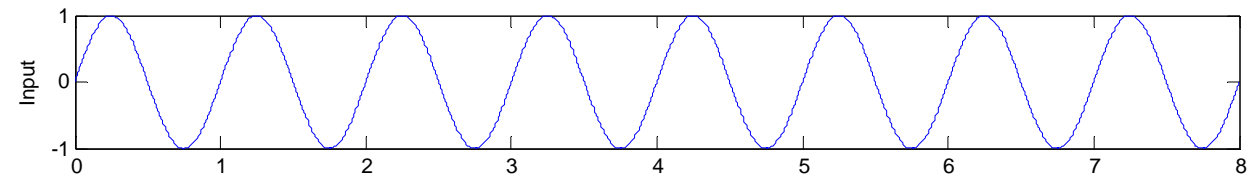

(b)

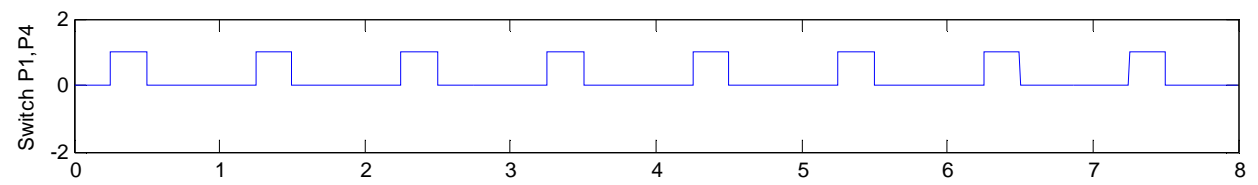

(c)

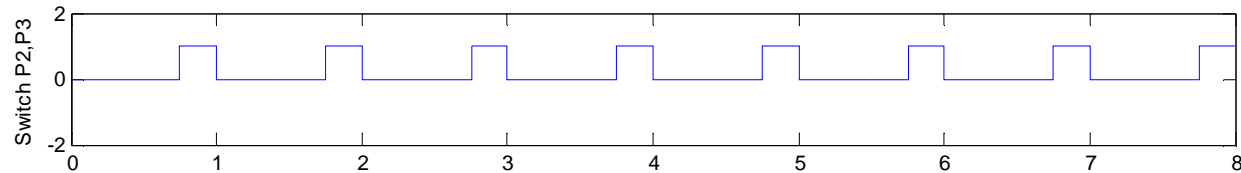

(d)

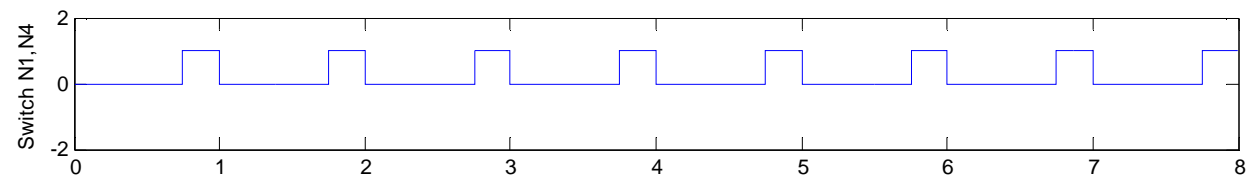

(e)

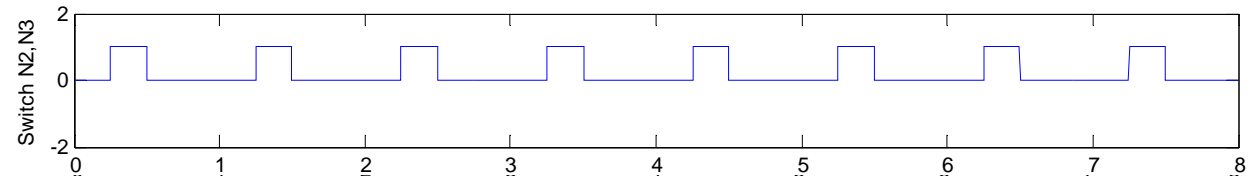

(f)

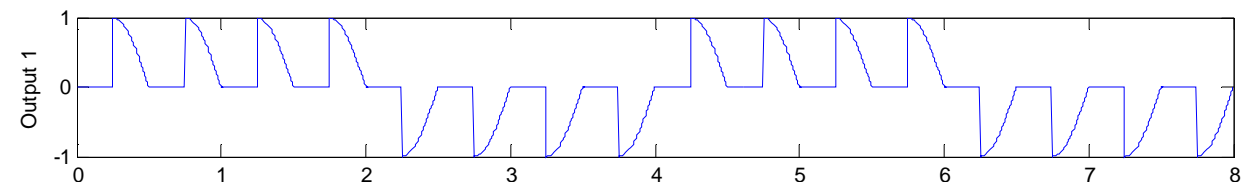

(g)

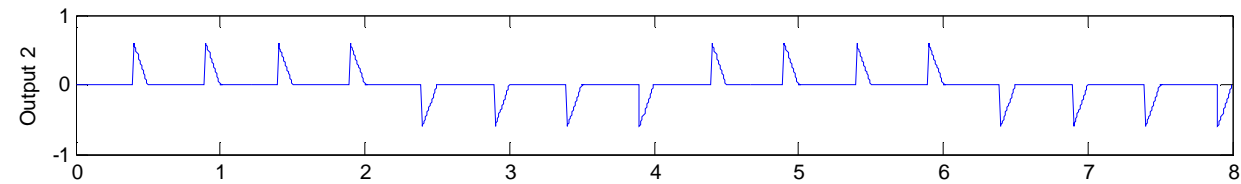

(h)

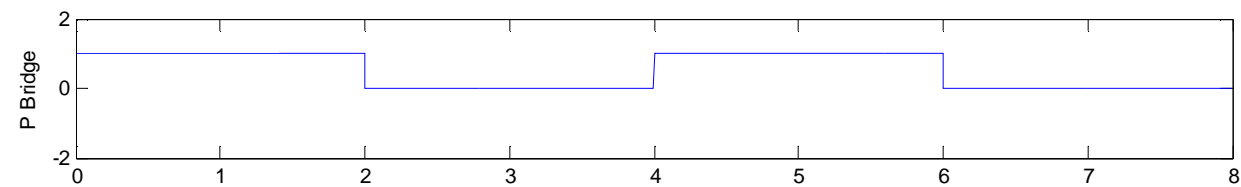

(i)

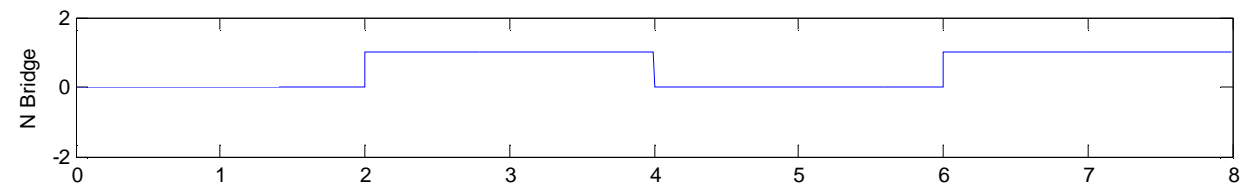

Figure 2-2. Theoretical single-phase/single-phase cycloconverter waveforms, fi/fo=4: (a) Vin, (b)-(e) switch conduction, (f) Vout at low firing angle, (g) Vout at high firing angle, (h) positive converter status, (i) negative converter status 


\subsection{Ideal Three-Phase/Single-Phase Cycloconverter}

An adaptation of the single-phase/single-phase cycloconverter is to increase the number of input phases. This has two important benefits. The first being a larger average output voltage at each converter bridge for the same firing angle. The second benefit has to do with the waveform shape. A three-phase AC input allows for six phase controlled out pulses per input cycle as opposed to only two pulses from a single-phase input. This increases the amount of switching for a given period which results in relatively higher frequency switching harmonics. This reduces the filtering requirements in order to make a more sinusoidal output. The major drawback is the increase in number of switches from eight to twelve as seen below in Figure 2-3.

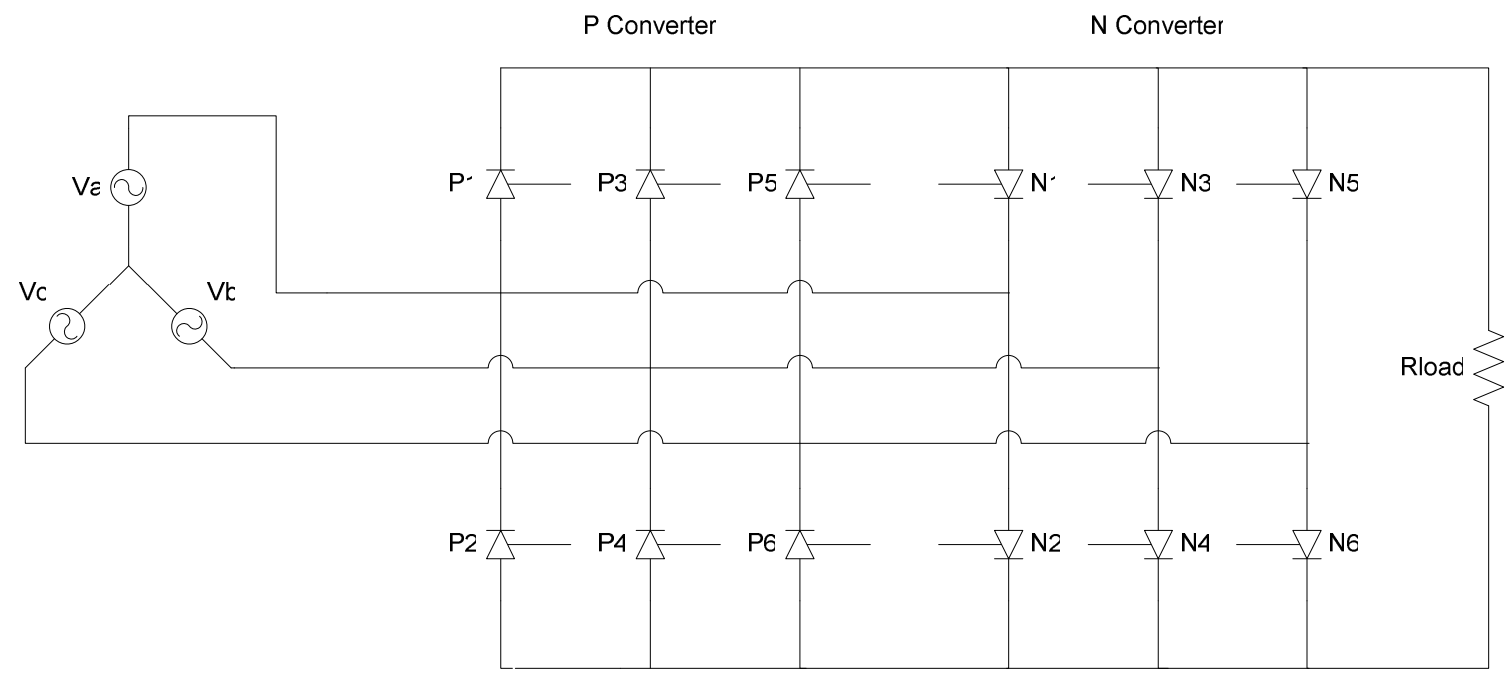

Figure 2-3. Three-phase/single-phase cycloconverter diagram

Analysis of this cycloconverter configuration is very similar to the previous case.

The input voltages are defined as shown below.

$$
\begin{gathered}
V_{a n}(t)=\sqrt{2} V_{L N} \sin \left(2 \pi f_{i} t+\phi\right)=V_{m} \sin \left(2 \pi f_{i} t\right) \\
V_{b n}(t)=\sqrt{2} V_{L N} \sin \left(2 \pi f_{i} t+\phi\right)=V_{m} \sin \left(2 \pi f_{i} t-2 \pi / 3\right)
\end{gathered}
$$




$$
V_{c n}(t)=\sqrt{2} V_{L N} \sin \left(2 \pi f_{i} t+\phi\right)=V_{m} \sin \left(2 \pi f_{i} t-4 \pi / 3\right)
$$

Next, the switching conduction waveform can be defined. Switches 1, 3, and 5 start conducting at the maxima of $\mathrm{V}_{\mathrm{an}}, \mathrm{V}_{\mathrm{bn}}$, and $\mathrm{V}_{\mathrm{cn}}$ respectively. Switches 2, 4, and 6 start conducting at the minima of the input voltages. These locations correspond to a zero firing angle for each switch. The on period of each switch is equal to exactly a third of a cycle of the input sine wave. The corresponding switch conduction waveforms can be seen in Figure 2-4. The configuration is very similar to the cycloconverter operation of Section 2-1 but with a three-phase input. Figure 2-5 shows the output waveforms.

(a)

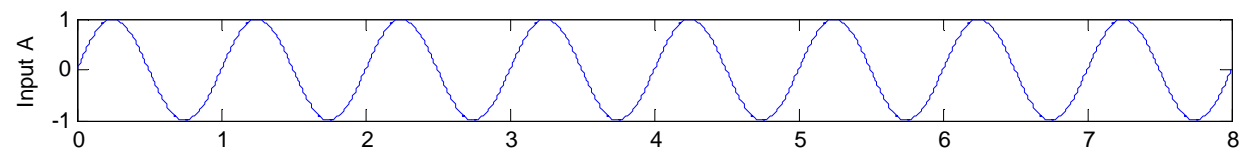

(b)

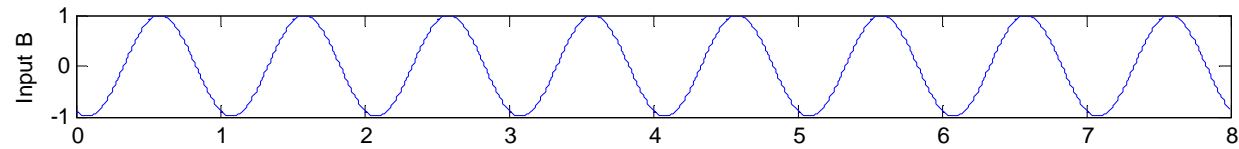

(c)

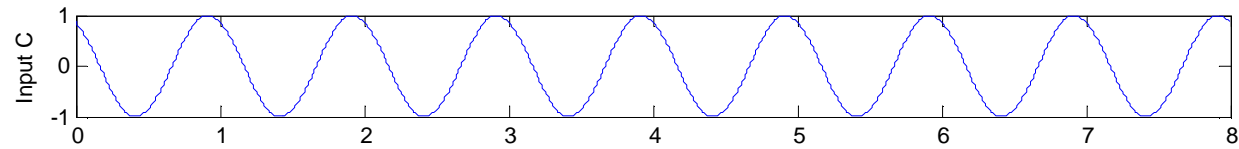

(d)

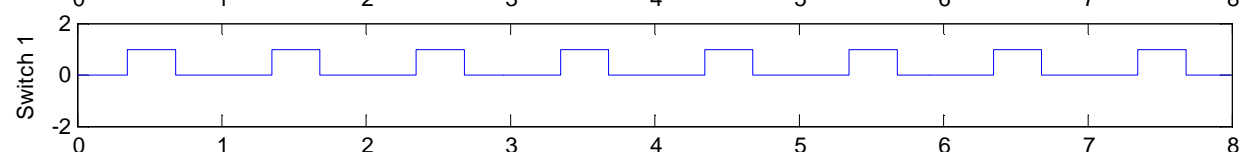

(e)

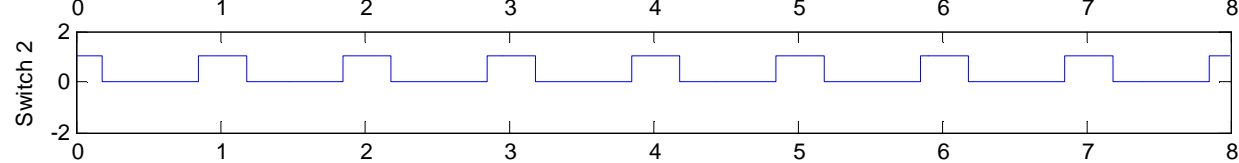

(f)

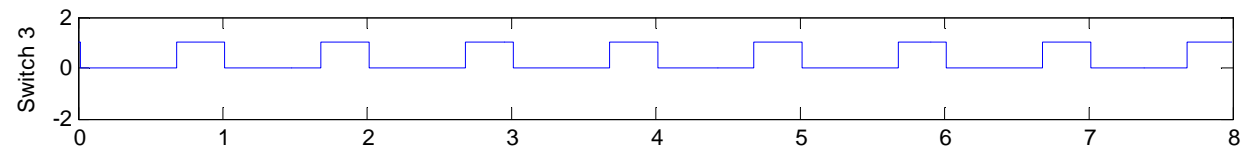

(g)

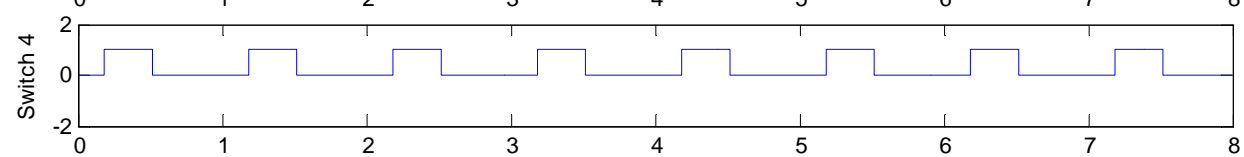

(h)

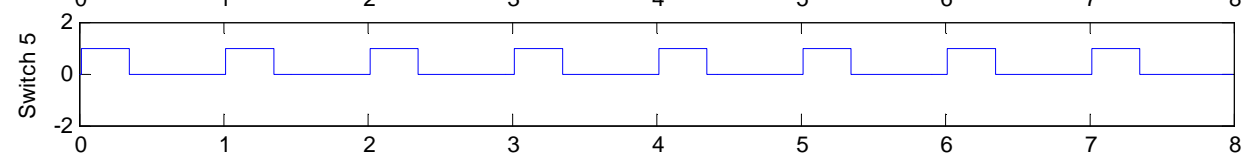

(i)

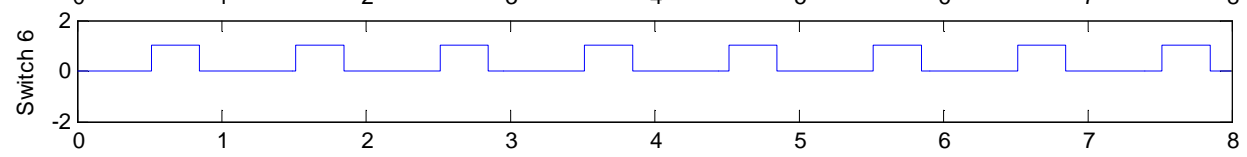

Figure 2-4. Three-phase/single-phase cycloconverter waveforms, fi/fo=4: (a)-(c) input voltage, (d)-(i) switch conduction for the positive converter (symmetrical for negative converter) 
(a)

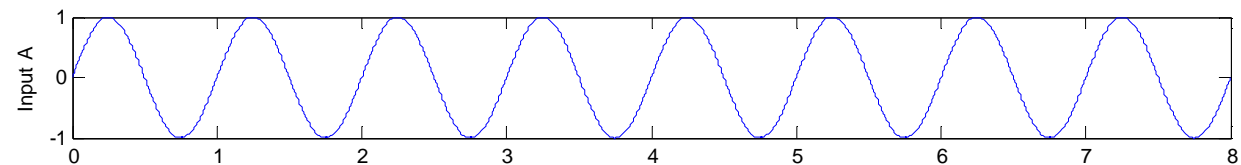

(b)

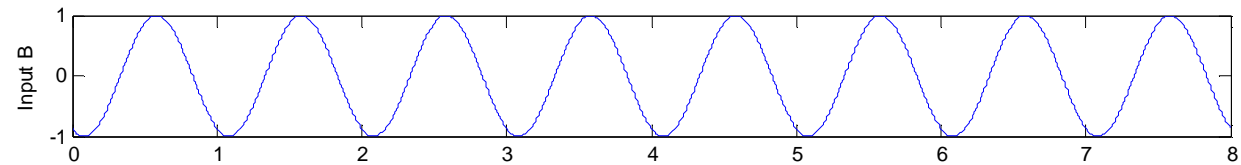

(c)

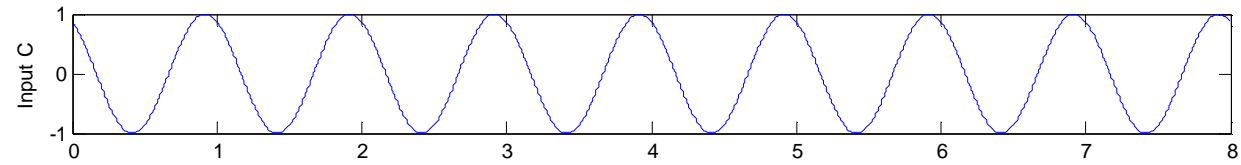

(d)

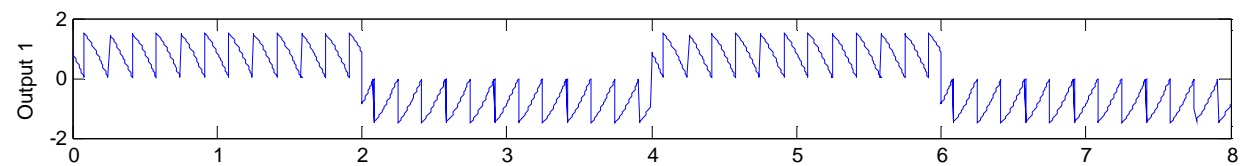

(e)

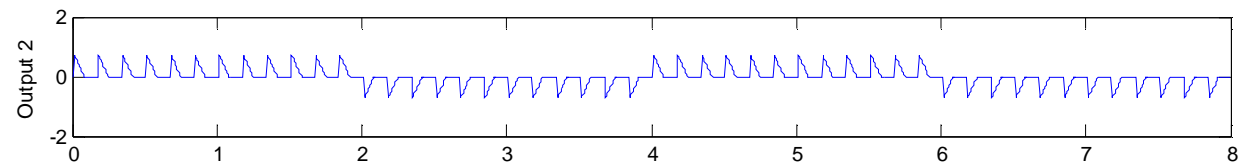

(f)

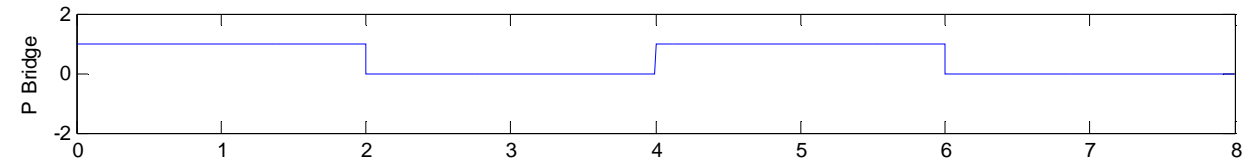

(g)

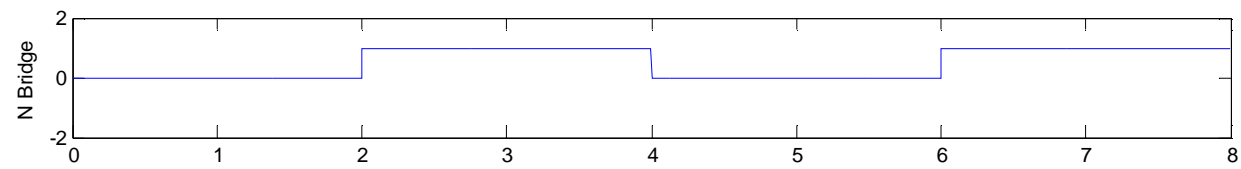

Figure 2-5. Three-phase/single-phase cycloconverter waveforms, continued: (a)-(c) input voltage, (d) $V_{\text {out }}$ at low firing angle, (e) $V_{\text {out }}$ at high firing angle, (f) positive converter status, (g) negative converter status

An important characteristic to note is the output ripple frequency. Initially, the ripple frequency is twice the input frequency for a single-phase/single-phase cycloconverter. By using a three phase input, the ripple frequency is six times the input frequency due to the six input pulses. In the frequency domain, the location of this harmonic is important because it determines filtering requirements. By taking the discrete Fourier Transform of the time domain voltage waveforms in Figure 2-2 and Figure 2-5, the frequency spectrum show the benefits of the three-phase cycloconverter over the single-phase cycloconverter due to lower amplitude and higher frequency location of the ripple component. These spectra are shown in Figure 2-6. 
(a)

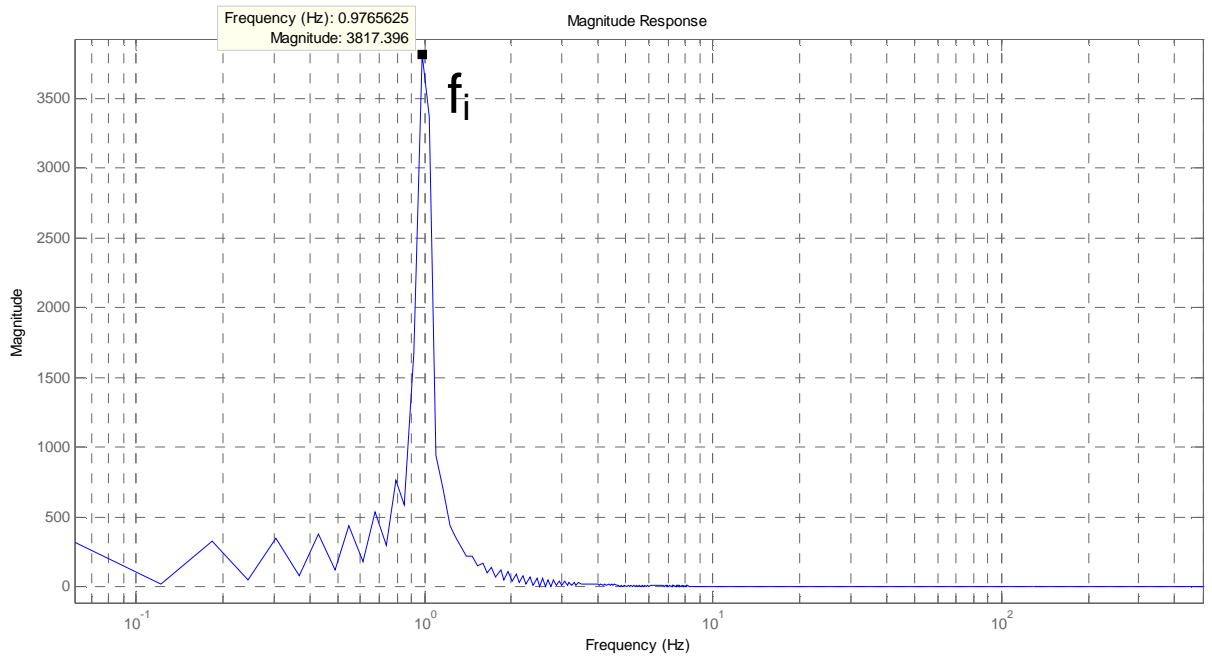

(b)
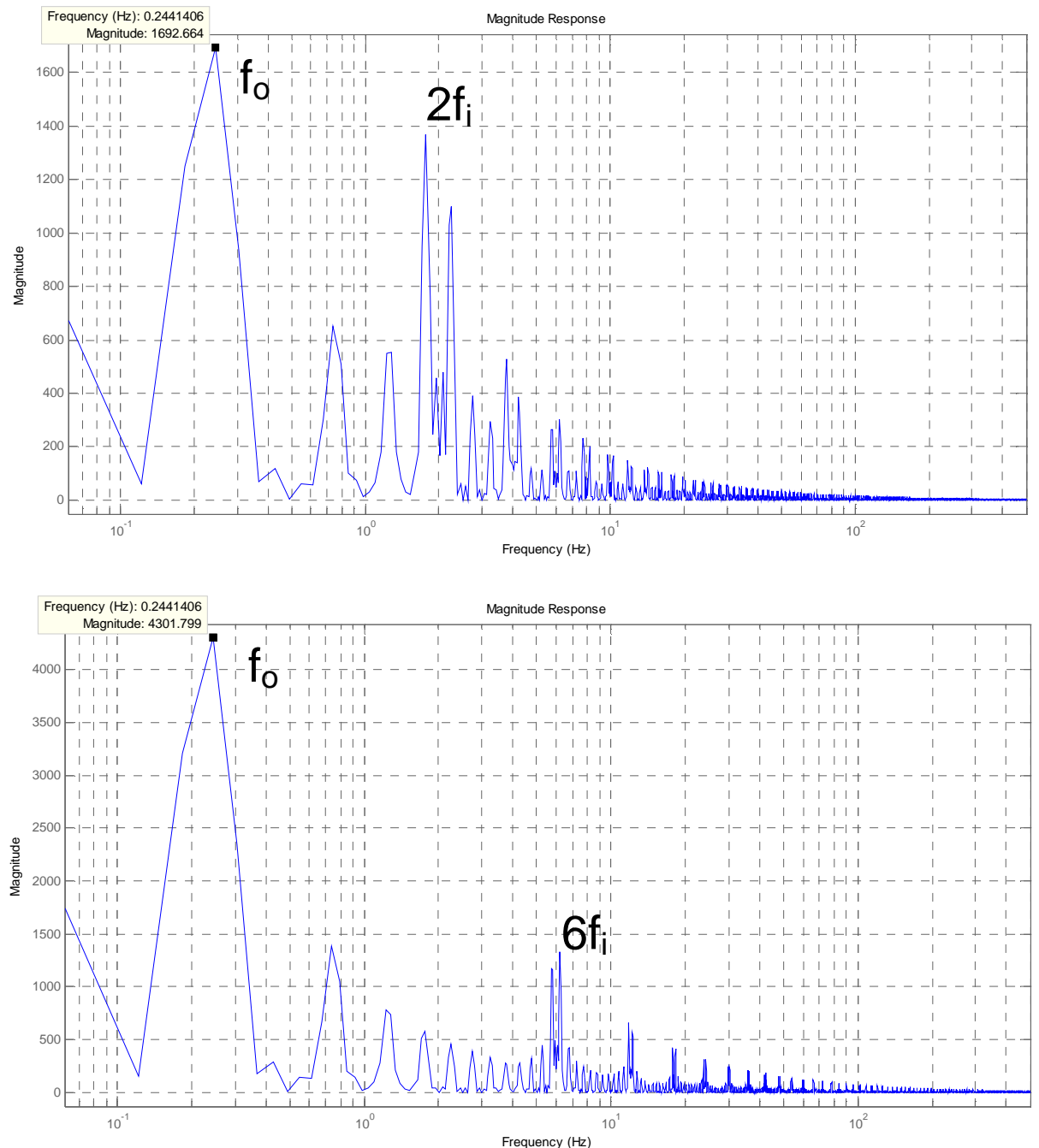

Figure 2-6: Theoretical cycloconverter frequency spectra: (a) input voltage, (b) single-phase cycloconverter output voltage, (c) three-phase cycloconverter output voltage 


\subsection{Firing Angle Control}

There are various ways to control the firing angle in cycloconverter operation. Firing angle control is important because the output waveform should contain the least distortion possible. The previous sections have dealt with fixed firing angle operation. This is the simplest method of cycloconverter control as each switch turns on at a constant interval. An example of this is shown in Figure 2-5 for a three-phase to singlephase cycloconverter. The drawback is that this is the worst case scenario of output waveform quality. Each bridge individually produces a constant average output voltage, proportional to the selected firing angle. Both bridges combined result in an average output voltage that is similar to a square wave and hence yields the appearance of harmonics at odd multiples of the input frequency.

A more common approach for dynamically determining the firing angles is the cosine wave crossing (CWC) method. This method compares the input waveform against a reference cosine wave. This reference cosine represents the desired output waveform in terms of both frequency and amplitude. When a particular input pulse intersects the reference wave, the corresponding switch relays that pulse to the output. This switch maintains conduction until the subsequent input pulse intersects the reference wave. At this point, the previous switch turns off and the subsequent switch turns on. The firing angle is directly related to when the input waveform intersects the reference waveform. If the amplitude of the cosine wave increases, the firing angle is smaller and the switches will conduct for a longer duration. This translates into a larger average output voltage as seen in Figure 2-7(b). The only concern is when the reference waveform has too low of a magnitude. In this case, the input waveform will almost always be larger than the 
reference voltage and the average output voltage is nearly constant. This is shown in Figure 2-7(d).

(a)

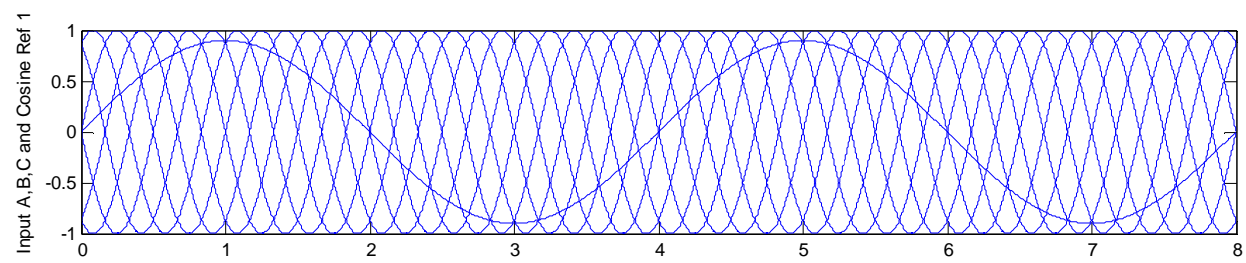

(b)

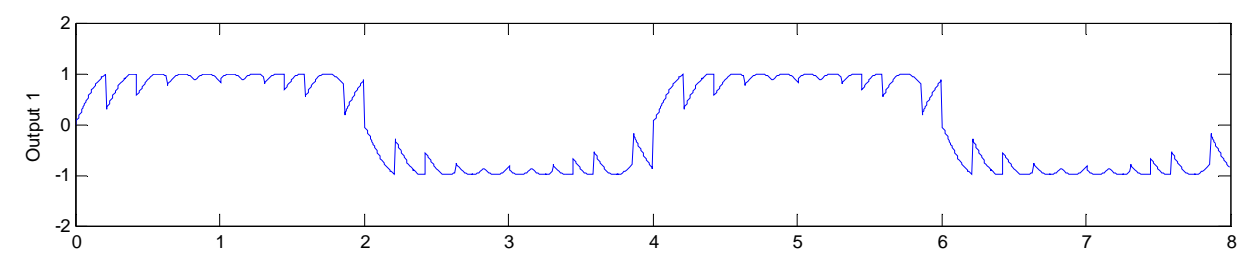

(c)

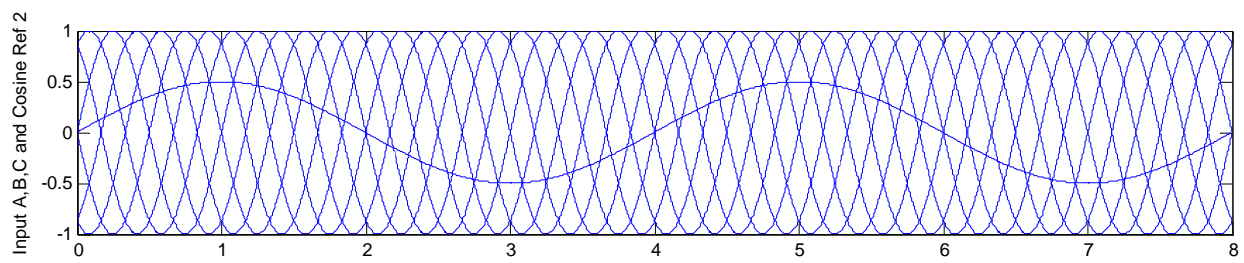

(d)

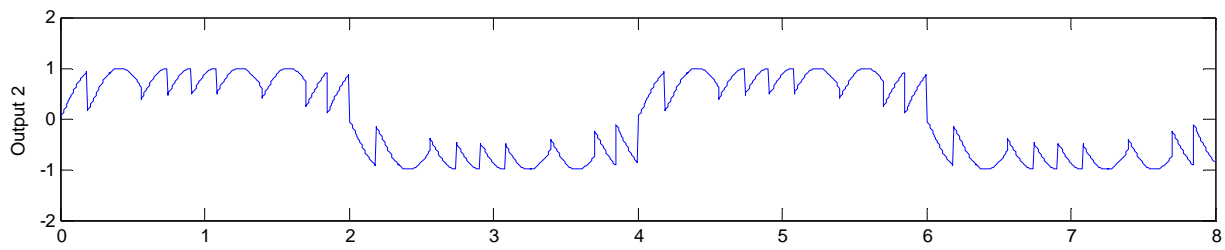

Figure 2-7. Three-phase/single-phase cycloconverter waveforms, CWC method: (a) input voltages and high amplitude reference cosine, (b) $V_{\text {out }}$ based on high amplitude reference cosine, (c) input voltages and low amplitude reference cosine, (d) $V_{\text {out }}$ based on low amplitude reference cosine

The benefit of the cosine wave crossing method is signal quality. The average of the waveform is more sinusoidal than with a fixed firing angle. This is confirmed by observing the frequency plot in Figure 2-8. The main drawback is complexity. Implementation would require sensing the input waveform and using comparators to determine the intersection points. This logic would only determine when the switches turn on. There must also be additional logic to turn off the switches in order to prevent cross-firing. Since the switch durations can vary dynamically, it is a more involved 
process to generate the switching controls. In order to observe cycloconverter operation in its most straightforward form, the cosine wave crossing method will not be used in later analysis. Fixed firing angles and switching durations will be generated similar to the ideal case outlined in Section 2-2.

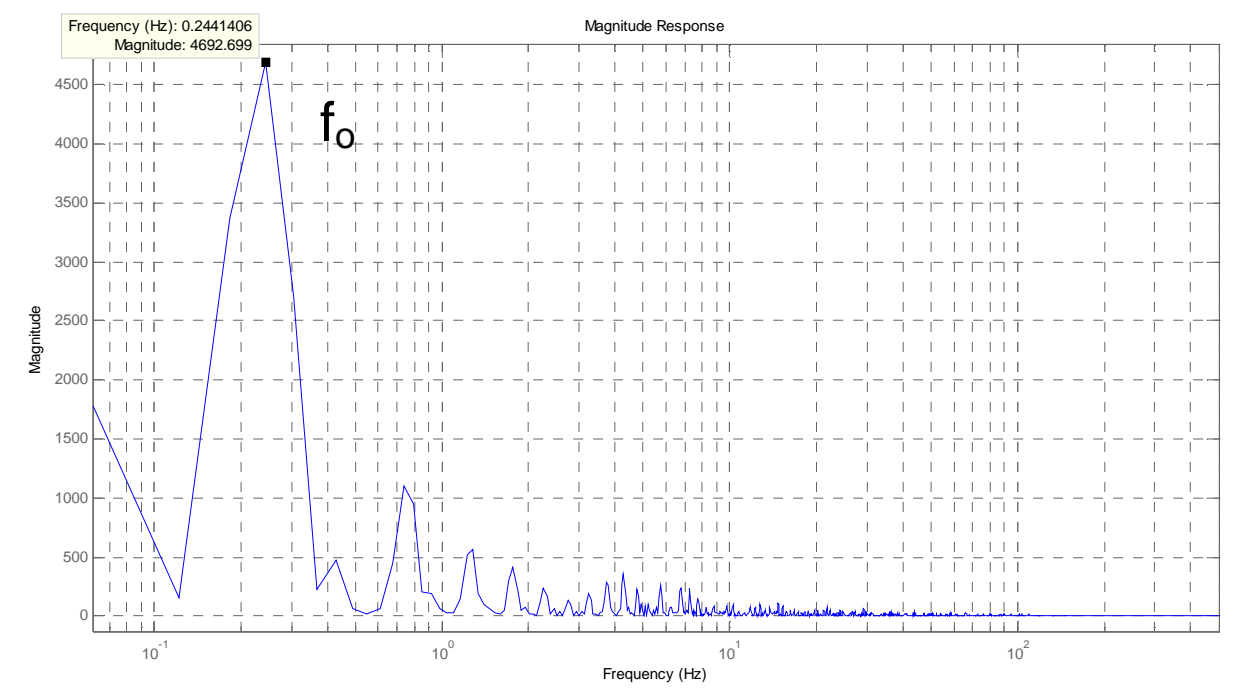

Figure 2-8. Theoretical cycloconverter frequency spectrum, CWC method, for three-phase cycloconverter output voltage

\subsection{Variable Frequency Operation}

One of the main goals of the cycloconverter is to allow for variable frequency operation. Input frequency is provided by the source. This is not controllable by the cycloconverter itself. On the other hand, variable output frequency is obtained by varying the periods of the positive and negative bridges, namely $\mathrm{T}_{\mathrm{P}-\mathrm{on}}$ and $\mathrm{T}_{\mathrm{N}-\mathrm{on}}$ as previously described in Section 2.1. This is executed entirely within the controls circuit. In many cases, the controls circuit will include a microcontroller. This microcontroller generates a clock signal that can be multiplied in order to represent the output waveform frequency. For each positive duration, this signal will correspond to $\mathrm{T}_{\mathrm{P}-\mathrm{on}}$ and each 
negative duration of this signal will correspond to $\mathrm{T}_{\mathrm{N} \text {-on }}$. Once again, only one bridge will be active for each half cycle.

There is an upper bound to the attainable output frequencies. For a single-phase to single-phase cycloconverter the output frequency cannot be greater than the input frequency. By observing Figure 2-2, the switches can conduct only once per half-cycle of the input. The output waveform requires a minimum of one positive pulse and one negative pulse to remain $\mathrm{AC}$ with no net DC component. For a three-phase to singlephase cycloconverter, the output frequency can be three times the input frequency. Figure 2-5 shows six input pulses in which the switches can conduct. Once again, the output waveform requires a positive and negative pulse. This results in a maximum of three output cycles per input cycle. A mathematical expression is shown below.

$$
f_{\text {out }} \leq f_{\text {in }} \cdot \frac{(\text { Number of Input Pulses })}{2}
$$

It is often desirable to have the output frequency not greater than the input frequency, even though the three-phase/single-phase cycloconverter allows for it. In terms of frequency spectrum, the output frequency location will increase while the ripple frequency harmonic is fixed based on the input frequency. If the output frequency is too close to the ripple frequency, the filtering requirements become much steeper. There is also the case in which the output frequency is the same as the ripple frequency. This occurs when both sides of the Equation 2-6 are equal. Although this may be desirable in theory, this is difficult to obtain in practice. The controls circuit must be able to set $\mathrm{T}_{\mathrm{P} \text {-on }}$ and $\mathrm{T}_{\mathrm{N} \text {-on }}$ precisely during the input pulses. This requires phase-locking for both the firing angles as well as the converter bridge conduction period. If the output frequency is kept sufficiently low, then only the firing angles require phase-locking. 


\section{Design and Analysis Requirements}

The main scope of this study is not based on cycloconverter design since cycloconverters have been around for many decades and there are industry standard implementations. Rather, the emphasis will be placed on performance analysis of a standard cycloconverter. In particular, the analysis will focus on cycloconverter power quality under variable input and output frequency operation. The power circuit and controls circuit will contain the necessary requirements for variable frequency operation for both the input and the output.

\subsection{Design Requirements}

The design requirements for this project are summarized in Table 3-1. The values defined under these requirements were chosen based on two main considerations:

- Results of this study will be a learning tool for the design of a power system distribution in a railway system

- The lab-scale prototype has to be tested based on the available equipment in the power electronics lab at Cal Poly

Table 3-1. Cycloconverter Design Requirements

\begin{tabular}{|c|c|c|}
\hline Location & Parameter & Requirement \\
\hline Input & Polyphase & Three-Phase \\
\cline { 2 - 3 } & Voltage & $120 \mathrm{~V}_{\mathrm{LN}-\mathrm{RMS}}$ \\
\cline { 2 - 3 } & Minimum Frequency & $180 \mathrm{~Hz}$ \\
\cline { 2 - 3 } & Maximum Frequency & $400 \mathrm{~Hz}$ \\
\hline Output & Polyphase & Single-Phase \\
\cline { 2 - 3 } & Voltage & $\sim 120 \mathrm{~V}_{\mathrm{RMS}}$ \\
\cline { 2 - 3 } & Power & $100 \mathrm{~W}, 200 \mathrm{~W}, 300 \mathrm{~W}$ \\
\cline { 2 - 3 } & Minimum Frequency & $30 \mathrm{~Hz}$ \\
\cline { 2 - 3 } & Maximum Frequency & $120 \mathrm{~Hz}$ \\
\hline
\end{tabular}


In summary, the system is a three-phase to single-phase cycloconverter. This is to simulate a diesel generator typically found in a locomotive. From the three-phase input, power would then be distributed to different subsystems in the railway trains. The parameters of interest are the input and output frequencies. The input frequency will be swept from $180 \mathrm{~Hz}$ to $400 \mathrm{~Hz}$ in increments of $20 \mathrm{~Hz}$. Initially the hardware firing boards were configured to accept an input frequency range of $180 \mathrm{~Hz}$ to $600 \mathrm{~Hz}$. However, input measurement equipment limitations prevented stable measurements at input frequencies higher than $400 \mathrm{~Hz}$. Due to this reason, the maximum frequency has been revised to $400 \mathrm{~Hz}$. This is compensated by using a smaller step size for greater resolution within this range. At each particular value of input frequency, the output frequency will be swept from $30 \mathrm{~Hz}$ to $120 \mathrm{~Hz}$ in increments of $10 \mathrm{~Hz}$. With these combinations, the maximum output frequency to minimum input frequency ratio is 0.667 which is much less than the theoretical limit of 1 . The main reason for varying the input and output frequencies is because presently there has not been any research or study done on which combination of input and output frequency would be the most efficient and optimized for the railway train system.

Also important is the output power requirement. Three different loads will be used to show the effect of load current on power quality. These different loads are selected to give a wide range of output current without reaching equipment limitations. This gives a nominal load of $200 \mathrm{~W}$ with additional loads of $100 \mathrm{~W}$ and $300 \mathrm{~W}$. At output power much higher than $300 \mathrm{~W}$, the switching pulse has a high instantaneous input current peak. The AC power source described in Section 5-2 is rated for $1500 \mathrm{VA}$ or 500 VA per phase. This yields a maximum RMS current of about 4 A per phase 
assuming an input RMS voltage of $120 \mathrm{~V}_{\mathrm{LN}}$. In order not to overload the machine, there will be a maximum current of approximately 2.4 A based on the $300 \mathrm{~W}$ load. The output voltage will be approximately $120 \mathrm{~V}$. This is done to preserve a 1:1 input line-neutral RMS voltage to output RMS voltage. The combination of $200 \mathrm{~W}$ nominal load and $120 \mathrm{~V}$ desired output voltage approximately results in a standard value $75 \Omega$ load resistor. Similarly for the $100 \mathrm{~W}$ and $300 \mathrm{~W}$ loads, the resistances are $150 \Omega$ and $50 \Omega$, respectively.

\subsection{Analysis Requirements}

The power quality analysis of the cycloconverter consists of various parameters. These are listed in Table 3-2. Each set of measurements will be made at a discrete value of input frequency, output frequency, and load.

Table 3-2. Cycloconverter Power Quality Analysis Requirements

\begin{tabular}{|c|c|}
\hline Measurement & Location \\
\hline Efficiency & System \\
\hline Power Factor & Input \\
\hline Total Harmonic Distortion & Input Current and Output Voltage \\
\hline
\end{tabular}

Efficiency will be taken as the ratio of average output power to average input power. Higher values mean that a greater percentage of power is delivered to the load. Power factor is defined as the ratio of average power to apparent power as seen in Equation 4-7. Power factor will only be observed at the input since the load is purely resistive. Apparent power $(\mathrm{S})$ should equal average power $(\mathrm{P})$ to yield an expected power factor value of 1. Total harmonic distortion (THD) is a measure of the quality of an AC waveform and how close in shape it is to a pure sinusoid. THD will be observed on the 
input current since switching action creates a discontinuous input current waveform.

Only one phase current will be observed since the other phases will be similar with only phase shifts. Hence the current THD should approximately be the same for all phases. Theoretically, little distortion should occur for the input voltage. This is verified in both simulation and hardware. The second THD measurement will be observed on just the output voltage. The output current waveform should be identical in shape to the output voltage waveform since there is minimal output reactance.

\subsection{Test Procedure}

The testing procedure will make use of the simplified cycloconverter block diagram shown in Figure 3-1.

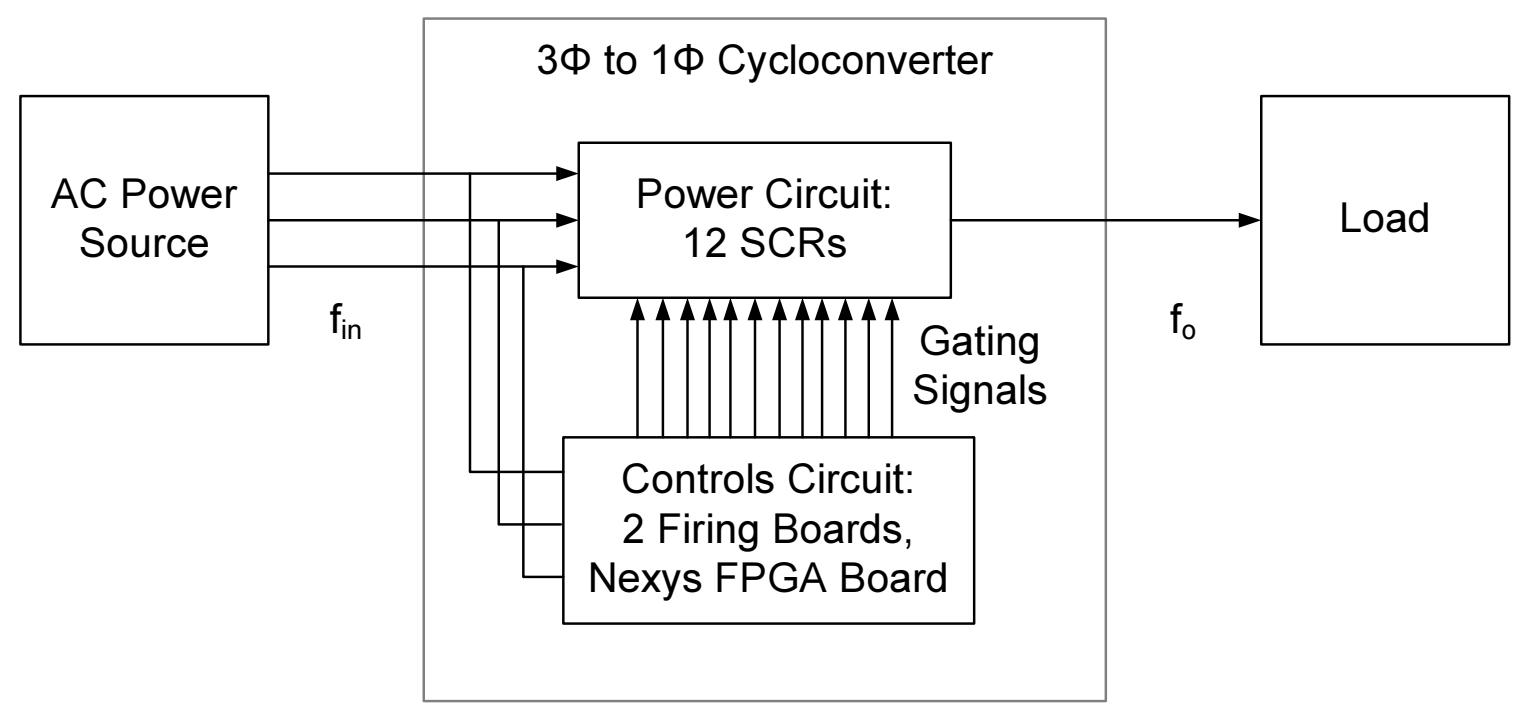

Figure 3-1. Simplified cycloconverter block diagram

The testing procedure will involve varying input frequency, output frequency and load.

The most efficient procedure for conducting the tests is based on the test matrix shown in

Figure 3-2. The first loop corresponds to the three different loads. This is done first to minimize the amount of load swapping. The second loop corresponds to the input 
frequencies. This involves changing the frequency of the AC source via the machine's internal switches. The third loop corresponds to the output frequencies. This is done by changing switches on the programmable Nexys board. The hardware components will be explained in more detail in Chapter 5.

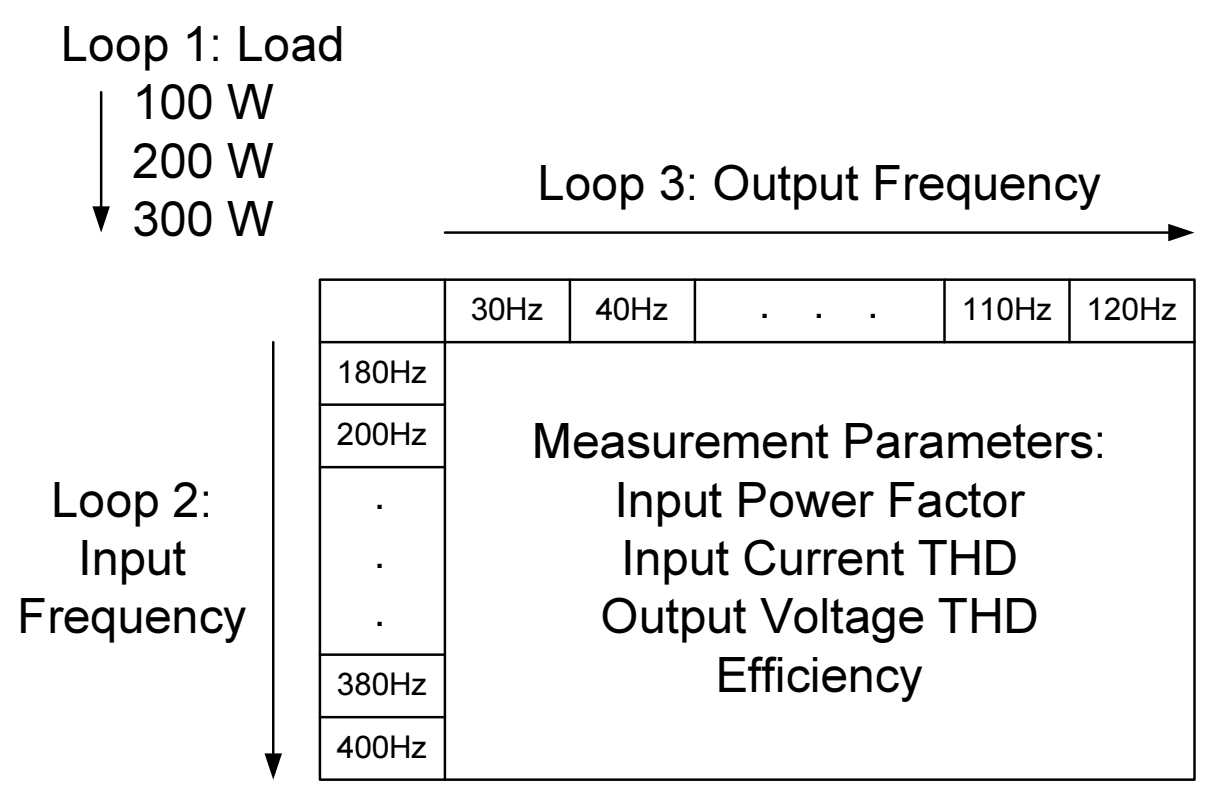

Figure 3-2. Cycloconverter test matrix 


\section{IV.Simulation and Analysis}

Given the design requirements in Section 3-1, simulation and analysis of this specific cycloconverter will be done in two steps. The first step is to analyze the cycloconverter from a theoretical standpoint. This includes calculations of the switching losses as well as modeling the switches. Since there are no straightforward equations representing total harmonic distortion and power factor, the analysis of these parameters will be reserved for simulation. The second part is simulation of the cycloconverter using the test matrix in Figure 3-2.

\subsection{Preliminary Switching Loss Analysis}

Switching loss analysis is important because it directly relates to efficiency. From a system standpoint as seen in Figure 1-1, the input power can be defined as a sum of the output average power and average power dissipated in the controls and power circuits. This satisfies conservation of power. Efficiency is the ratio of output to input power.

$$
\begin{gathered}
P_{\text {In }}=P_{\text {Out }}+P_{\text {Power }}+P_{\text {Controls }} \\
\eta=\frac{P_{\text {Out }}}{P_{\text {In }}}=\frac{P_{\text {Out }}}{P_{\text {Out }}+P_{\text {Power }}+P_{\text {Controls }}}
\end{gathered}
$$

As explained in Section 1, the controls circuit mainly consists of logic signals. The power loss of the controls circuit is therefore minimal compared to the output power and power dissipated in the power circuit. In addition, the power circuit consists entirely of switches. Therefore, the only significant power loss is within the switches themselves. This neglects the minimal amounts of wire inductances and parasitic capacitances present in hardware. Equations 4-1 and 4-2 can be simplified as follows. 


$$
\begin{gathered}
P_{\text {In }}=P_{\text {Out }}+P_{\text {Switch }} \\
\eta=\frac{P_{\text {Out }}}{P_{\text {In }}}=\frac{P_{\text {Out }}}{P_{\text {Out }}+P_{\text {Switch }}}
\end{gathered}
$$

Switching losses are directly related to the type of switches used.

Cycloconverters tend to utilize thyristors for their high power and high current handling capabilities. The switch used in this analysis is the silicon-controlled rectifier (SCR), which is a type of thyristor. The thyristor is different than a transistor because it is not fully controllable. It can be thought of as a diode that only turns on when triggered by a current pulse. When the device is in the forward state, a positive current will latch the device into the on state. The thyristor turns off when it becomes reversed biased. The model and current-voltage characteristics are shown in Figure 4-1.

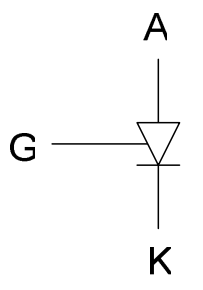

(a)

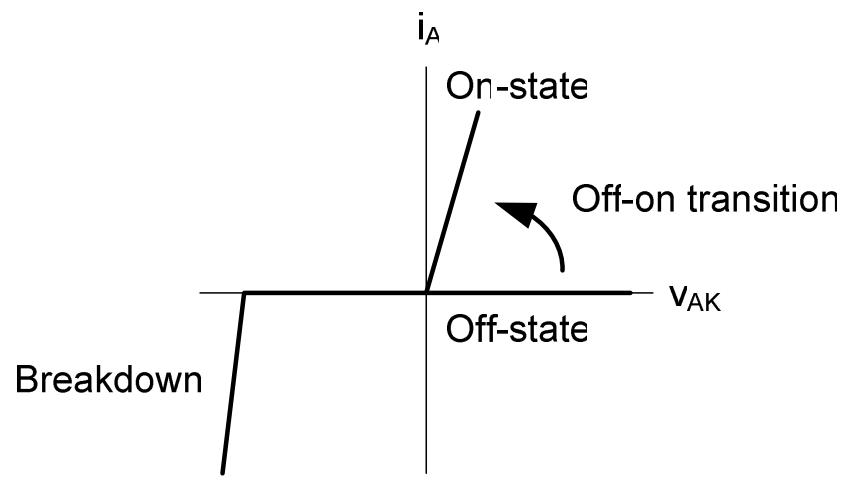

(b)

Figure 4-1. Thyristor: (a) symbol and (b) current-voltage characteristics

There are four main components of switching loss. The first component is the conduction loss. This is the amount of power dissipated while the switch is conducting in the on-state. The second component is the non-conduction loss, or the power loss when the switch is off. The third and fourth components are the transition losses occurring when the switch turns on and the switch turns off, respectively. In general, the transition 
losses are the largest for very high switching applications while the non-conduction loss may become significant in high output power applications. This gives rise to the following equation for $\mathrm{P}_{\text {Switch }}$.

$$
P_{\text {Switch }}=P_{C}+P_{N C}+P_{o f f-o n}+P_{o n-o f f}
$$

In order to determine equations for the components of Equation 4-5, actual thyristor specifications will be used. Based on the datasheet for the Semikron SKKT $92 / 16 \mathrm{E}$, the turn-off time is specified as $100 \mu \mathrm{s}$. The turn on time is approximately $2 \mu \mathrm{s}$. The next step is to determine the on-state characteristics of the SCR. The forward voltage drop across the SCR will be based on the maximum threshold voltage of $1.65 \mathrm{~V}$. The design specifications of Section 3 yields an output current of approximately $1.64 \mathrm{~A}$ at a nominal load of $75 \Omega, 200 \mathrm{~W}$. This will be the forward current in the on-state. In the off-state, the reverse voltage will be set equal to the output voltage of $122 \mathrm{~V}$ for simplicity. A typical diode reverse saturation current of $1 * 10^{-14}$ A will also be used. These parameters are shown in Table 4-1.

Table 4-1. Estimated Parameters for Modeling Switching Loss

\begin{tabular}{|c|c|c|c|c|}
\hline & Off-On Transition & Conduction State & On-Off Transition & Non-Conduction State \\
\hline $\mathbf{V}_{\mathbf{A K}}$ & $122 \mathrm{~V}$ to $1.65 \mathrm{~V}$ & $1.65 \mathrm{~V}$ & $1.65 \mathrm{~V}$ to $122 \mathrm{~V}$ & $122 \mathrm{~V}$ \\
\hline $\mathrm{I}_{\mathbf{A}}$ & $1 \mathrm{E}-14 \mathrm{~A}$ to $1.64 \mathrm{~A}$ & $1.64 \mathrm{~A}$ & $1.64 \mathrm{~A}$ to $1 \mathrm{E}-14 \mathrm{~A}$ & $1 \mathrm{E}-14 \mathrm{~A}$ \\
\hline Time & 2 us & $1 /\left(6 \mathrm{f}_{\mathrm{i}}\right)$ & $100 \mathrm{us}$ & $1 / \mathrm{f}_{\mathrm{S}}-\left[1 /\left(6 \mathrm{f}_{\mathrm{i}}\right)+100 \mathrm{us}+2 \mathrm{us}\right]$ \\
\hline
\end{tabular}

Note that the conduction and non-conduction time durations are not fixed. This is done to see the effect of varying input frequency. For a three-phase to single-phase cycloconverter, each switch conducts for a total duration of one third of the input period. However for this model, each switch will conduct twice during each input period while retaining the total duration time. This is done to represent a worst case switching 
scenario as well as represent the operation of the firing board used in the hardware section.

The effect of varying output frequency on switching loss is minimal. This is due to the fact that regardless of which converter is active, the output current will flow through two switches at any given time. Since the switches are very symmetrical, there should be little noticeable fluctuation in switching loss. The following analysis will only vary the input frequency at nominal load. The input frequency range has been defined in Section 3 as $180 \mathrm{~Hz}$ to $400 \mathrm{~Hz}$ in steps of $20 \mathrm{~Hz}$. The calculations are performed in MATLAB with the code shown below and the output waveforms shown in Figure 4-2.

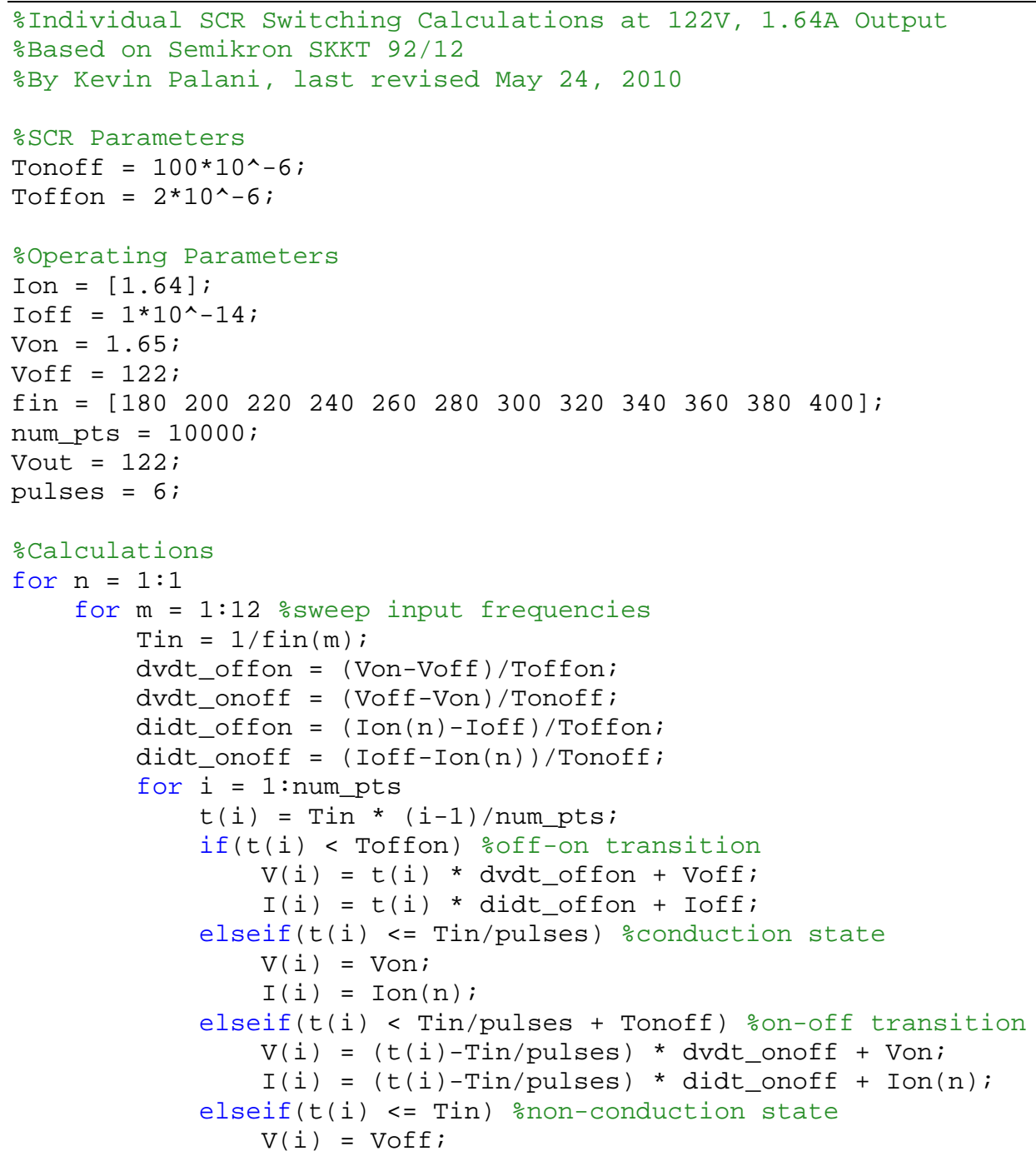



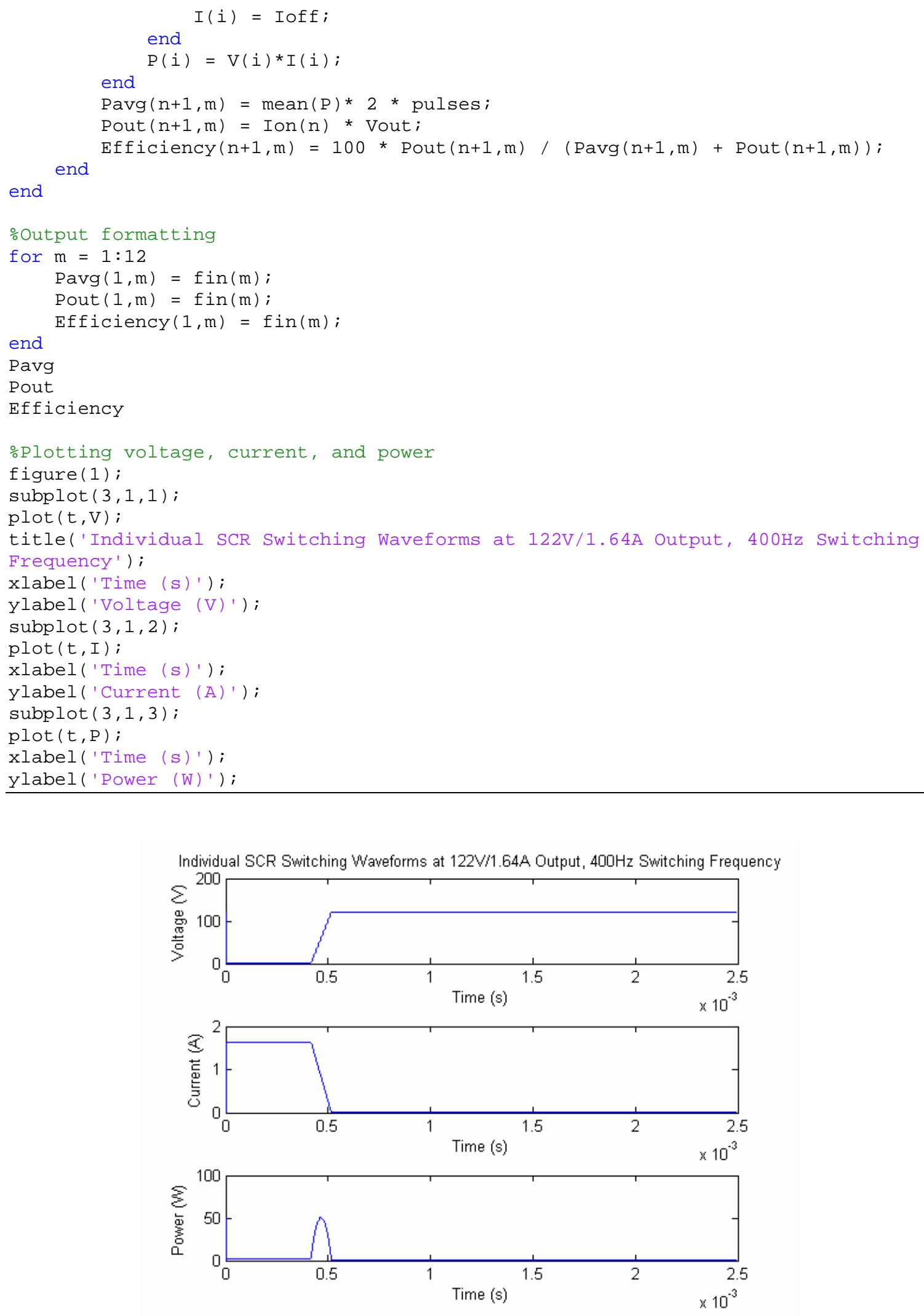

Figure 4-2. Theoretical switching waveforms for one input period 
The largest switching losses occur during the transitions. This is because the voltage and current are both much larger than zero during the transition intervals. The effect of variable input frequency can be seen in Table 4-2 and Figure 4-3. The switching loss is calculated as the average power across one input period multiplied by twelve.

This accounts for the fact that two switches conduct for each switching pulse and there are six switching pulses for each input period of a three-phase cycloconverter.

Table 4-2. Calculated Switching Loss and Efficiency Values

\begin{tabular}{|c|c|c|c|}
\hline $\begin{array}{c}\text { Input Frequency } \\
(\mathbf{H z})\end{array}$ & $\begin{array}{c}\text { Output Power } \\
(\mathbf{W})\end{array}$ & $\begin{array}{c}\text { Switching Loss } \\
\mathbf{( W )}\end{array}$ & Efficiency \\
\hline 180 & 200.08 & 12.94 & 93.93 \\
\hline 200 & 200.08 & 13.77 & 93.56 \\
\hline 220 & 200.08 & 14.62 & 93.19 \\
\hline 240 & 200.08 & 15.45 & 92.83 \\
\hline 260 & 200.08 & 16.29 & 92.47 \\
\hline 280 & 200.08 & 17.13 & 92.11 \\
\hline 300 & 200.08 & 17.96 & 91.76 \\
\hline 320 & 200.08 & 18.80 & 91.41 \\
\hline 340 & 200.08 & 19.64 & 91.06 \\
\hline 360 & 200.08 & 20.48 & 90.71 \\
\hline 380 & 200.08 & 21.31 & 90.37 \\
\hline 400 & 200.08 & 22.15 & 90.03 \\
\hline
\end{tabular}

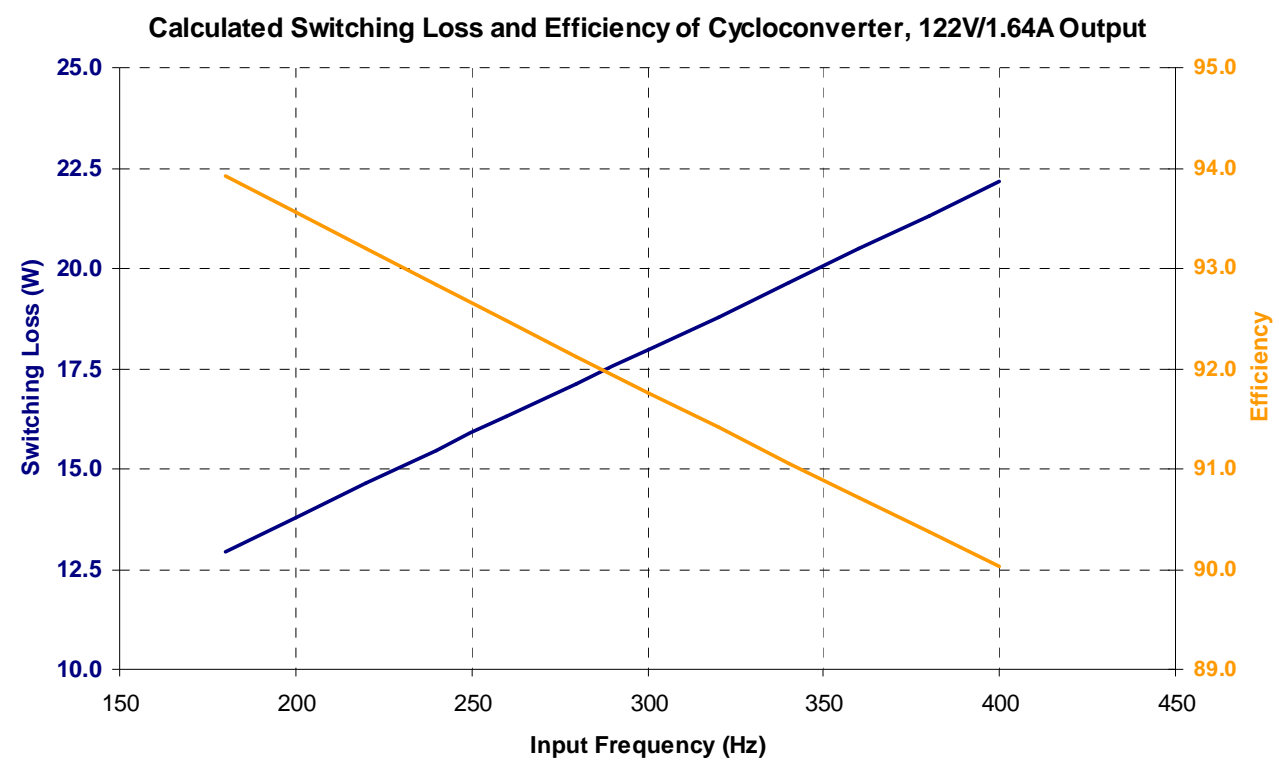

Figure 4-3. Theoretical efficiency of a three-phase input cycloconverter 
Since the largest losses occur during the transitions, it is logical that higher frequency switching will result in higher average losses. This is because the transition durations remain constant while the conduction and non-conduction durations decrease. The average power loss over a full input period linearly increases and the efficiency linearly decreases. These results aid the modeling of the SCR for simulation in the next section.

\subsection{Modeling the SCR}

Cycloconverter operation can be simulated in PSpice in a relatively straightforward manner. However, the overall goal is power quality and this requires a fairly accurate model of the circuit under test. There is no readily available PSpice subcircuit definition for the Semikron SKKT 92/16E used for the hardware section. This means that a model will have to be created to represent the SCR. The starting point of this model is the VSWITCH part. This part is a voltage controlled switch that acts as a low impedance and high impedance when on and off, respectively. These impedances are modeled after the SCRs conduction and non-conduction modes outlined in Section 4-1. An additional VSWITCH is connected in series to represent the converter bridge firing durations. In order to make the switch turn off when reversed biased, a diode is placed in series. Additional capacitors and resistors are placed in the circuit to recreate the delayed rise and fall times of the SCR. The only caveat with this model is that the switch turns off when the applied control signal turns off. This is different than actual SCR operation in which the switch turns off only when the anode-cathode voltage reaches zero as shown in Figure 4-1(b). The control voltage makes up for this by staying on for the full conduction duration as opposed to a typical short duration current pulse. 
This schematic model with corresponding parameter values are shown in Figure 4-4. The output nodes are the cathode $(\mathrm{K})$, anode $(\mathrm{A})$, control voltage $(\mathrm{C})$, and bridge voltage $(\mathrm{B})$.

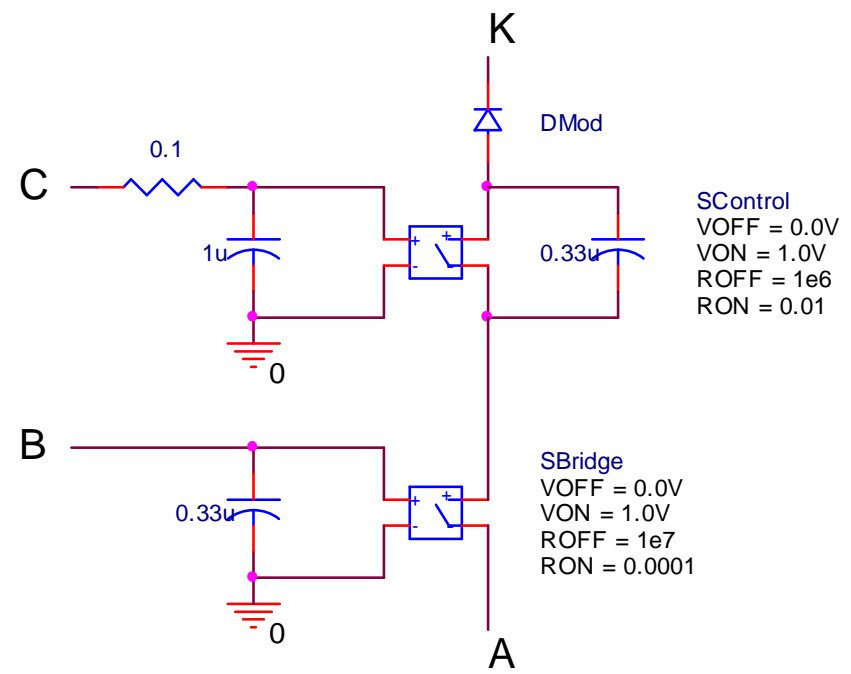

Figure 4-4. Simple SCR model for PSpice simulation

\subsection{PSpice Simulation Procedure}

Based on the above model, a PSpice simulation input deck can be formed as shown on the next page. V01 to V03 represent the input three-phase voltage at a voltage and frequency represented by parameter values. V11 and V12 represent the converter bridge voltage with frequency equal to the output frequency. V21 to V24 are the individual pulse waveforms driving the SCRs with the conduction duration equal to a third of the input voltage period and frequency equal to the input voltage period. The time delays correspond to Figure 2-4. The SCRs are defined as the configuration shown in Figure 2-3. The load is purely resistive and also represented by a parameter value. The simulation duration is $100 \mathrm{~ms}$ with step size of $0.01 \mathrm{~ms}$. The parameter values for the input frequency (fi), the output frequency (fo), and the load resistance (ro) will be swept according to the test matrix in Figure 3-2. 


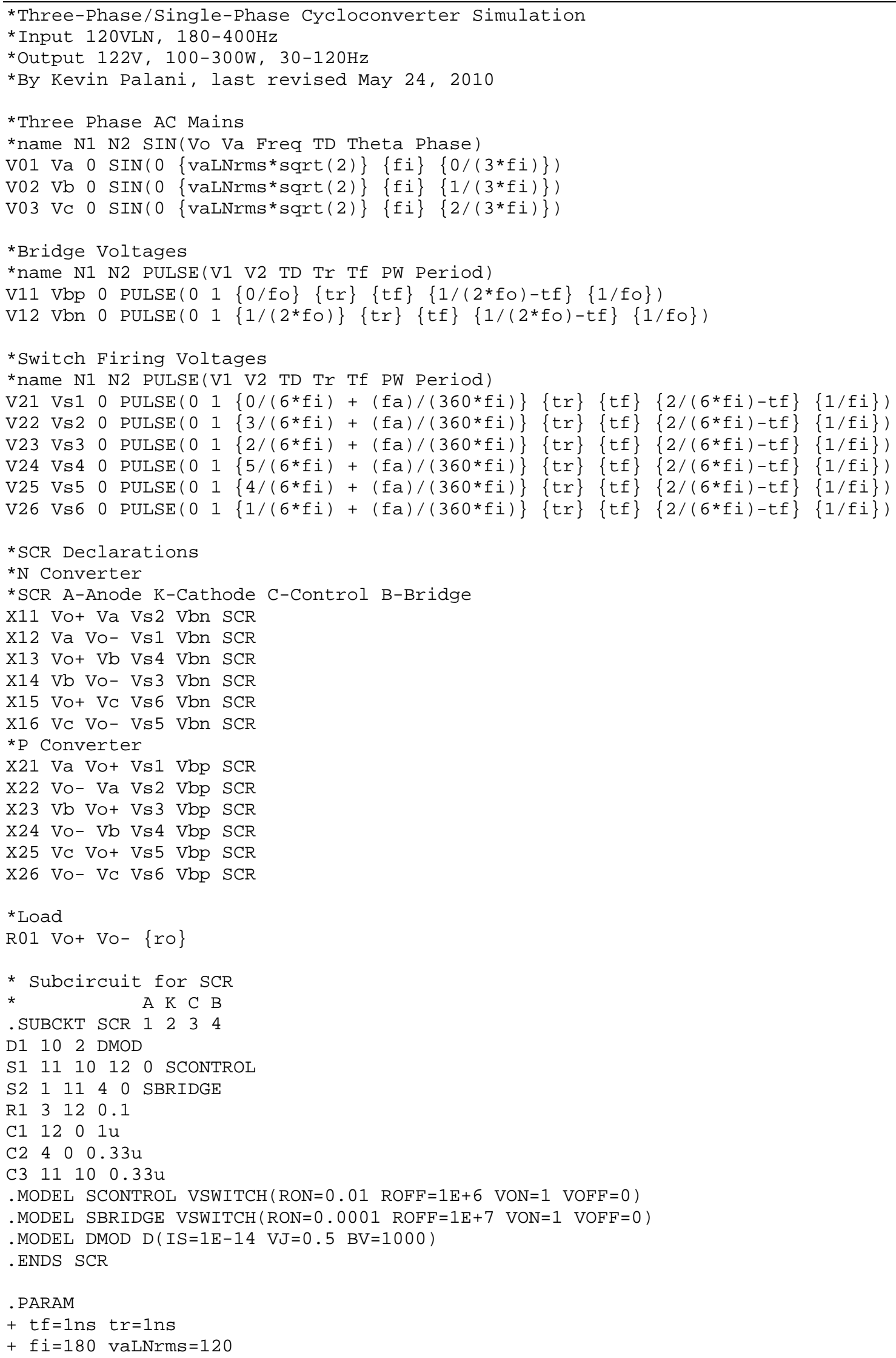


$+\mathrm{fa}=100.5$

$+\mathrm{fo}=30 \quad \mathrm{ro}=75$

.TRAN $0.01 \mathrm{~m} 110 \mathrm{~m} 10 \mathrm{~m} \quad 0.01 \mathrm{~m}$ UIC

. PROBE

*.FOUR 180 I (V01)

*.FOUR 30 I (R01)

.OPTIONS GMIN=1E-7 ABSTOL=1E-7 CHGTOL=1E-7 TRTOL=7 .END

(b)

(a) $\left.{ }^{200 \mathrm{~V}}\right]_{-200 \mathrm{~V}}^{2}$

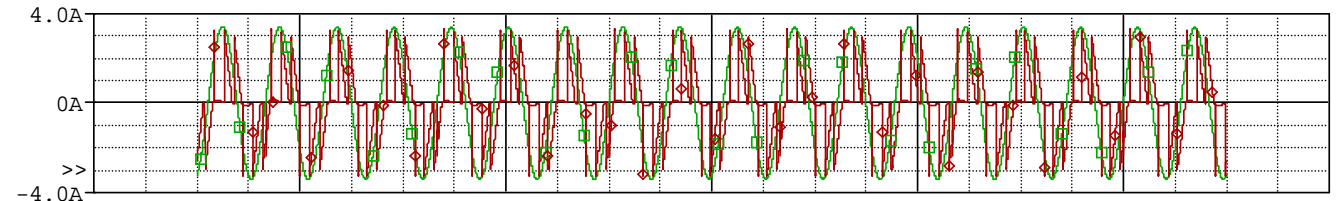

$1 \square \mathrm{V}(\mathrm{VA}) \quad 2 \diamond-i(\mathrm{v} 01)$

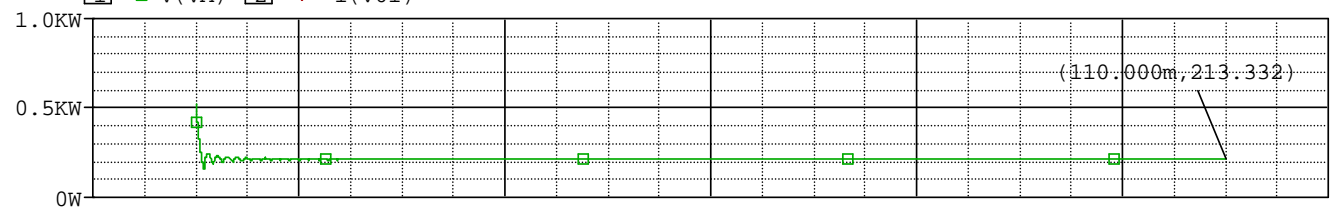

-(avg (W (V01)) +avg (W (V02)) +avg (W (V03) ))

(c)

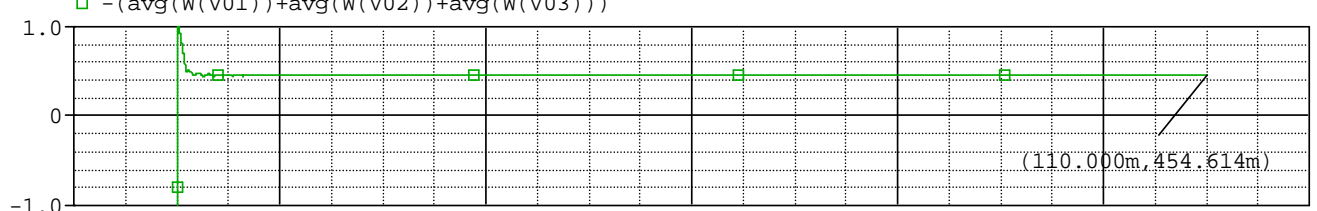

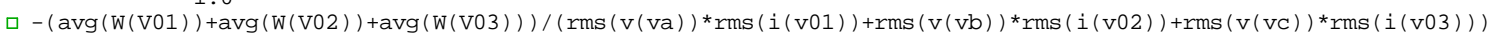

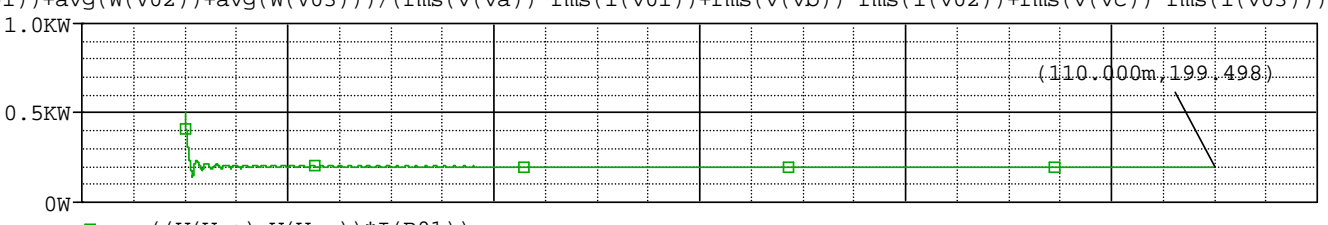

(d)

(e)

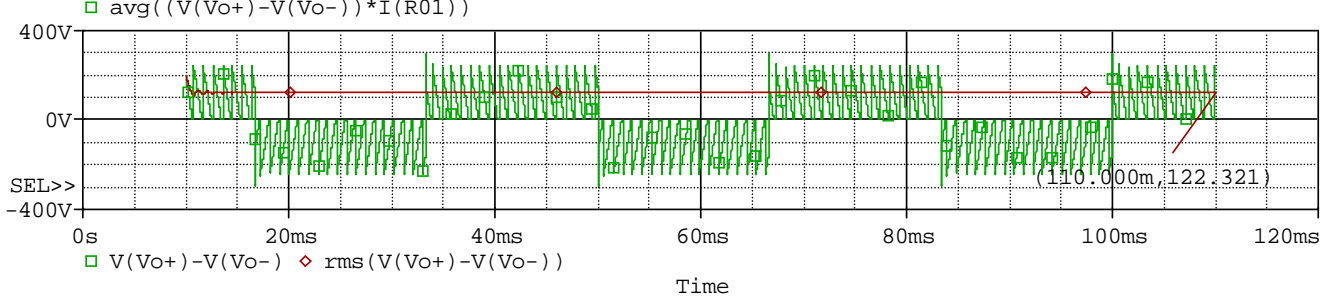

Figure 4-5. Simulated 200W, 180Hz:30Hz cycloconverter waveforms: (a) input voltage and current, (b) input average power, (c) input power factor, (d) output average power, (e) output voltage

An important thing to note is the firing angle parameter (fa). The firing angle is 180 degrees for minimum output voltage and zero degrees for maximum output voltage. In order to obtain the correct output voltage and power for each test set, the firing angle is initially adjusted downwards until $200 \mathrm{~W}$ appears at the load. This occurs at a firing 
angle of approximately 100.5 degrees. The waveforms in Figure 4-5 show a specific example simulation for $180 \mathrm{~Hz}$ input, $30 \mathrm{~Hz}$ output at $200 \mathrm{~W}$.

Figure 4-5(a) shows both the input voltage and input current. The input voltage is purely sinusoidal while the input current is discontinuous due to the SCR switching pulses. The input average power is calculated as the sum of the average power of each phase as shown in Figure 4-5(b). This yields a value of 213.3 W. The input power factor is more complicated since the input voltage and current are not both sinusoidal. There are two ways to calculate power factor as shown below.

$$
\begin{gathered}
P F=\cos \left(\theta_{V}-\theta_{I}\right) \\
P F=\frac{P}{S}
\end{gathered}
$$

Equation 4-6 assumes both sinusoidal current and voltage waveforms. Since this does not hold true, this relationship cannot be used. Alternatively, power factor can be calculated using Equation 4-7. This states that power factor is equal to the ratio of average power to apparent power. Average power was calculated earlier as shown in Figure 4-5(b). Apparent power can be calculated as the sum of RMS current-voltage products for each phase. The division of these two quantities results in a power factor of 0.45 as seen in Figure 4-5(c). Figure 4-5(d) shows the output power calculation with an ensuing value of $199.5 \mathrm{~W}$. Efficiency of this cycloconverter circuit is calculated based on Equation 4-4 to be 93.5\%. The final plot shown in Figure 4-5(e) confirms that the output voltage is roughly $122 \mathrm{~V}_{\text {rms }}$. Output current follows the output voltage since the load is purely resistive. The THD of the input current and output voltage waveforms are calculated by executing PSpice's Fourier command. These values are contained in the circuit's output file. They yield $68.8 \%$ for the input current waveform and $42.5 \%$ for the 
output voltage waveform. This wraps up this specific example simulation for $180 \mathrm{~Hz}$ input, $30 \mathrm{~Hz}$ output at $200 \mathrm{~W}$.

Another simulation plot is shown in Figure 4-6 for the case of a $400 \mathrm{~Hz}$ input, 30 Hz output at $200 \mathrm{~W}$. The behavior is very similar to the previous case.

(a)

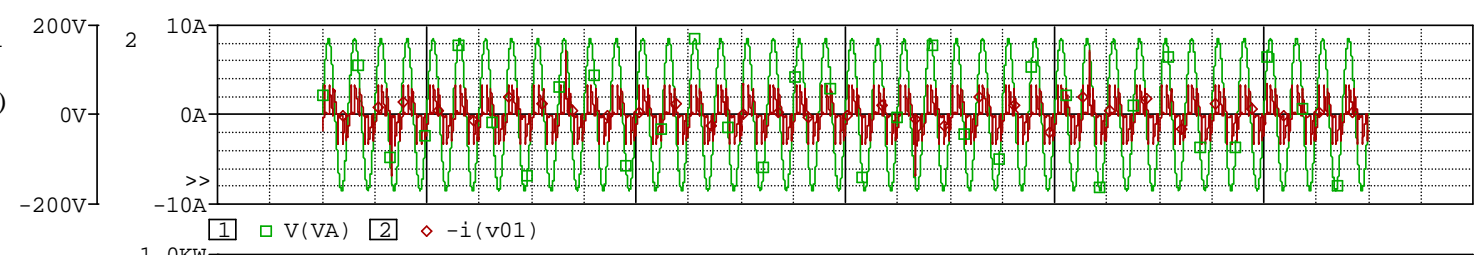

(b)

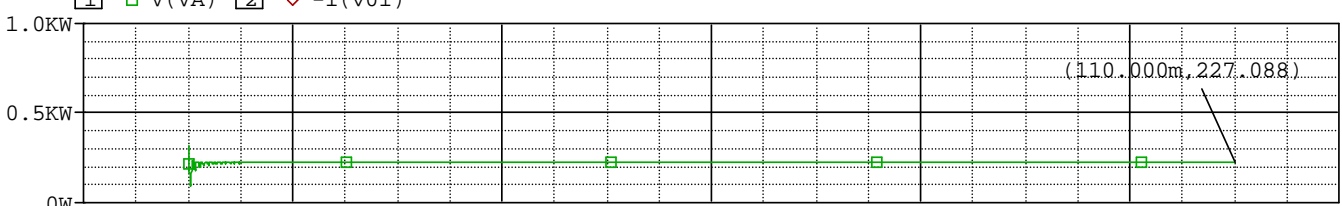

$\square-(\operatorname{avg}(W(\operatorname{Vo1}))+\operatorname{avg}(W(\operatorname{VO} 2))+\operatorname{avg}(W(\operatorname{Vo3})))$

(c)

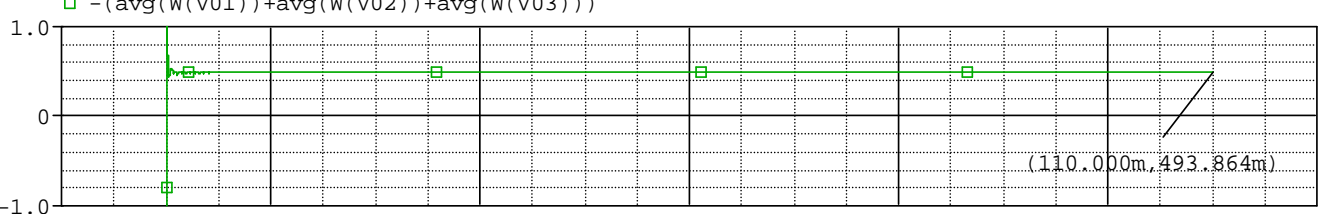

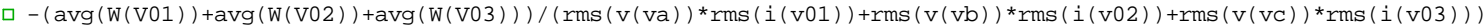

(d)

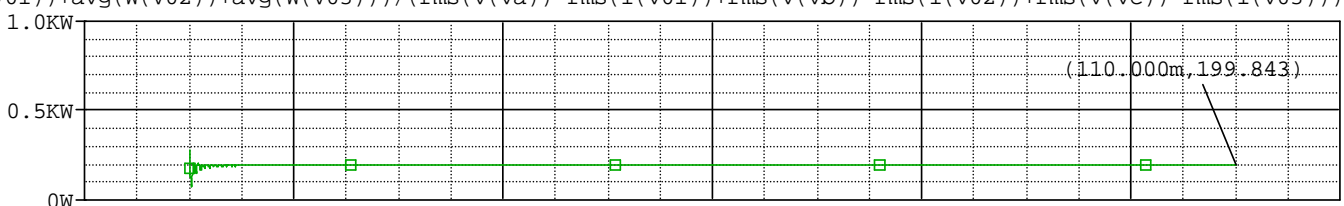
$\square \operatorname{avg}((\mathrm{V}(\mathrm{VO}+)-\mathrm{V}(\mathrm{VO}-)) * \mathrm{I}(\mathrm{R} 01))$

(e)

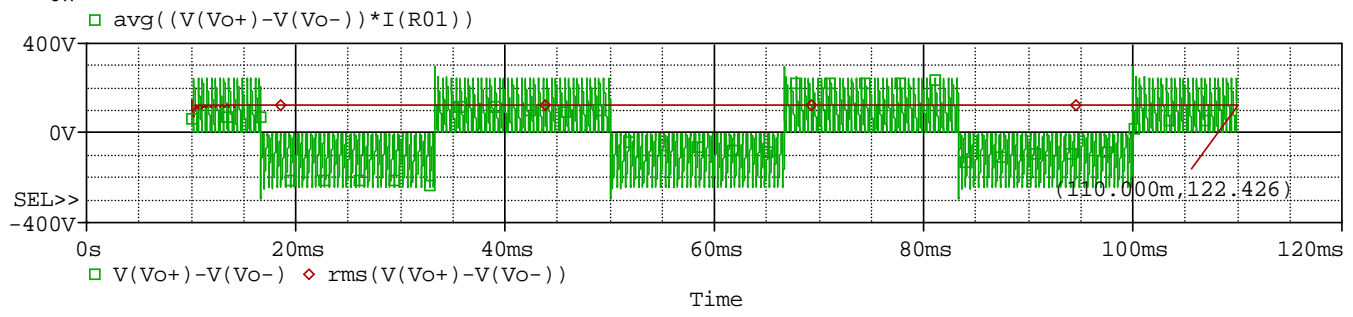

Figure 4-6. Simulated 200W, 400Hz:30Hz cycloconverter waveforms: (a) input voltage and current, (b) input average power, (c) input power factor, (d) output average power, (e) output voltage

However there are a few things to note. The first being the significant increase in input average power over the previous case while delivering roughly the same output power. This contributes to a noticeable efficiency drop to approximately $88 \%$. The input power factor increased slightly to 0.49 . Output voltage stayed constant at approximately $122 \mathrm{~V}$. Similarly, the input current THD and output voltage THD stayed fairly constant at $69.2 \%$ 
and $42.8 \%$ respectively. The frequency spectra of the input current and output voltage waveforms are shown in Figure 4-7.

(a)

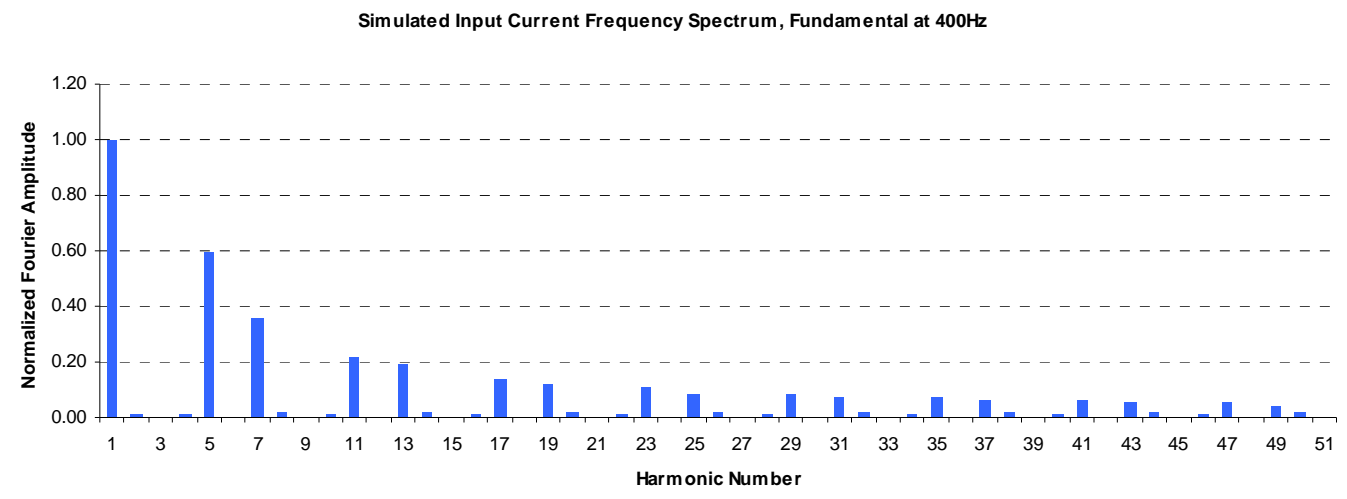

Simulated Output Voltage Frequency Spectrum, Fundamental at $30 \mathrm{~Hz}$

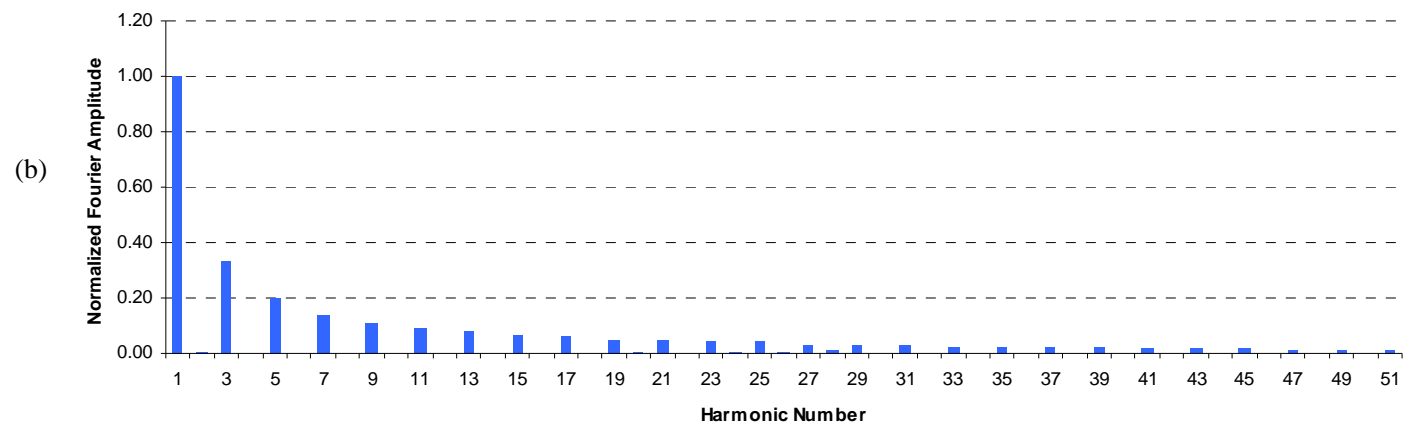

Figure 4-7. Simulated 200W, 400Hz:30Hz cycloconverter frequency spectra: (a) input current, (b) output voltage

There are a few observations to be made. In terms of the input current, the even number harmonics are relatively close to zero since the current waveform is fairly symmetrical as seen in Figure 4-6(a). Notice that the triplen harmonics, or the odd multiples of the third harmonic, are zero since the load is linear. This will not be the case if an output filter was present. The output voltage spectrum shows the expected trends as theoretically observed in Figure 2-6(c). The ripple frequency component of six times the input frequency does not appear within the first 51 harmonics because the output frequency is much lower than the input frequency. 


\subsection{PSpice Simulation Results}

Based on the test matrix in Figure 3-2 and simulation procedure in Section 4-3, there are four power quality measurements of interest. These include input power factor, input THD, output THD, and power efficiency. Each of the following subsections will contain three-dimensional plots of each of the measurement variables plotted on the $\mathrm{z}$ axis. The $x-y$ plane contains the input and output frequency matrix. There are three plots for each measurement corresponding to each of the three loads.

Input power factor is the first measurement. By observing Figure 4-8 through Figure 4-10, the first observation is that variations in output frequency has little to no effect on the input power factor. This is understandable since the input current always passes through two switches.

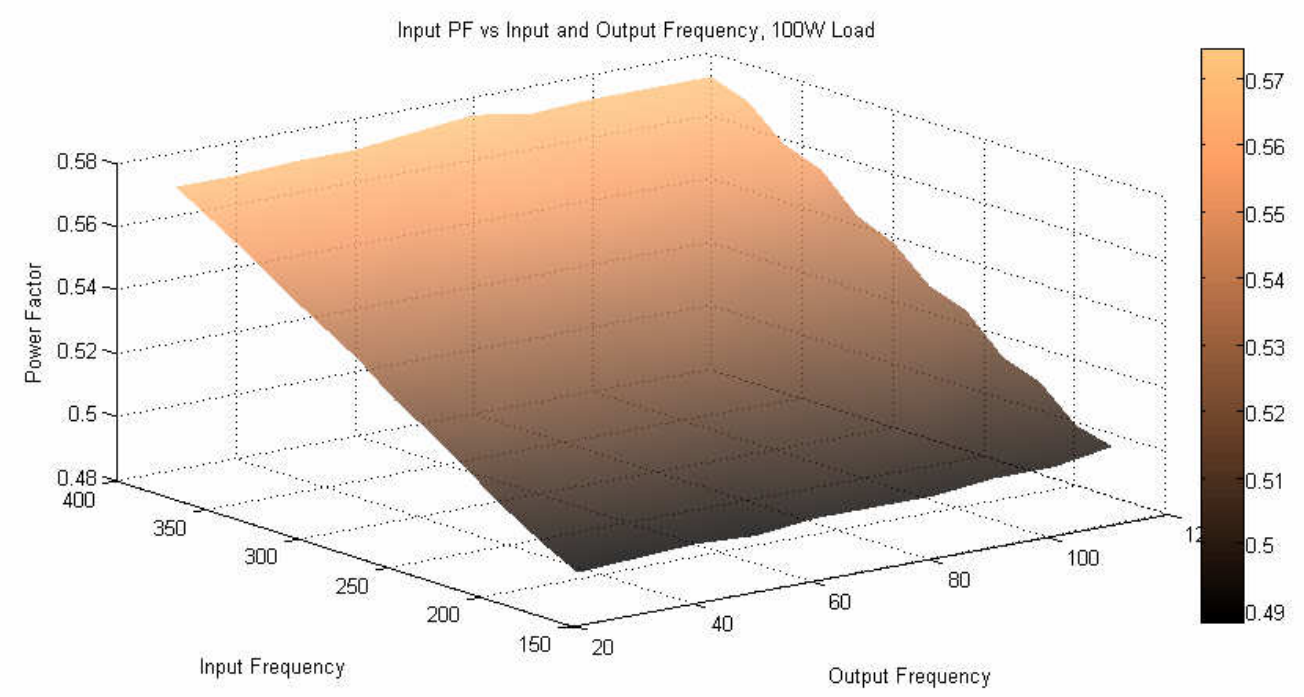

Figure 4-8. Simulated input power factor at 122V/100W load 


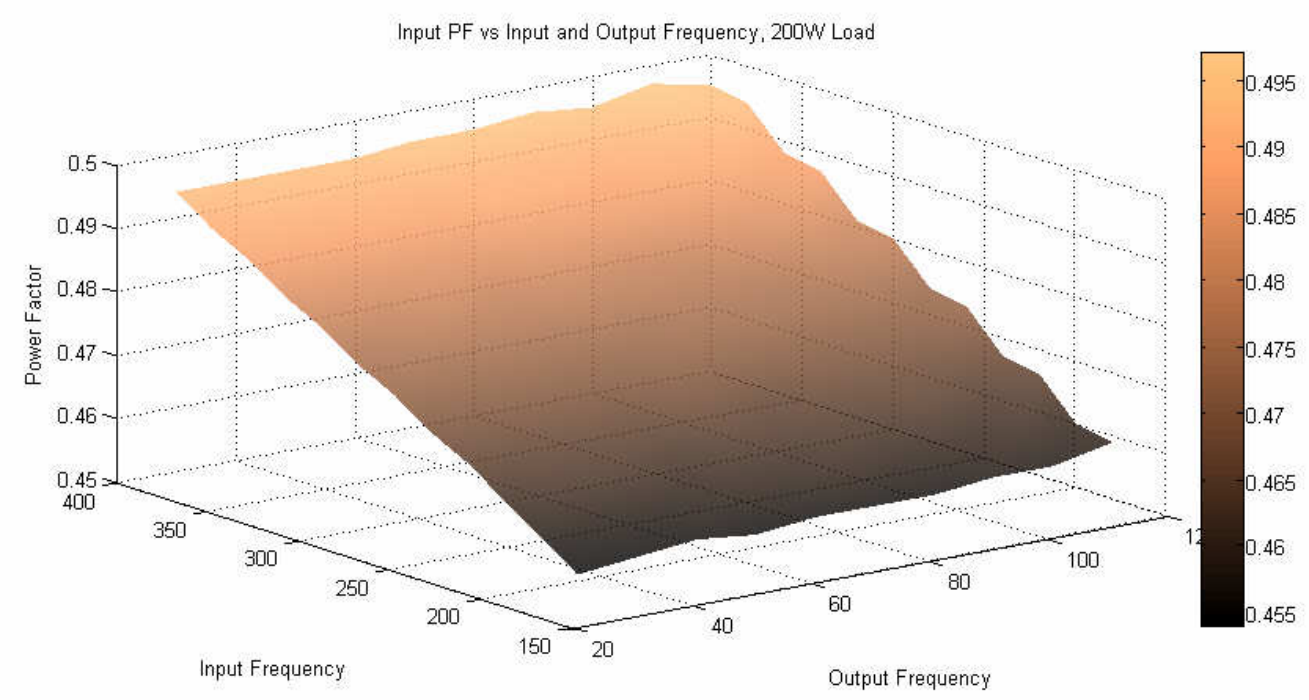

Figure 4-9. Simulated input power factor at $122 \mathrm{~V} / 200 \mathrm{~W}$ load

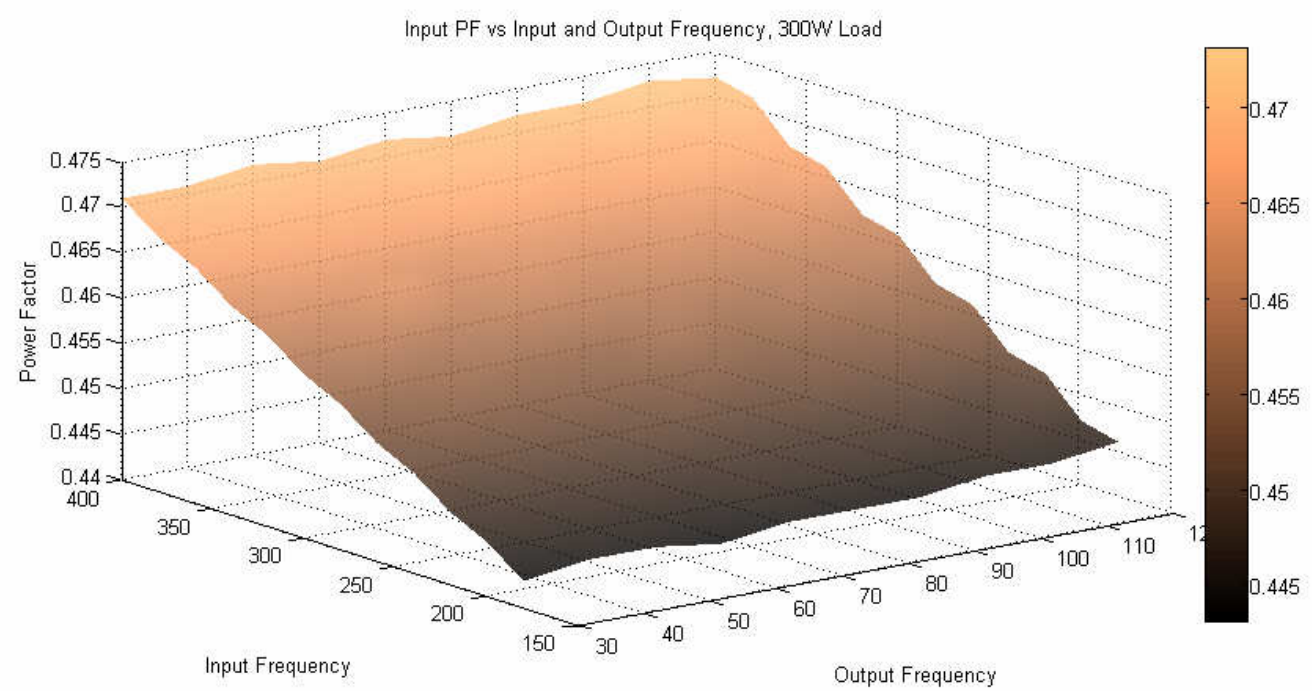

Figure 4-10. Simulated input power factor at $122 \mathrm{~V} / 300 \mathrm{~W}$ load

Variations in output frequency only change which two switches the current travels through. Since symmetrical switches are assumed, power factor would not change based on output frequency. This is only valid for a resistive load. The power factor would change more significantly with the presence of an output filter. This is because the input current waveform shape changes based on the charging and discharging time of the filter, which changes based on output frequency. 
There is a positive linear slope between input frequency and power factor. As seen in Section 4-3, increasing input frequency at a fixed output frequency results in an increase in input average power. By observing Equation 4-7, higher input average can result in a higher power factor. This is only true if there is a fairly constant apparent power. This can be assumed since the input voltage magnitude is constant and input current magnitude changes minimally. This brings about the point that increasing the input frequency is beneficial in increasing the power factor.

There is a negative linear slope between load and power factor. In other words, as the load increases, the power factor slightly decreases. In one sense, input average power increases from one load to another. However, apparent power also increases. This is due to the fact that the input voltage magnitude remains the same but the input current magnitude increases in order to supply enough current for the larger load. Based on these two observations, it is reasonable to say that the power factor will either remain fairly constant or decrease.

The next measurement is input total harmonic distortion. The corresponding plots are shown in Figure 4-11 through Figure 4-13. Similar to the previous case, variations in output frequency do not have a large impact on the input current THD. This is due to the fact that the input current waveform remains constant regardless of which converter bridge is active, since current will always be drawn from the source through two switches. Variations in input frequency minimally affect the input current THD. This is due to the fact that the THD equation is not a function of frequency. This is seen by observing Equation 4-8. 


$$
T H D_{\mathrm{I}}=\frac{\sqrt{\sum_{n=2}^{\infty}\left(I_{n, r m s}\right)^{2}}}{I_{1, r m s}}
$$

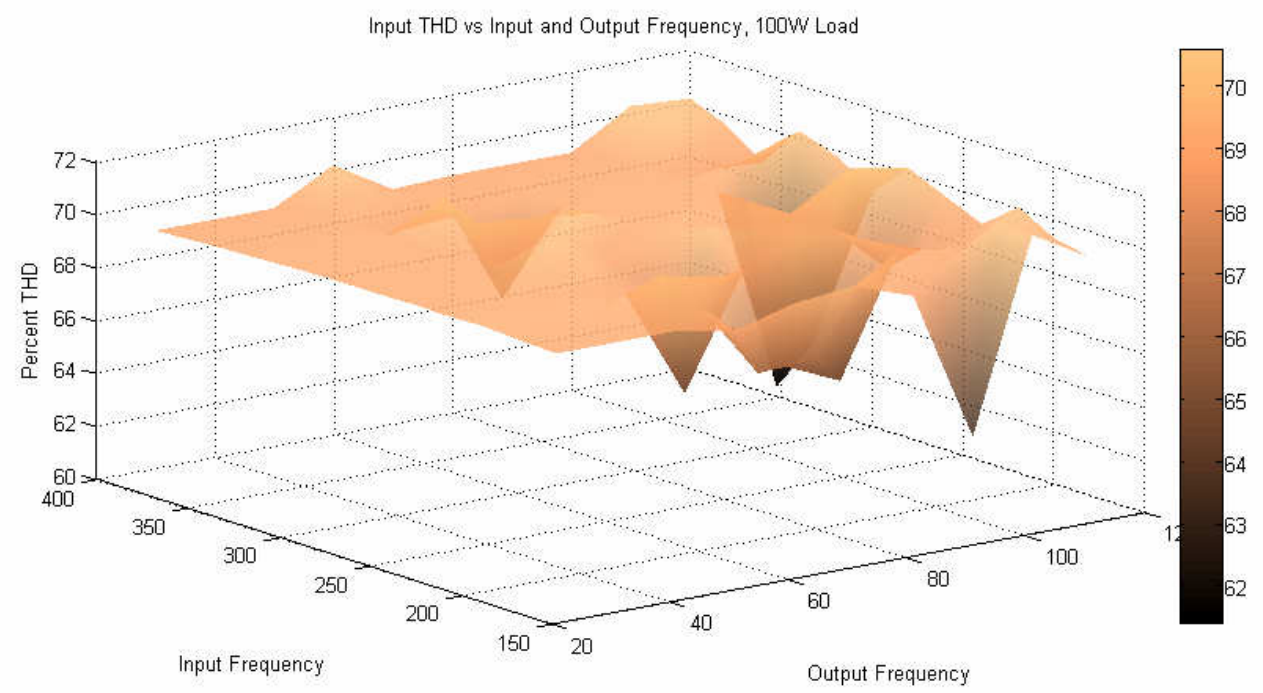

Figure 4-11. Simulated input total harmonic distortion at 122V/100W load

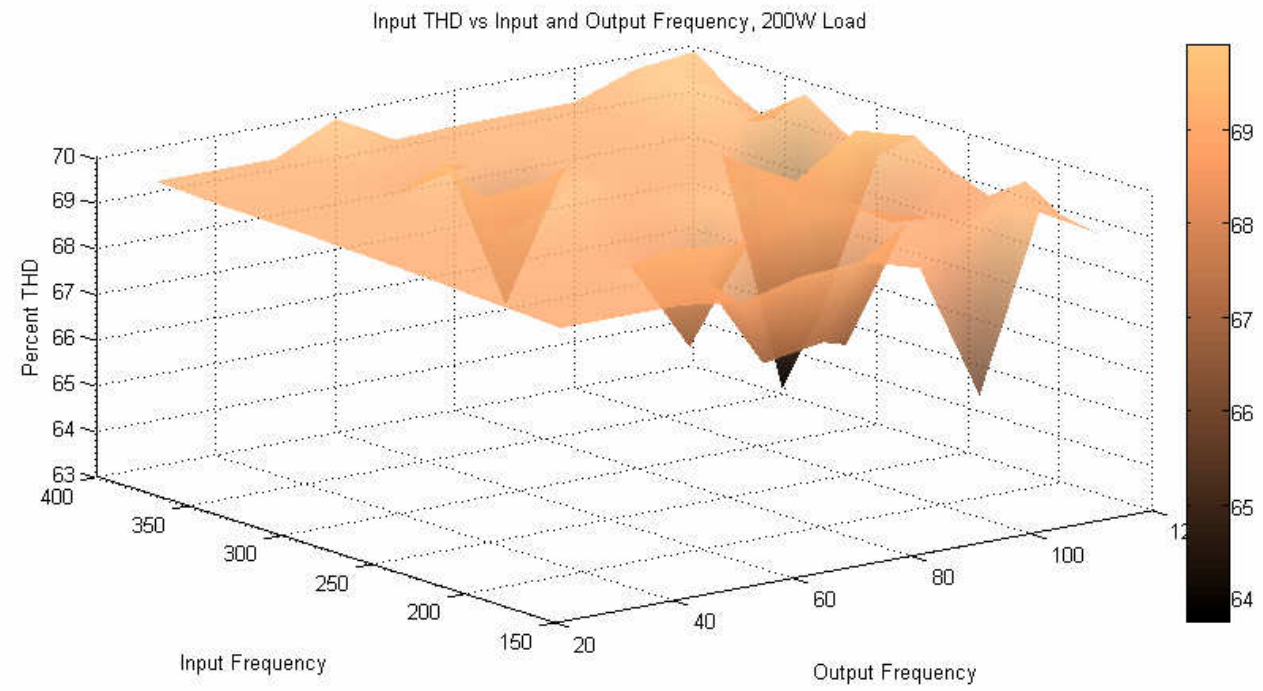

Figure 4-12. Simulated input total harmonic distortion at 122V/200W load 


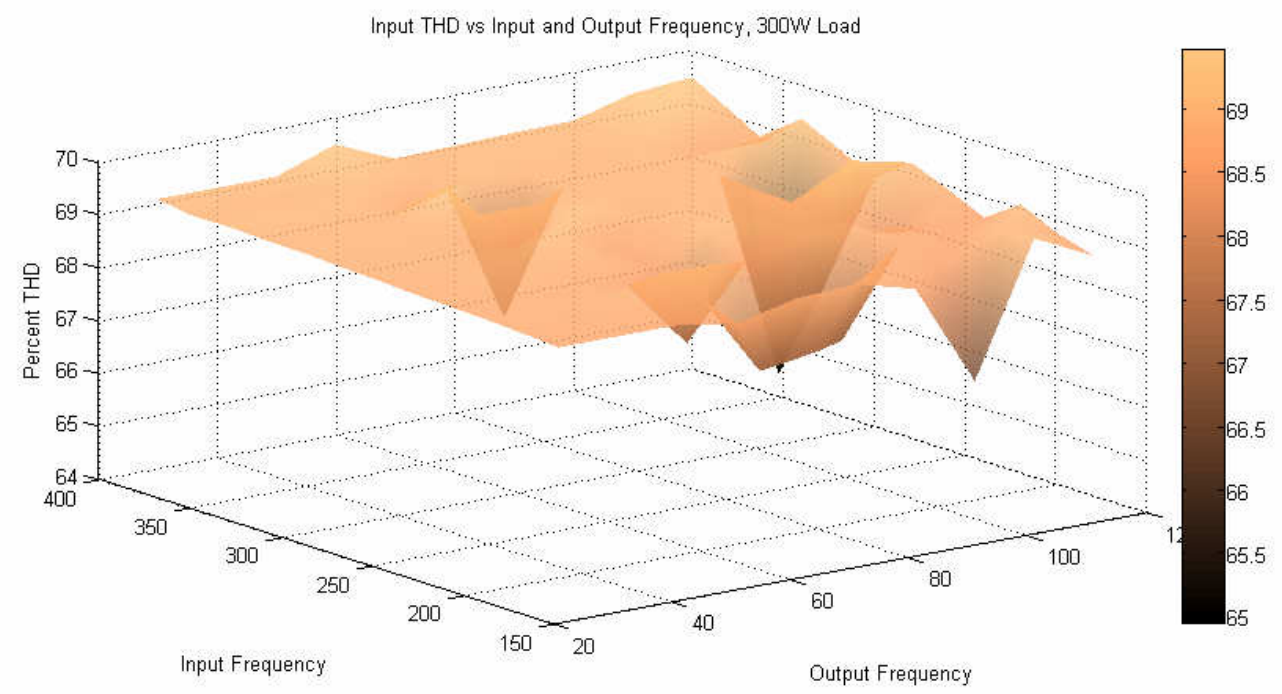

Figure 4-13. Simulated input total harmonic distortion at 122V/300W load

The THD relationship in Equation 4-8 has no relationship to specific frequency locations. It is true that by changing the input frequency, the current harmonics change in frequency locations. However, their positions relative to the fundamental input frequency are the same. In this manner, there is a minimal effect between input frequency and input current THD. There are a few noticeable dips in the THD plots. This phenomenon can occur when the output frequency is a low integer multiple of the input frequency. Note that PSpice's THD calculations are based on a finite number of harmonics. A relatively large RMS current can occur at a high harmonic integer outside the range of the calculation, thereby reducing the numerator quantity of Equation 4-8. This in turn reduces the THD at those particular input and output frequency combinations, as shown by the dips.

Changes in load do not appear to affect the input current THD. It is true that increasing the load will undoubtedly increase the RMS input current. This does not mean that only the RMS current at the fundamental frequency increases. All the harmonics' 
magnitudes increase as well, resulting in a fairly constant numerator to denominator ratio in Equation 4-8. Therefore, input current THD remains constant in this case.

It is also important to observe total harmonic distortion of the output voltage waveform. The corresponding plots are shown in Figure 4-14 through Figure 4-16. Once again, the input frequency, output frequency, and load have little to no effect on the output voltage THD.

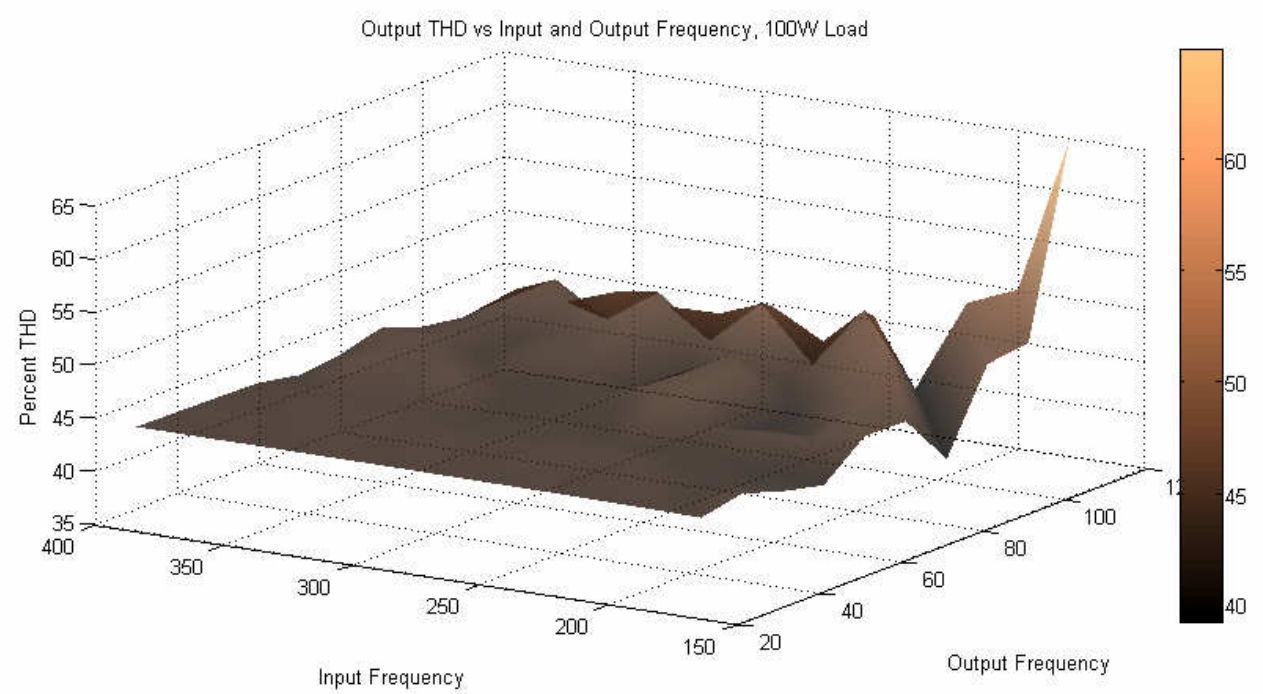

Figure 4-14. Simulated output total harmonic distortion at 122V/100W load

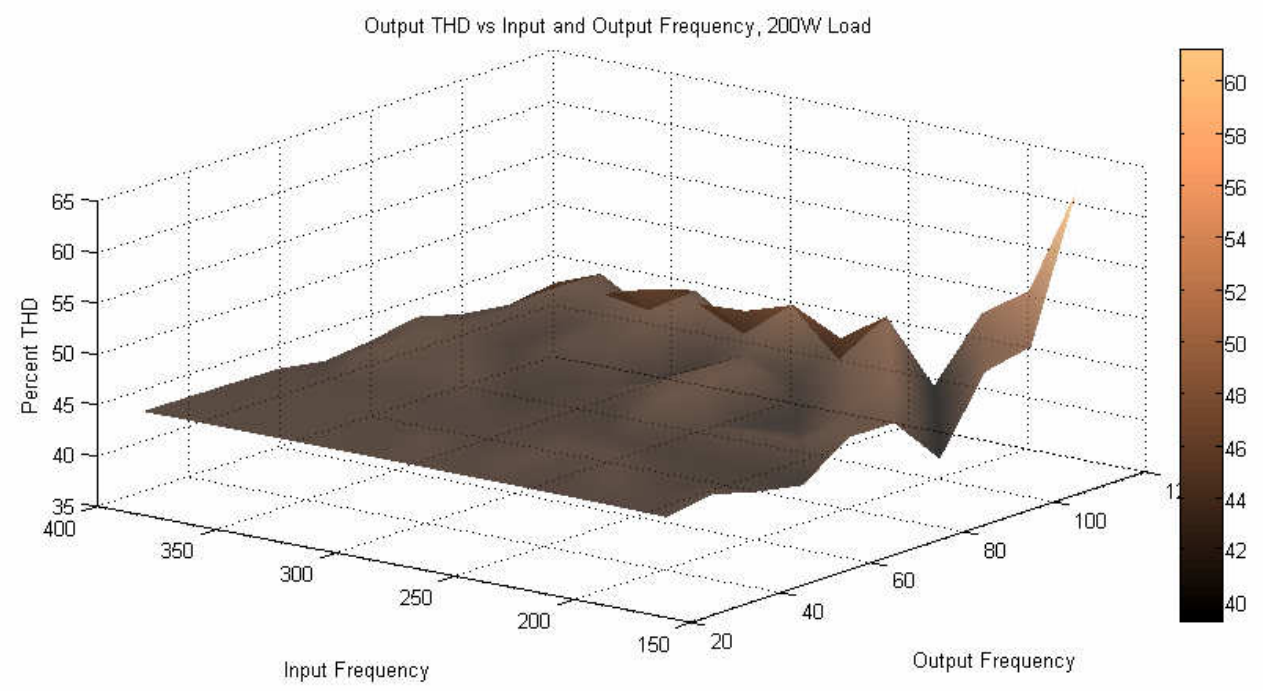

Figure 4-15. Simulated output total harmonic distortion at 122V/200W load 


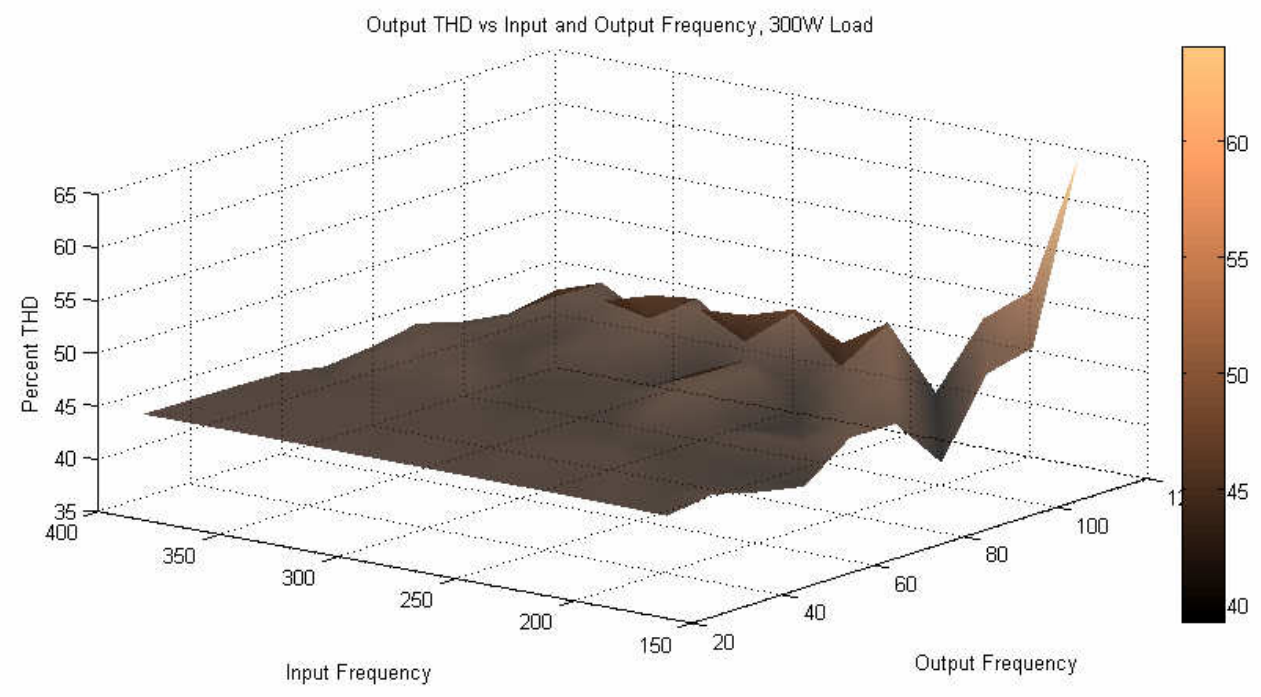

Figure 4-16. Simulated output total harmonic distortion at 122V/300W load

There is also a spike in the output THD when the output frequency is at a maximum of $120 \mathrm{~Hz}$ and the input frequency is a minimum of $180 \mathrm{~Hz}$. From Section 2-2, the ripple frequency of the output voltage occurs at six times the input frequency. When the output frequency is high and the input frequency is low, the ripple component appears within the first few harmonics of the output voltage. This then gets factored into PSpice's THD calculation. In the case where the output frequency is low and the input frequency is high, the ripple frequency is out of range of PSpice's THD calculation. This explains why the spike only occurs in a specific region of the THD plots in Figure 4-14 through Figure 4-16.

The last measurement is power efficiency. The efficiency plots are shown in Figure 4-17 through Figure 4-19. Similar to all of the other measurements, output frequency has little effect on the efficiency. Two switches are always conducting, resulting in constant switching losses. Expectedly, efficiency decreases as input frequency increases. This was predicted from the preliminary calculations in Section 4-1 and the trend shown in Figure 4-4. For a fixed output time period, higher input frequency 
results in more switching. This can be seen by comparing Figure 4-6(e) with Figure 4-7(e). More switching intervals result in more switching losses. This is a result of more switching transitions, the source of the largest switching loss. This results in a decrease in efficiency as input frequency increases.

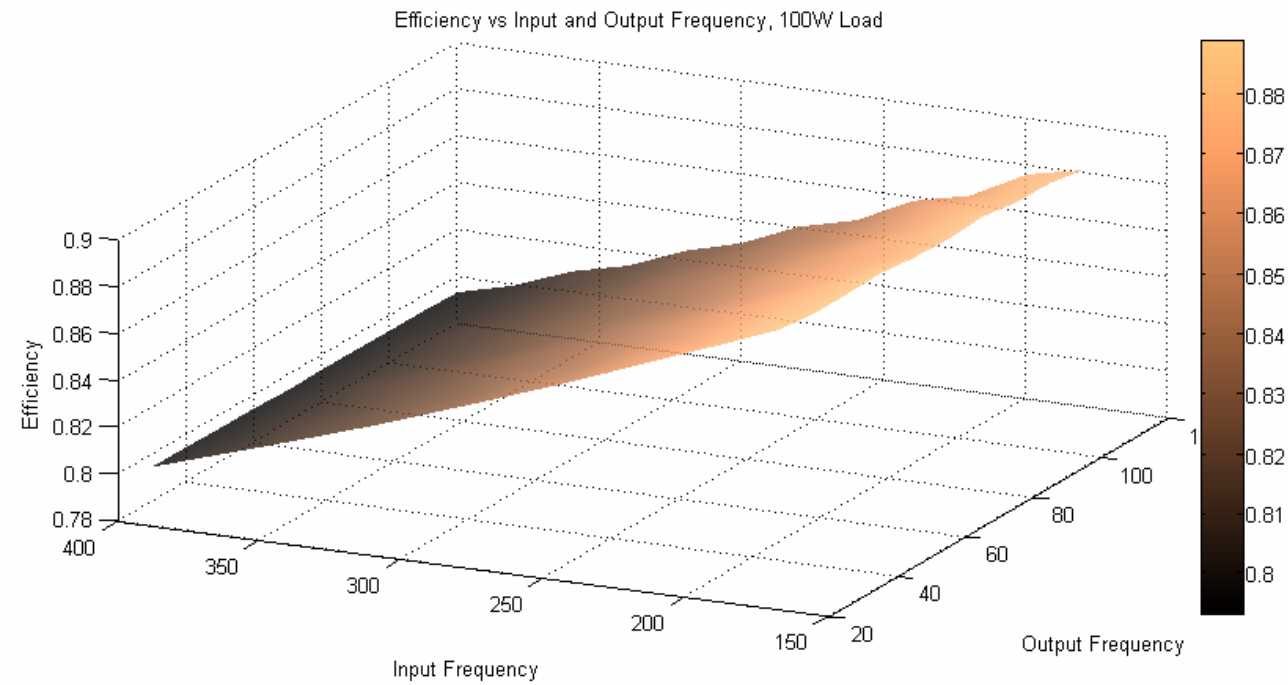

Figure 4-17. Simulated efficiency at 122V/100W load

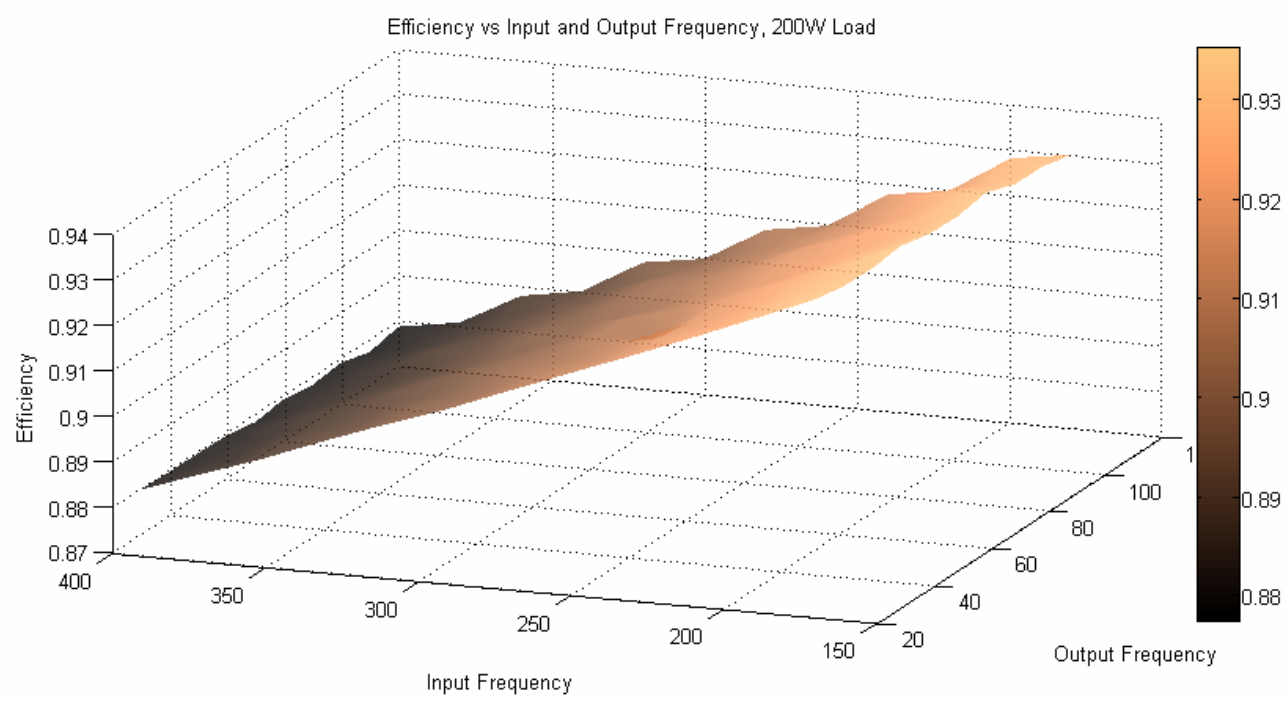

Figure 4-18. Simulated efficiency at $122 \mathrm{~V} / 200 \mathrm{~W}$ load 


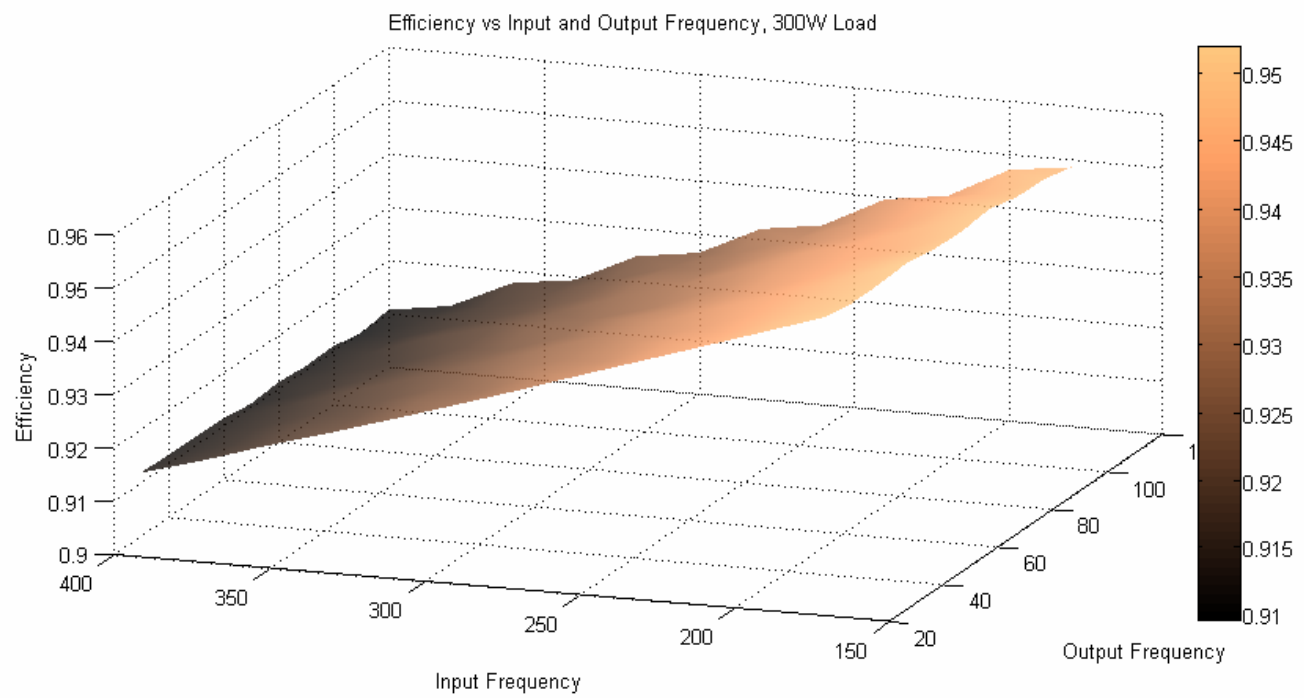

Figure 4-19. Simulated efficiency at $122 \mathrm{~V} / 300 \mathrm{~W}$ load

There is also the effect of increasing efficiency as the load increases. Observing Equation 4-4, the switching losses become less dominant as the output power increases. In a sense, output power scales more quickly than switching loss. Therefore, higher power applications tend to yield better efficiency as an insignificant amount of power is lost within the switches. The use of a cycloconverter in low power scenarios can yield a significant ratio of switching loss to output power, making it unfeasible for these applications.

In summary, there are many trends to observe. The main tradeoff is efficiency and power factor. On one hand, high input frequencies can yield higher power factor but lower efficiency. Lower input frequencies yield higher efficiency but utilizes more reactive power at the input, hence a lower power factor. Similarly, increasing the load also yields higher efficiency and lower power factor. For a given input frequency, the power quality metrics do not significantly change for different output frequencies. The only scenario to avoid is a low input frequency and high output frequency, in which the output voltage THD becomes significantly high. 


\section{Hardware and Analysis}

Implementation of the hardware requirements presented in Chapter 3 will be

outlined in this chapter. Section 5-1 deals with power circuit layout as well as control circuit design. Emphasis will be placed on the control circuit logic in order to successfully produce the desired cycloconverter output. The test measurement setup is covered in Section 5-2. The subsequent sections contain the recorded measurements from this test setup as well as detailed analysis of the results.

\subsection{Hardware Components}

The first part of the hardware implementation is the power circuit. This circuit is comprised of twelve SCRs, a load resistor bank, and the necessary wiring to handle the associated current and power. The SCRs are model SKKT 92/16E from Semikron which are rated for a reverse breakdown voltage of $1700 \mathrm{~V}$ and a forward current of $95 \mathrm{~A}$. These SCRs are typically used in high power applications. However, they will be tested under relatively low power conditions since the available power source in the power electronics lab at Cal Poly cannot supply the necessary power for a kilowatt system. Since the power quality measurements follow certain trends, the measured data can be extrapolated to larger loads. The SCRs are configured as a standard three-phase to single-phase cycloconverter as pictured in Figure 2-3. The implementation diagram is shown in Figure 5-1. A photo of this power circuit constructed in the power electronics lab is shown in Figure 5-2.

The load resistor bank is comprised of up to three Vishay Dale wirewound resistors connected in parallel. Each resistor is rated for $225 \mathrm{~W}$ at $150 \Omega \pm 5 \%$. 


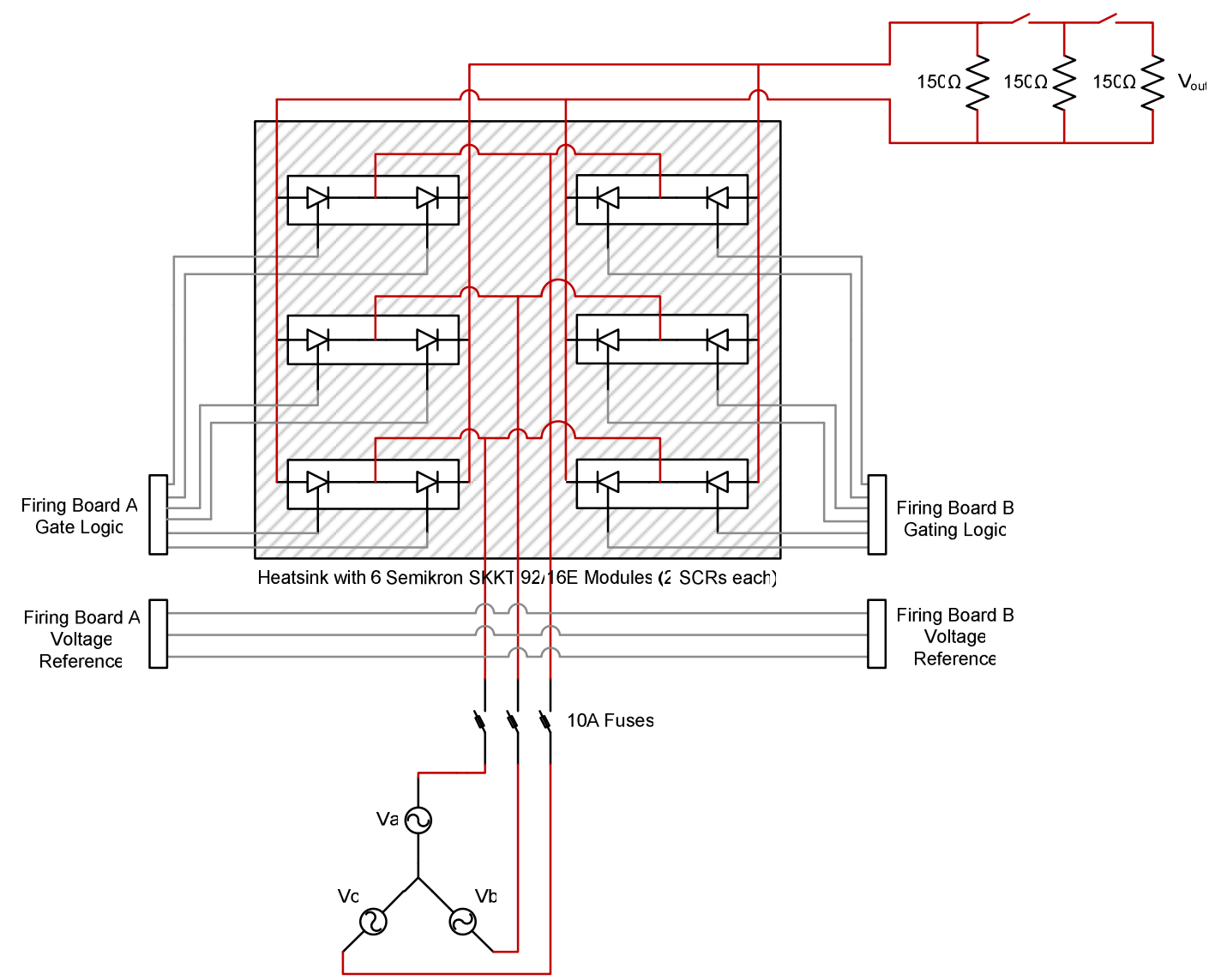

Figure 5-1. Power circuit implementation diagram, high current path shown in red

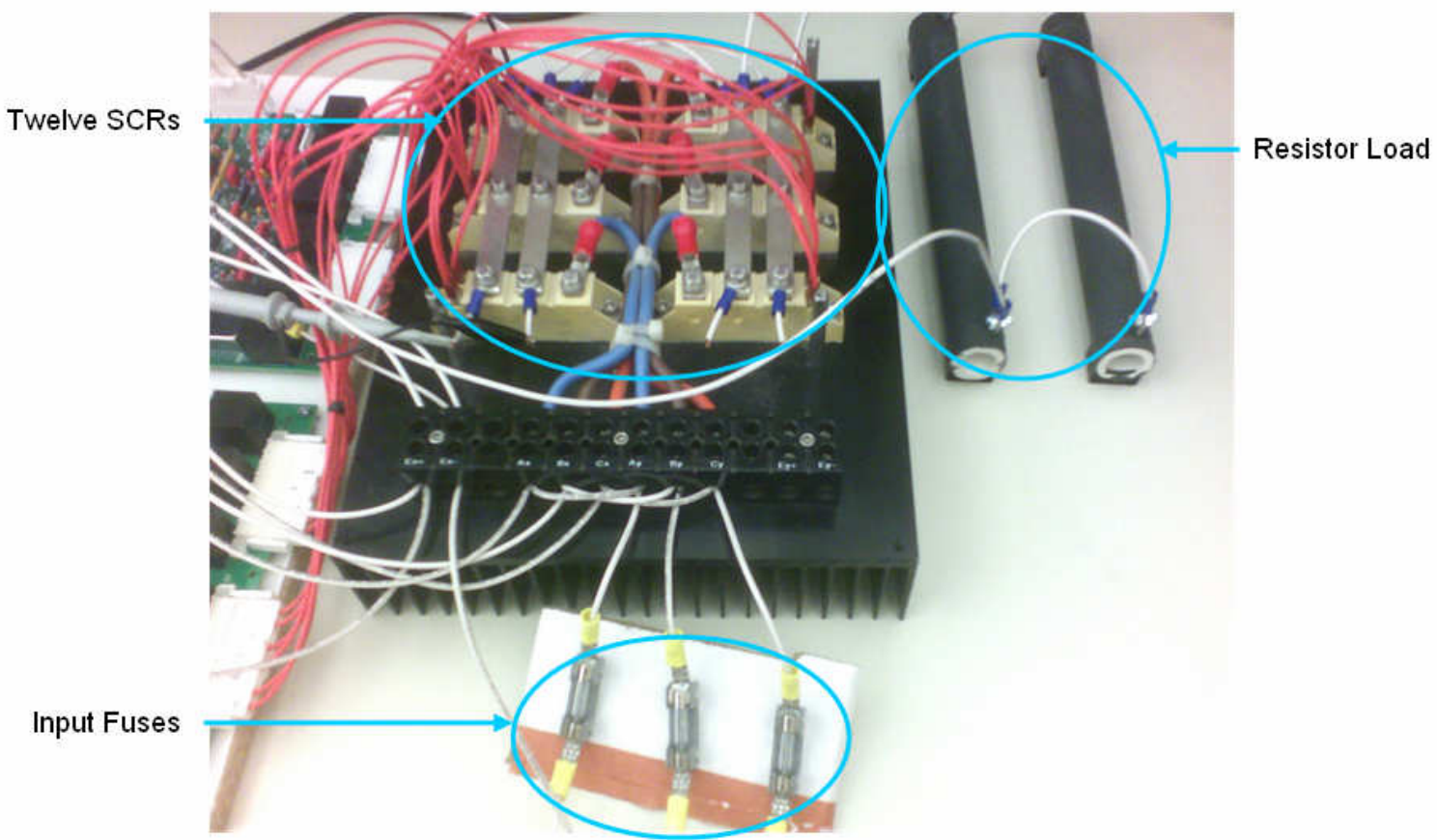

Figure 5-2. Photo of hardware power circuit 
One resistor is used for the $100 \mathrm{~W}$ load. The $200 \mathrm{~W}$ load uses two parallel resistors for an equivalent resistance of $75 \Omega$. The $300 \mathrm{~W}$ load uses three parallel resistors for an equivalent resistance of $50 \Omega$. In all cases the output voltage will be approximately $122 \mathrm{~V}$ according to Ohm's law, which is close to the design requirement of $120 \mathrm{~V}$. The necessary input and output current will be provided using 14 AWG stranded wire that is rated for $600 \mathrm{~V}$ and approximately $15 \mathrm{~A}$. A benefit of the large conductor size is reduced wire resistance. In addition, fuses are placed at the three-phase input to the circuit. These are rated for $250 \mathrm{~V}$ and $10 \mathrm{~A}$. The fuses are mainly present as a protection mechanism for current spikes that can damage the power circuit or more importantly, the control circuit.

The core of the controls circuit consists of the firing boards. A firing board is a printed-circuit board containing logic that drives the gating signals of the SCRs using only a small number of control signals. It is a complicated task to design the switching controller from scratch to allow for sufficient signal isolation and a variable frequency input. Signal isolation is important because it prevents switches from unintentionally conducting at an incorrect interval, which can create a short circuit across either the source or the load. Variable frequency input can only be accommodated by sensing the input frequency. This is commonly performed using a phase-locked loop and is especially complex for a wide input frequency range. The specific firing board utilized in this hardware implementation is the Enerpro FCOVF6100. A schematic of the FCOVF6100 firing board is shown in Figure 5-3 and a photo of the full controls circuit showing both firing boards is shown in Figure 5-4. The board houses an internal phaselocked loop as well as individual SCR gate drivers for signal isolation. 


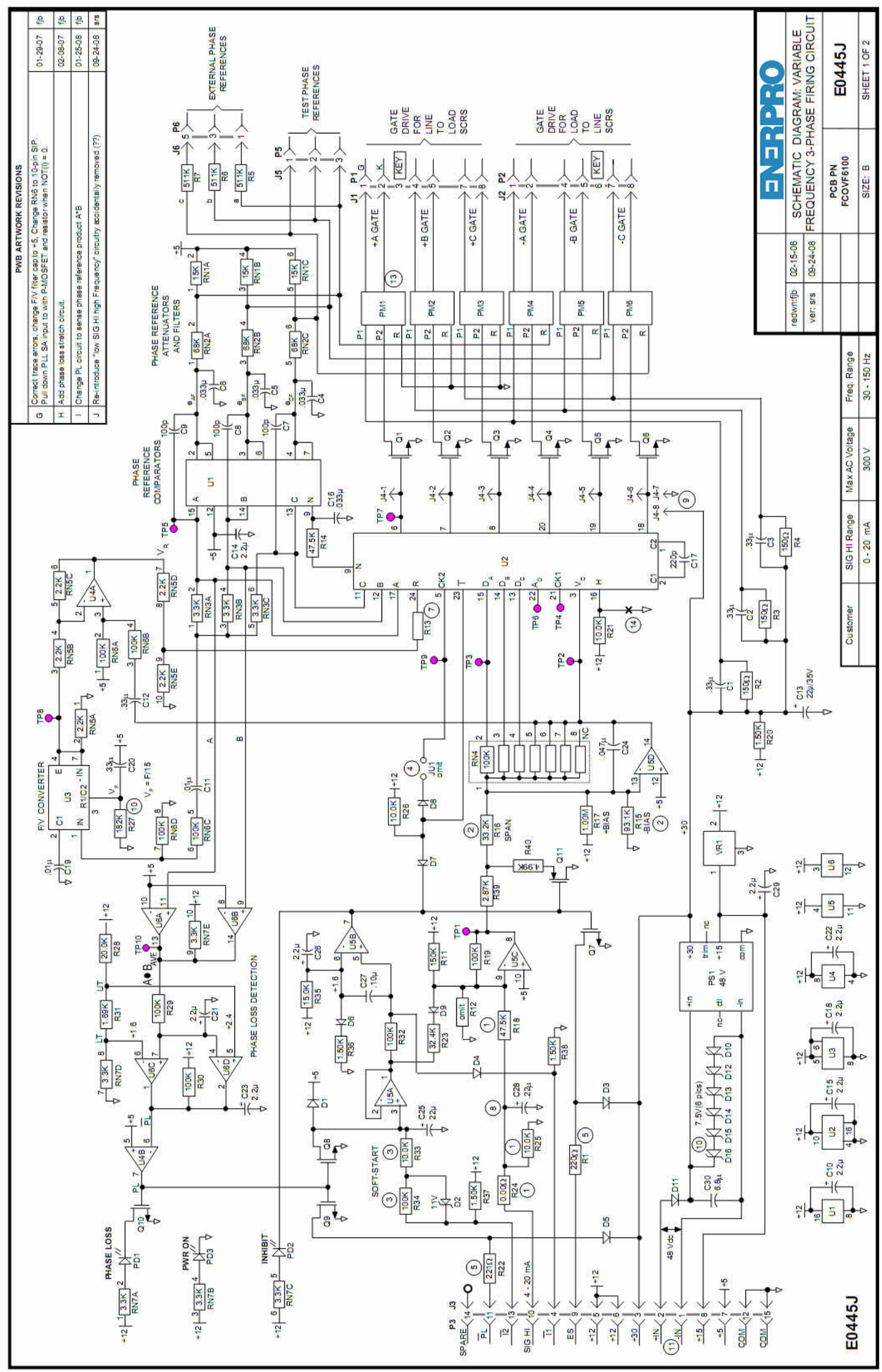

Figure 5-3. Enerpro FCOVF6100 firing board schematic 


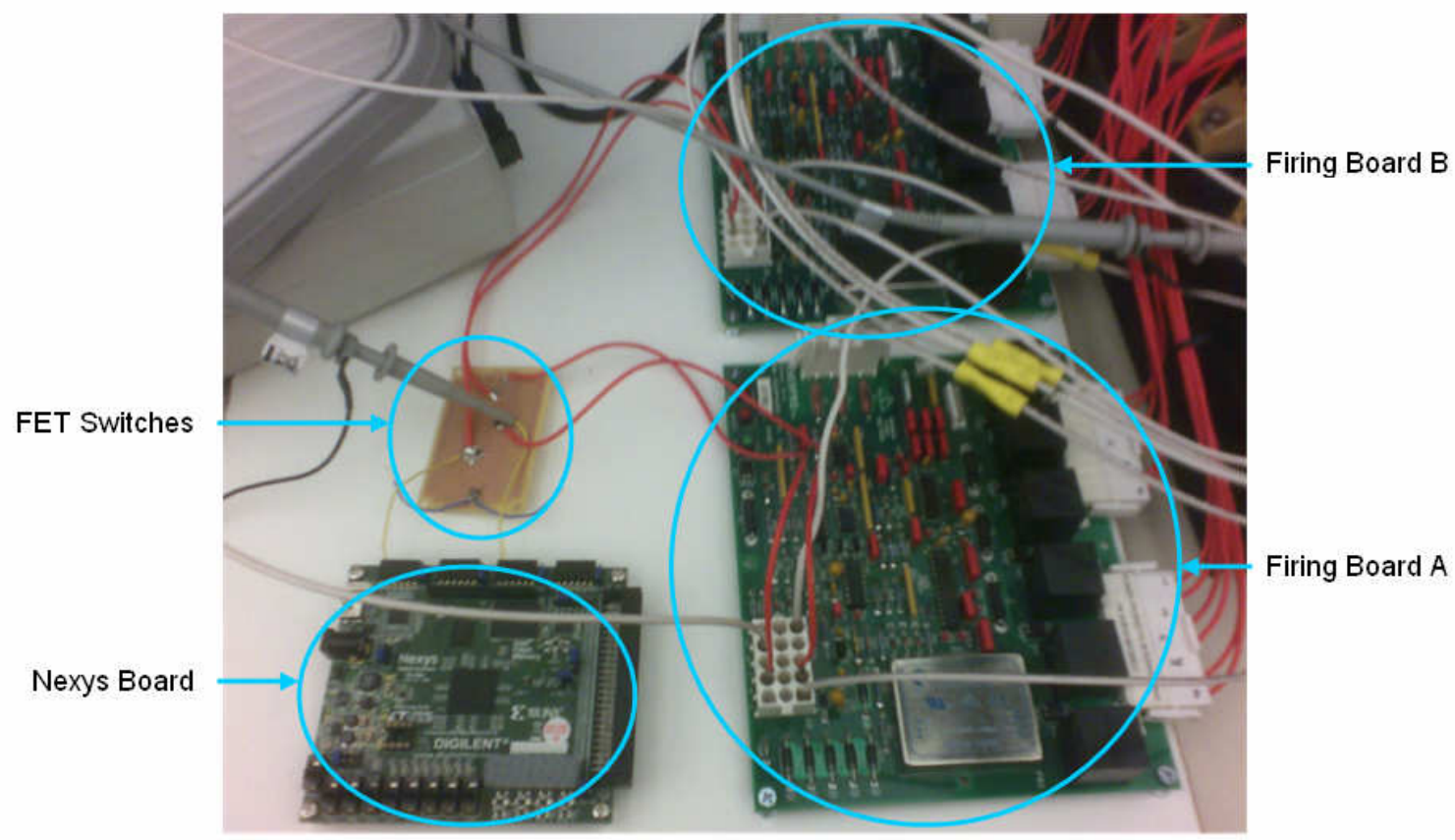

Figure 5-4. Photo of hardware controls circuit

The main disadvantage of this particular firing board is that an individual board can only provide a unipolar output. In other words, the output voltage can only go from zero volts to the maximum voltage determined by the firing angle. Hence two boards are required to output both the positive and negative halves of the output waveform. This is the same concept as the positive and negative converter bridges discussed at the beginning of Chapter 2. Enerpro does produce bipolar boards but they can only be configured for single input frequency operation.

The following board header descriptions apply for both firing boards used in the hardware implementation. Header J6 at the upper right corner of the schematic in Figure 5-3 connects directly to the three-phase AC power source. This provides the voltage sensing required for the board to determine the input frequency via the phase-locked loop. Headers $\mathrm{J} 1$ and $\mathrm{J} 2$ at the lower right of the schematic send out the pulse signals that connect to the gates of the SCRs. Header J3 at the bottom left of the schematic contains 
all of the necessary pins for firing board functionality. A DC power supply at $30 \mathrm{~V}$ is connected to pin 3 of this header to supply board power. A secondary DC power supply at $5 \mathrm{~V}$ is connected to pin 10 of header J3. This voltage corresponds to the firing angle. Zero volts at this pin equates to a 180 degree firing angle, which results in approximately zero volts at the output of the converter. Five volts at pin 10 equates to a zero degree firing angle, which results in the maximum possible voltage at the output of the converter. More details on setting the firing angle will be explained in Section 5-2.

Pin 4 of header $\mathrm{J} 3$ is the enable/inhibit pin of the board. This pin controls whether the board actively switches the SCRs or inhibits all of them. Latching pin 4 to pin 5 will enable the board while leaving these two pins open will inhibit the board. In order to vary the output frequency, the conduction time of each firing board correlates with Equation 2-2. Each firing board turns on for half of the desired output period. In other words, one firing board will be enabled while the other is inhibited for exactly half of the output period. The effect is similar to what is shown in Figure 2-5 for the positive and negative converter bridge waveforms.

The next issue is how to alternatively enable and inhibit the two firing boards at precisely the desired output frequency. In this case, Digilent's Nexys board containing the Xilinx Spartan3 field-programmable gate array (FPGA) will be used to accurately create the timing signals. This FPGA is programmed with VHDL code in the Xilinx ISE WebPack software. The code simply uses the Nexys board clock of $50 \mathrm{MHz}$ to create a timer loop. For example, suppose the desired output frequency is $400 \mathrm{~Hz}$. Each clock cycle is $20 \mathrm{~ns}$ and the desired output period is $2.5 \mathrm{~ms}$. Therefore, it takes 125,000 clock cycles for each output period. To allow for symmetrical positive and negative bridges, 
each bridge requires 62,500 clock cycles. However, this alone is not sufficient. The problem is that if one board were to inhibit at the exact time the other board enables, there is the likelihood of a short circuit and a dangerous current spike. A dead time is required in which both boards are fully inhibited before one board is re-enabled. This is arbitrarily set to 1,500 clock cycles or $30 \mu$ s. Therefore for each half period of the 400 $\mathrm{Hz}$ output example, a single board will be enabled for 61,000 clock cycles after which both boards inhibit for 1,500 clock cycles.

Two binary outputs of the Nexys board create the switching signal based on the clock cycles. The output is either at a low voltage of $0 \mathrm{~V}$ or at a high voltage of $3.3 \mathrm{~V}$. In order to latch pin 4 to pin 5 of the firing board header J3 as explained earlier, the output pins of the Nexys board will drive the gates of two field-effect transistors (FET) similar to the pass transistor concept. If the gate voltage is high, each FET turns on and the two firing board pins will be latched together. If the gate voltage is low, the FET turns off and the pins are left open. The transistor used is the NXP Semiconductor BSH103 MOSFET. The key specifications are a low gate threshold at $400 \mathrm{mV}$ and a low switching time at a maximum $27 \mathrm{~ns}$. The low threshold voltage ensures that the Nexys board can physically drive the transistors. The low switching time allows for faster enabling and inhibiting transitions. The Nexys board is shown at the bottom left of Figure 5-4 and the FETs are located on the small protoboard right above the Nexys board. 


\subsection{Hardware Procedure}

This section covers equipment and configurations required to make the power quality measurements as well as specific circuit measurement procedures. The measurements will be performed in the power electronics lab at Cal Poly. The available three-phase power source is the California Instruments $1503 \mathrm{~T}$ AC power source as seen in the lower right corner of Figure 5-5. This power source is connected through the fuses to the cycloconverter. The source is configured for $120 \mathrm{~V}_{\mathrm{LN}}$ with variable frequency between $180 \mathrm{~Hz}$ to $400 \mathrm{~Hz}$ in increments of $20 \mathrm{~Hz}$. Two DC power supplies at the top left corner of Figure 5-5 are used for the $30 \mathrm{~V}$ firing board supply as well as the firing voltage adjustment between $0 \mathrm{~V}$ and $5 \mathrm{~V}$. There is also a cooling fan present on the right of Figure 5-5 used to cool down the resistors since they build up heat over time. This is especially noticeable at higher output power. The fan helps maintain a reasonably constant load resistance since resistance changes as a function of temperature, which can create large fluctuations in the measurements.

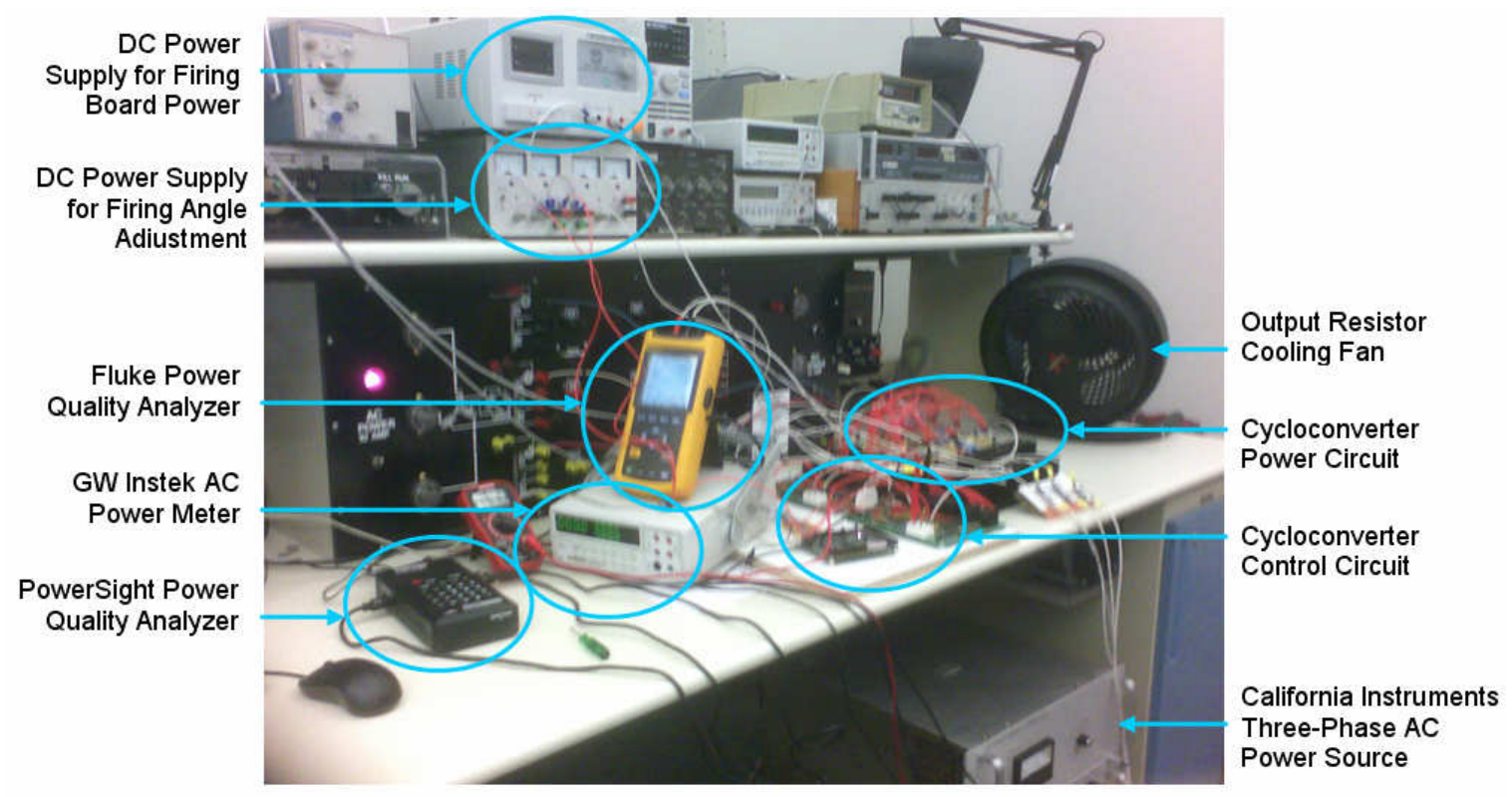

Figure 5-5. Photo of hardware test bench setup 
Measurements will be recorded from three different machines. The three phase AC input will be measured using the PowerSight PS3000 power quality analyzer. This analyzer is responsible for average power and power factor measurements at the input. The voltage is measured using banana leads and the current is sensed with current probes. The single phase AC output will be measured using the GW Instek GPM-8212 AC power meter. The meter is connected in line between the SCRs and the load. This power meter measures output average power. Total harmonic distortion measurements are recorded using the Fluke 43B Power Quality Analyzer. It was initially assumed that since the analyzer is dual channel, input current THD and output voltage THD measurements can be made simultaneously. However, the second channel used for measuring current requires voltage sensing on the first channel. Measurements have to be made in succession, especially since there is only one analyzer in lab capable of a wide frequency range. In addition, a GW Instek digital oscilloscope and a Tektronics current probe amplifier are used for capturing voltage and current waveforms.

In order to turn on the circuit, the DC power supply for firing board power as well as the AC power source are turned on to allow the firing board to lock onto the input frequency. The Nexys board is then turned on and the desired output frequency is selected via programmed switches. When the Nexys board enables each firing board, that firing board sends picket-fence gate drive signals to the SCRs. The picket-fence signal turns on the SCR with a higher current firing pulse followed by a lower current sustaining pulse for each conduction interval. In other words, each switch starts out with a high gating voltage and ramps down. This can be seen in Figure 5-6 showing the switching waveforms for all SCR gating signals. The SCR numbering convention is 
preserved as initially seen in Figure 2-3. Next, the DC power supply for firing angle adjustment is turned on at $0 \mathrm{~V}$. This corresponds to a 180 degree firing angle and no voltage appears at the output as expected. This voltage is slowly increased until the desired output average power appears on the GW Instek AC power meter. It was observed that small firing angle adjustments on the DC power supply can result in a large changes in output power. A 25-turn potentiometer is used as a voltage divider between the power supply fixed at $5 \mathrm{~V}$ and the corresponding firing board pins. This allows for fine tuning of the firing angle without subjecting the load to unnecessarily high power.

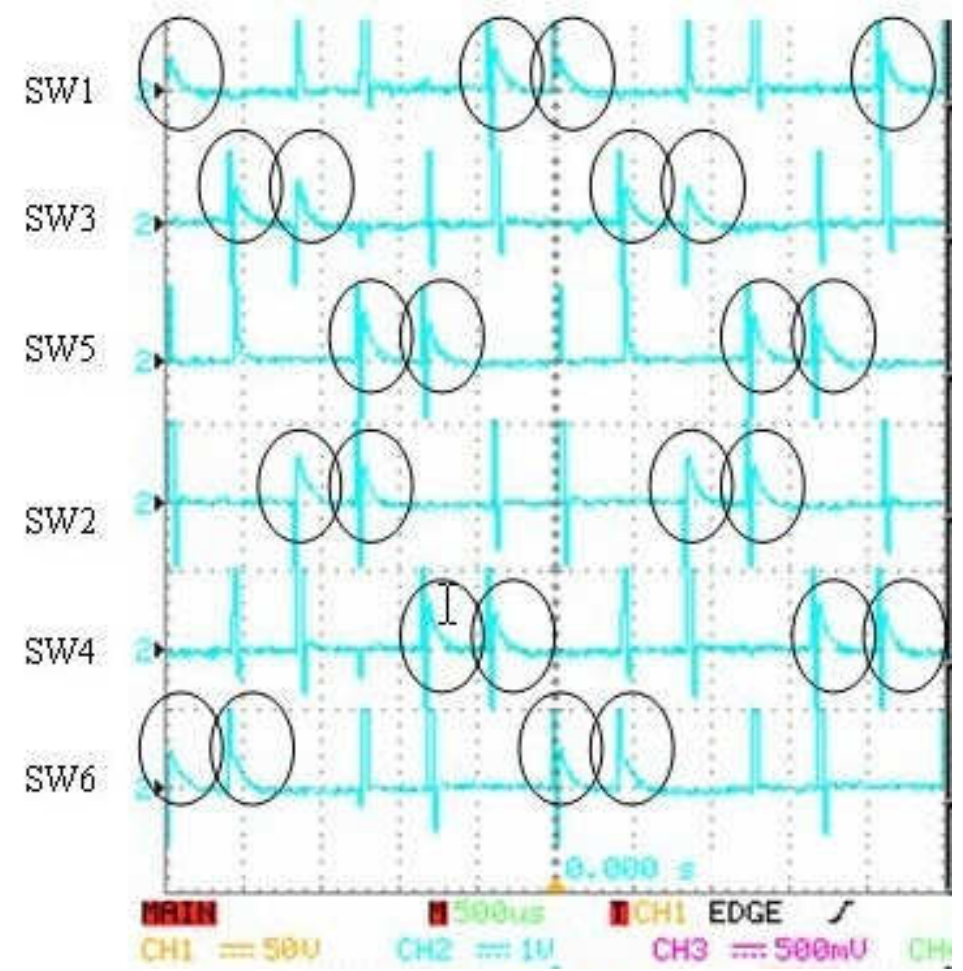

Figure 5-6. Oscilloscope captures of SCR gating signals for an arbitrary 1.07V firing angle adjustment voltage

After completing this procedure to turn on the firing boards and obtain the desired output power, the measurements can be made. Input and output measurements for average power can be made in a simple manner with the equipment permanently fixed in their respective locations. Total harmonic distortion measurements can only be made one 
at a time for either the input current or output voltage. Caution must be exercised to prevent shorting the input or the load while switching the test leads for each THD measurement. The measurement data based on the above procedure can be found in Section 5-3.

\subsection{Hardware Results}

This section will focus mainly on presenting the hardware results along with important trends. Detailed comparisons for specific cases can be found in Section 5-4 through Section 5-6. Before presenting the main data, oscilloscope captures of the input and output waveforms are shown in Figure 5-7 and Figure 5-8, respectively. In the oscilloscope captures, the current probe amplifier shows $1 \mathrm{~A}$ per $10 \mathrm{~mW}$ of oscilloscope vertical division. This yields a RMS input current of approximately $1.5 \mathrm{~A}$ and a RMS output current of $1.66 \mathrm{~A}$. The RMS input voltage is $120 \mathrm{~V}$ and the RMS output voltage is $121 \mathrm{~V}$. Example input and output frequency domain spectra are shown in Figure 5-9.

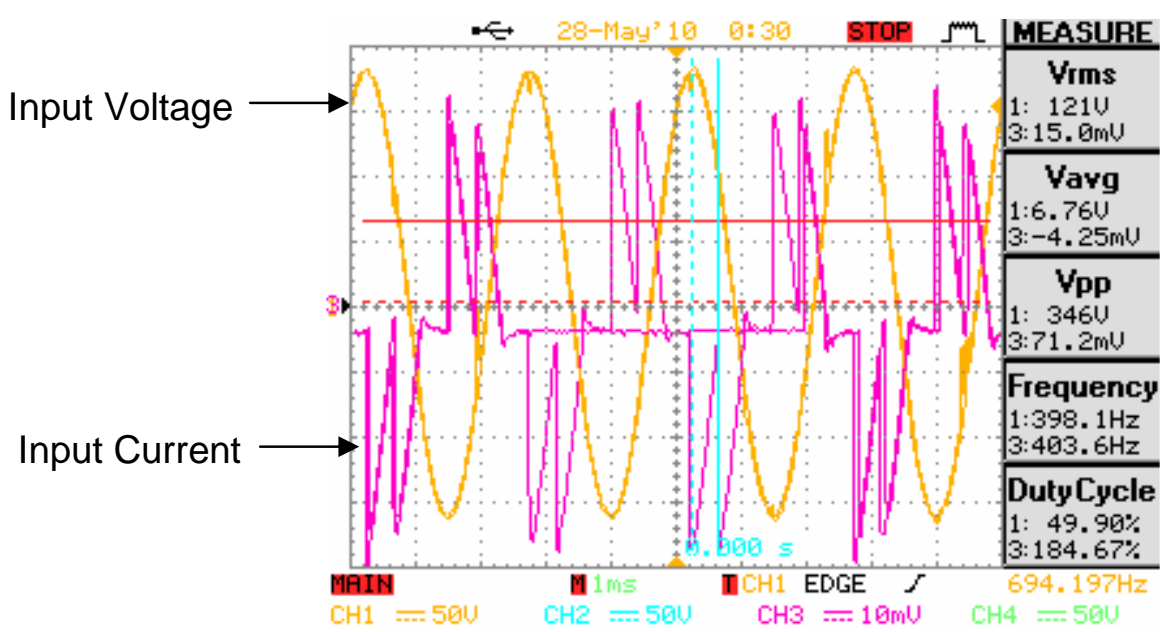

Figure 5-7. Oscilloscope captures of input voltage and current waveforms 


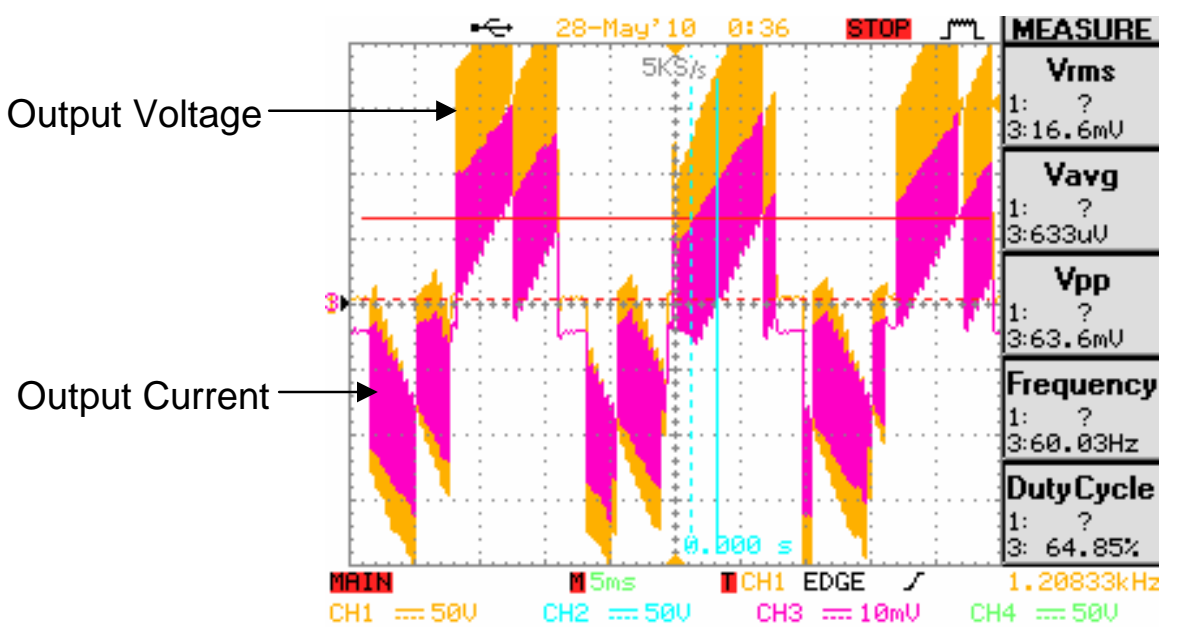

Figure 5-8. Oscilloscope captures of output voltage and current waveforms

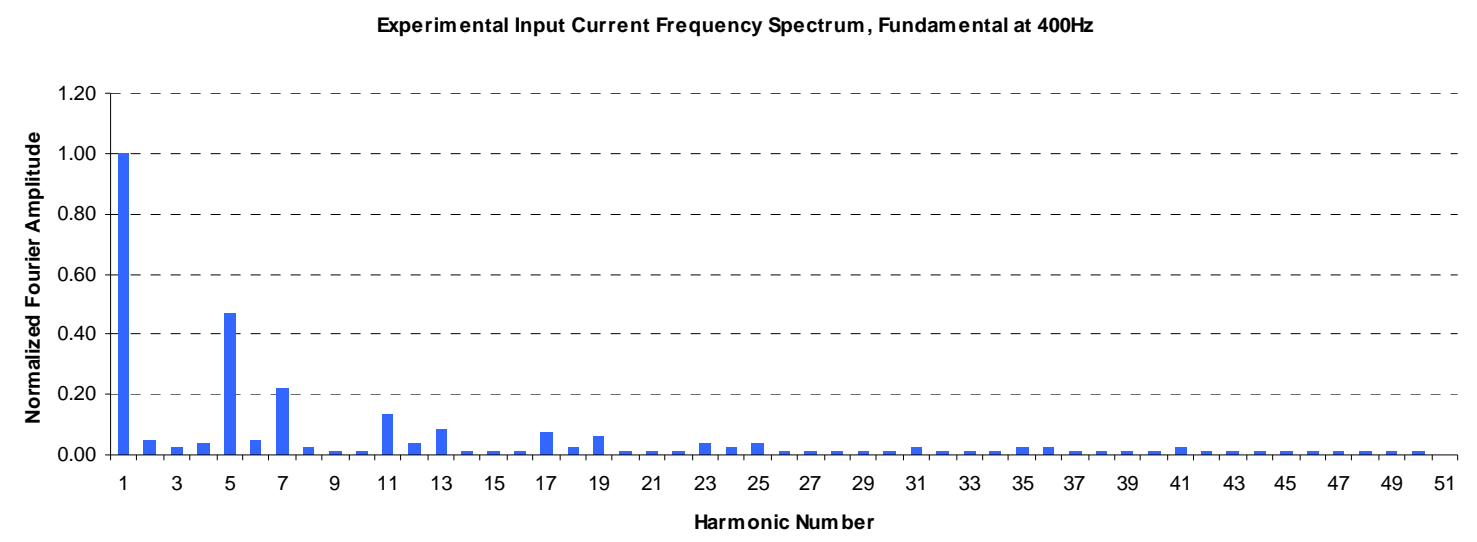

Experimental Output Voltage Frequency Spectrum, Fundamental at $30 \mathrm{~Hz}$

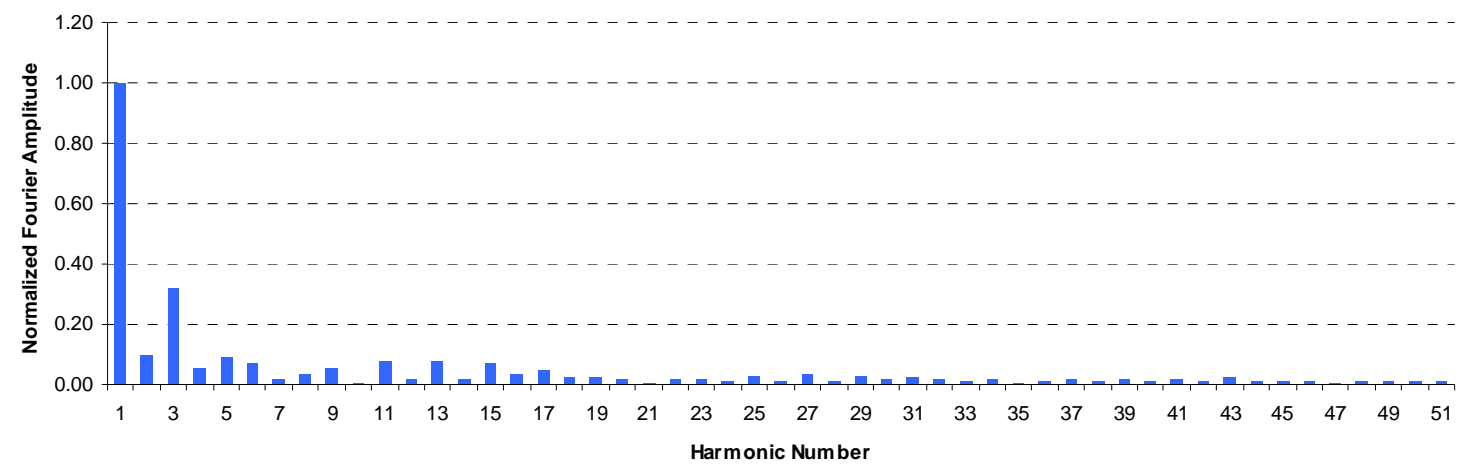

Figure 5-9. Experimental $200 \mathrm{~W}, 400 \mathrm{~Hz}: 30 \mathrm{~Hz}$ cycloconverter frequency spectra: (a) input current, (b) output voltage

The spectra are similar to Figure 4-7 but with greater fluctuation. The input current triplen harmonics are not perfectly zero, due to a small amount of circuit reactance. 
Similar to Section 4-4, there will be four groups of plots for input power factor, input THD, output THD, and power efficiency. Each plot group will contain three plots for each measurement corresponding to each of the three loads. The plots are three-dimensional with each measurement variable plotted on the z-axis. The x-y plane contains the input and output frequency matrix.

The first measurement is input power factor. The plots are shown in Figure 5-10 through Figure 5-12. Power factor remains fairly constant with output frequency as expected. The two other trends are distinctly different from simulation data. The first is that there is a negative linear slope between input frequency and power factor. The other trend is that power factor appears to increase with load. Both of these trends contradict the findings in simulation. There are two possible reasons for this outcome. The first reason is that the PowerSight analyzer does not make very accurate measurements at higher frequency. By observing the experimental and simulation plots at approximately $180 \mathrm{~Hz}$ input frequency, the difference in power factor is much less than at $400 \mathrm{~Hz}$ input frequency.

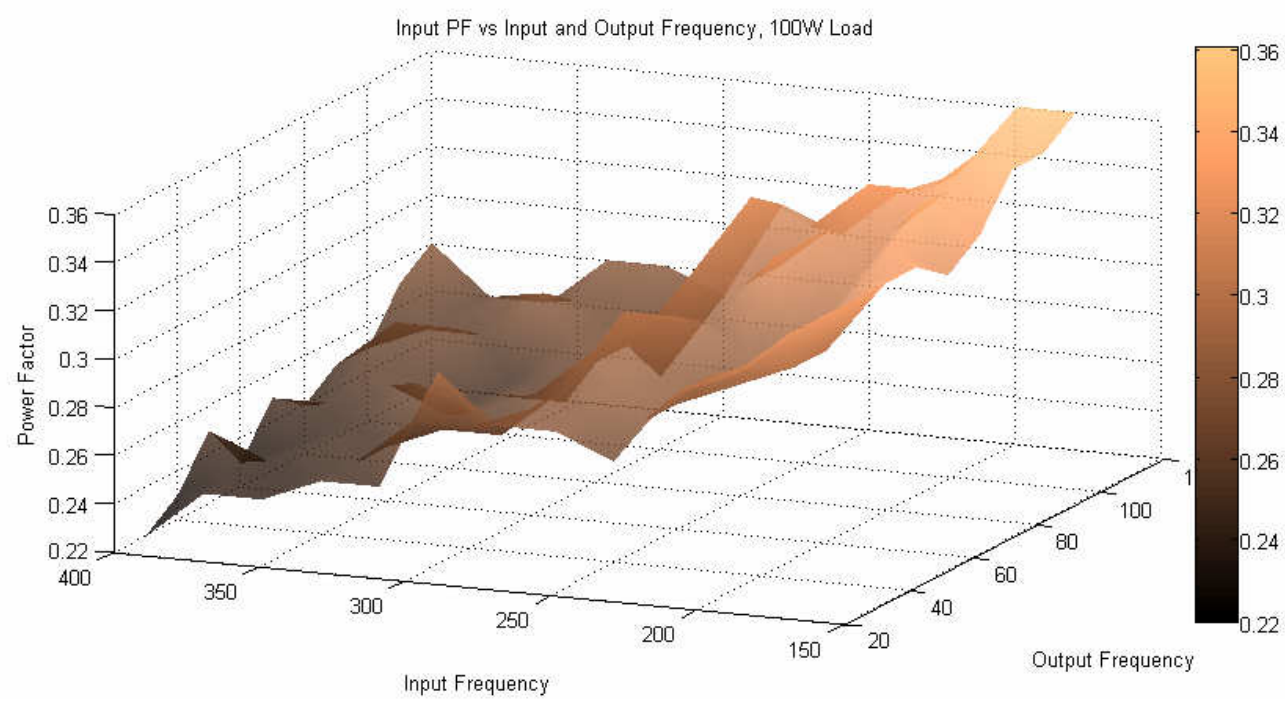

Figure 5-10. Experimental input power factor at 122V/100W load 


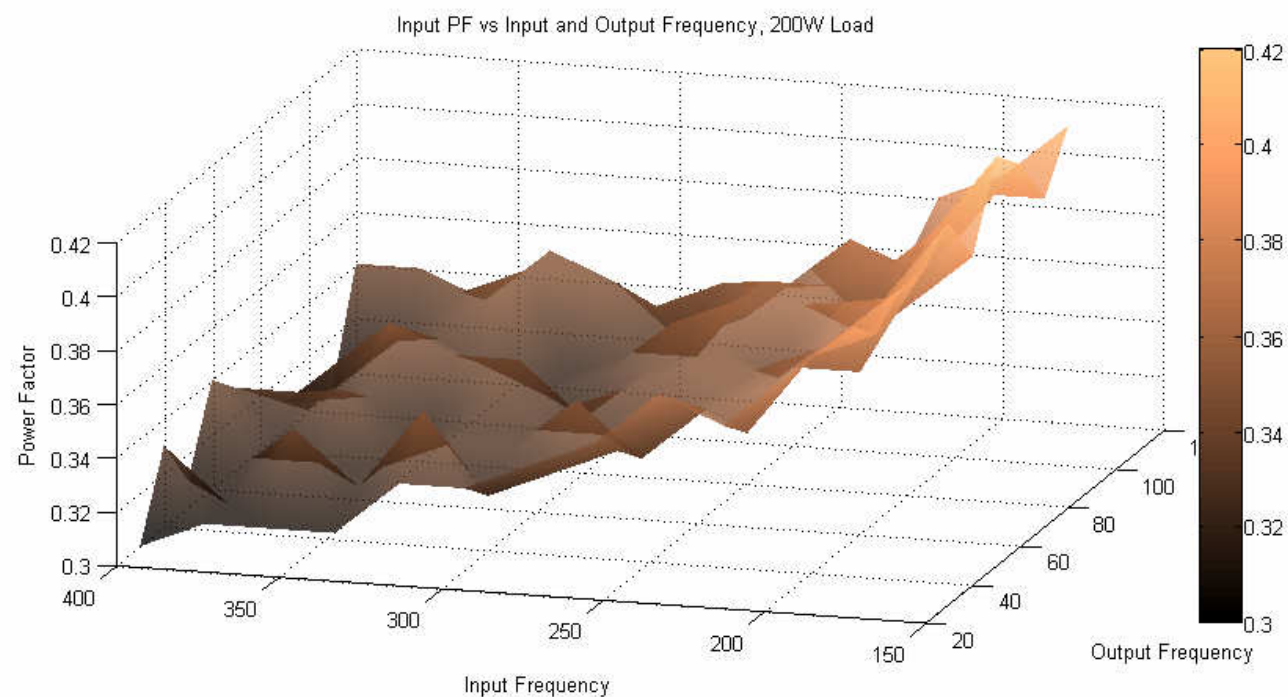

Figure 5-11. Experimental input power factor at 122V/200W load

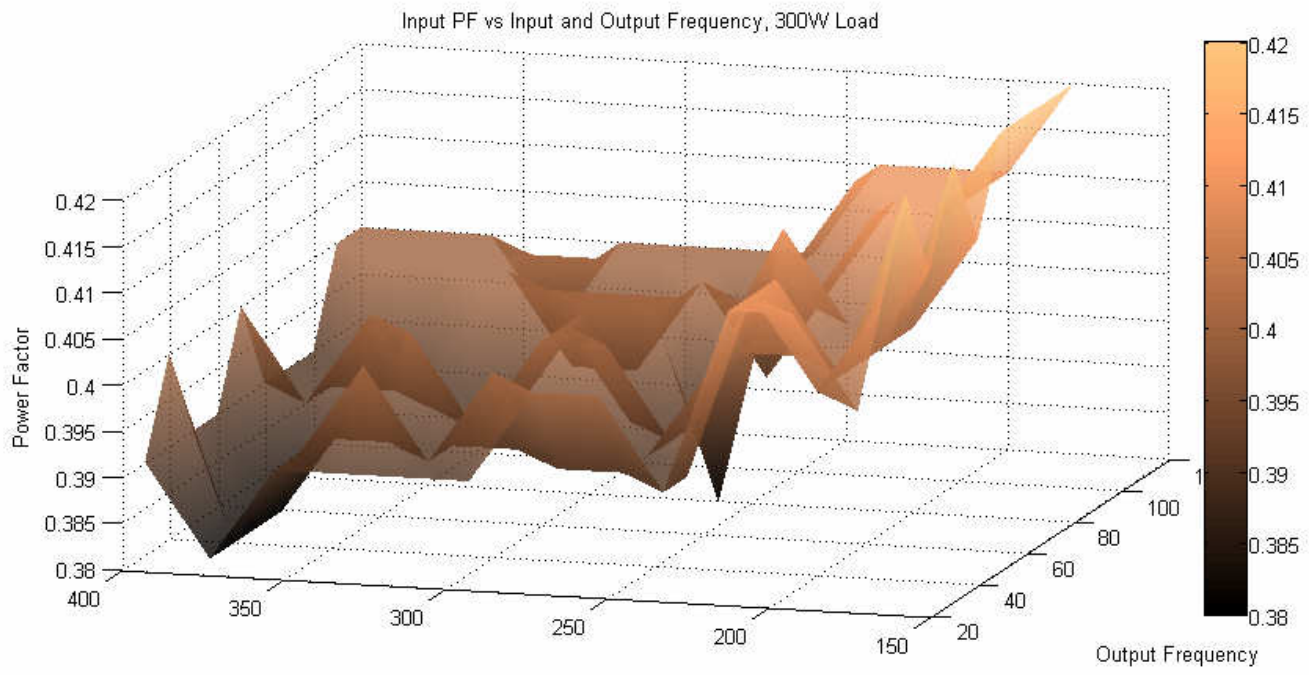

Figure 5-12. Experimental input power factor at $122 \mathrm{~V} / 300 \mathrm{~W}$ load

This also brings about the second reason that the simulation model may not be perfectly accurate. With the power factor decreasing experimentally with higher input frequency and lower load, there appears to be more capacitance in the circuit. It is difficult to incorporate all of the possible circuit capacitances in order to truly represent the hardware configuration. It is reasonable to conclude that the data correlates more closely at higher 
loads and lower input frequencies. A maximum deviation of 0.2 power factor is observed.

The next set of measurements is input total harmonic distortion. These plots can be seen in Figure 5-13 through Figure 5-15. There is an average deviation between experimental and simulation data of about $20 \%$ THD. This can be explained by the fact that PSpice and the Fluke power quality analyzer measure THD somewhat differently.

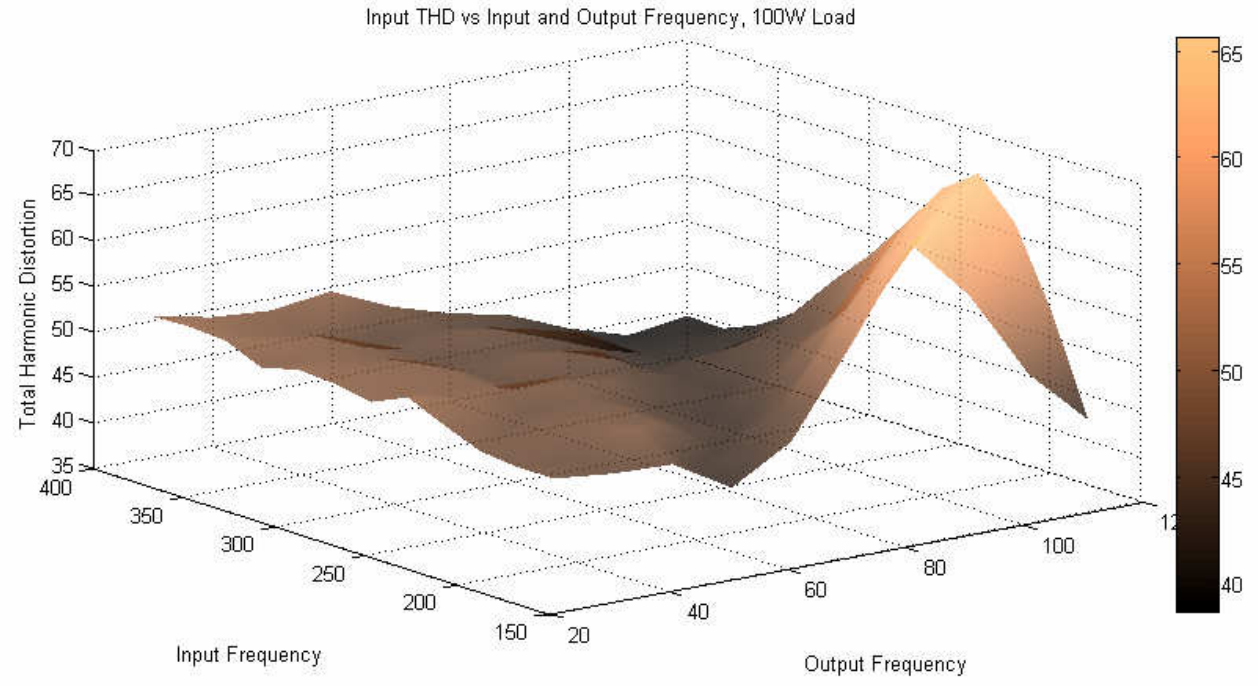

Figure 5-13. Experimental input total harmonic distortion at 122V/100W load

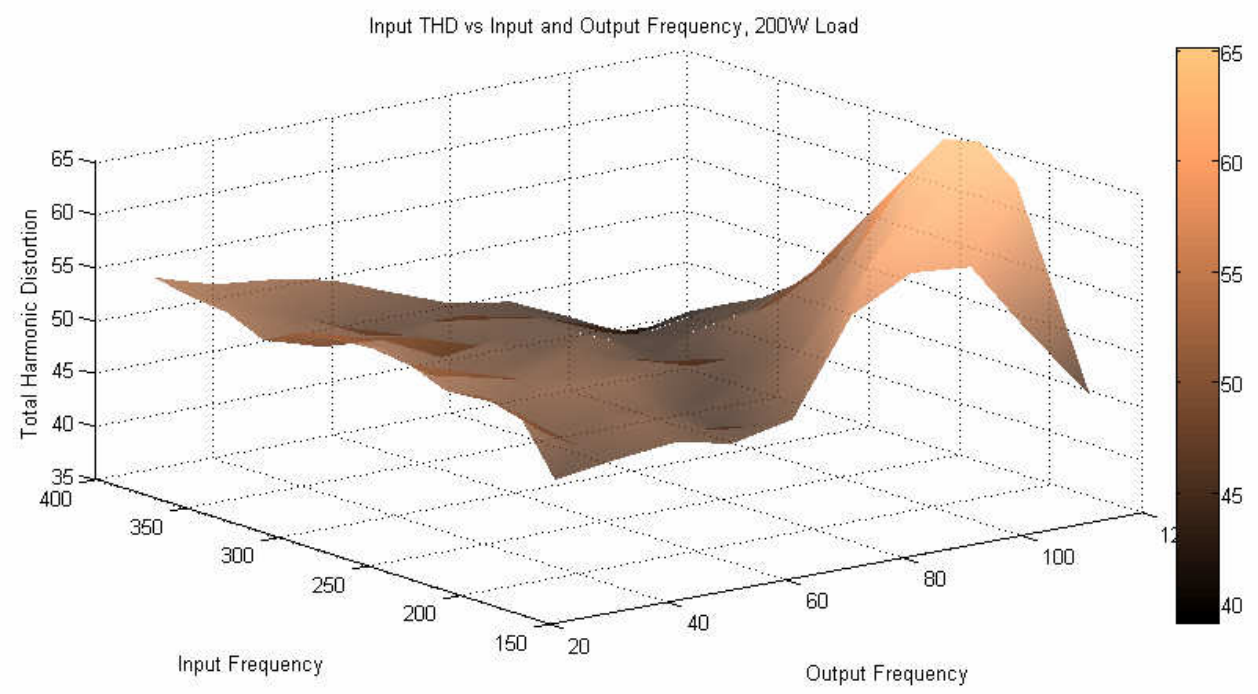

Figure 5-14. Experimental input total harmonic distortion at 122V/200W load 


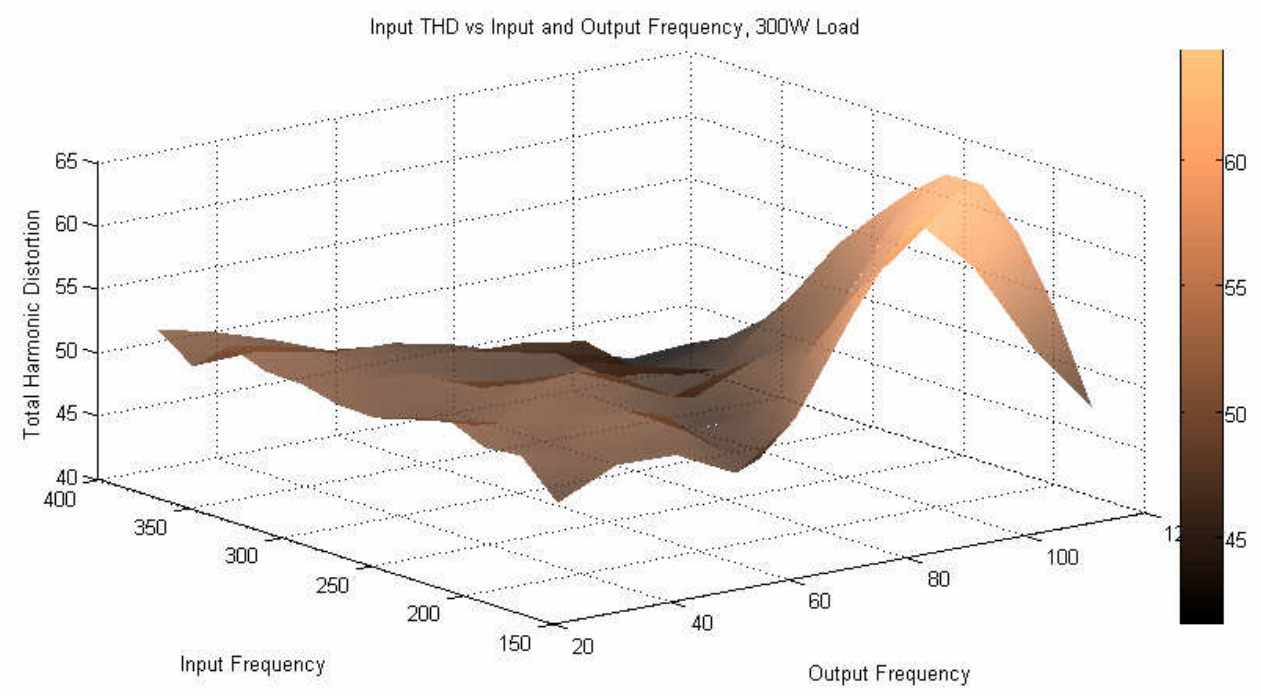

Figure 5-15. Experimental input total harmonic distortion at 122V/300W load

The input THD waveform appears to peak when the input frequency is twice the output frequency. The simulation results in Section 4-4 show that input THD can fluctuate especially when the input frequency is an integer multiple of the output frequency for the same reasons previously mentioned. Although this is not unexpected, the change in THD can be quite significant. A deviation of $30 \%$ can occur when the input frequency increases between 1.5 times and 2 times the output frequency.

Output total harmonic distortion is the next power quality parameter. The corresponding plots are shown in Figure 5-16 through Figure 5-18. There is much less average deviation between experimental and simulation data. However, the instantaneous deviation is fairly significant. This is mainly due to the fact that the output frequency is not perfectly locked onto the input. The output frequency control from the Nexys board can be thought of as an open loop system. It does not monitor the input frequency or the status of gate pulses from the firing board. This is the preferred method of implementing the cycloconverter in order to avoid complex control system design. The disadvantage of this approach is that the output waveform harmonics are always 
fluctuating since the phase difference between the output waveform and the input waveform is never constant. Although the instantaneous deviation between experimental and simulation data can be as high as $20 \%$ THD, the average deviation is much lower at approximately $5 \%$.

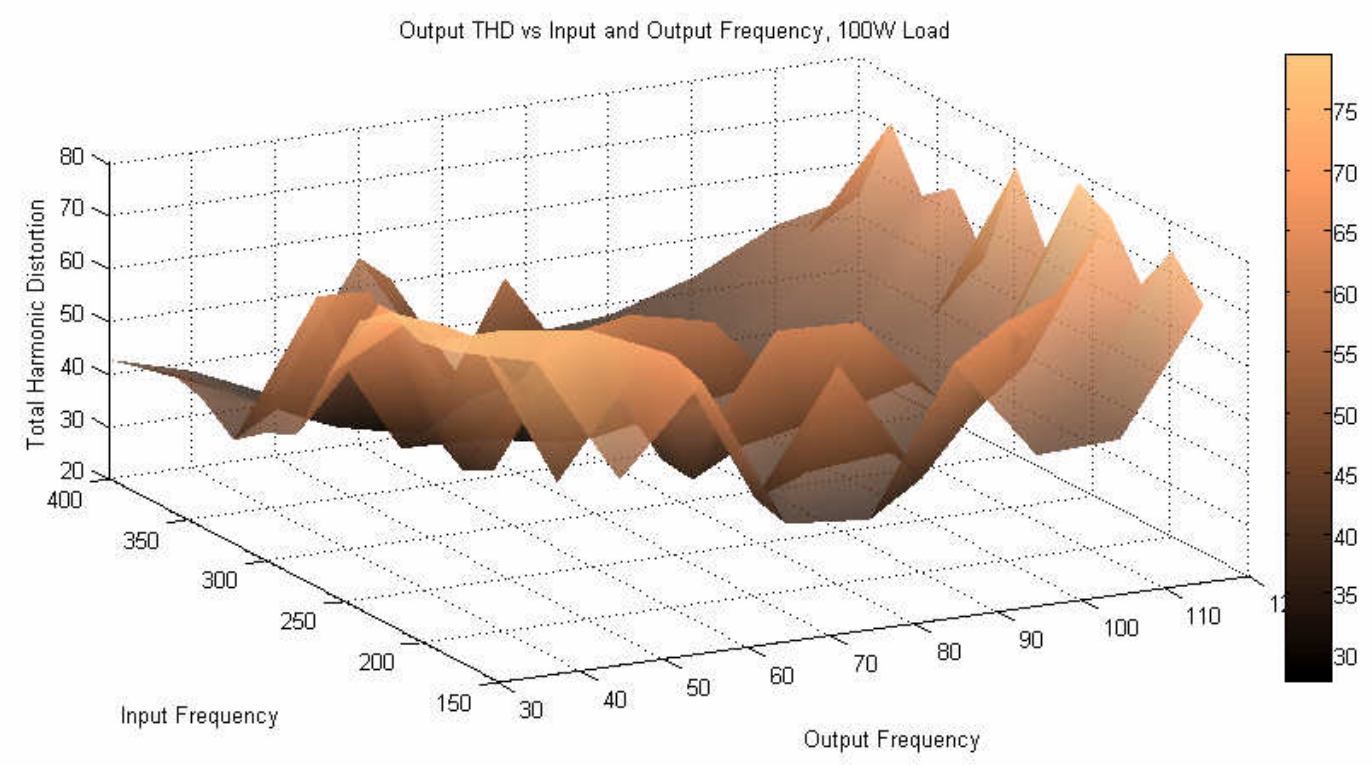

Figure 5-16. Experimental output total harmonic distortion at 122V/100W load

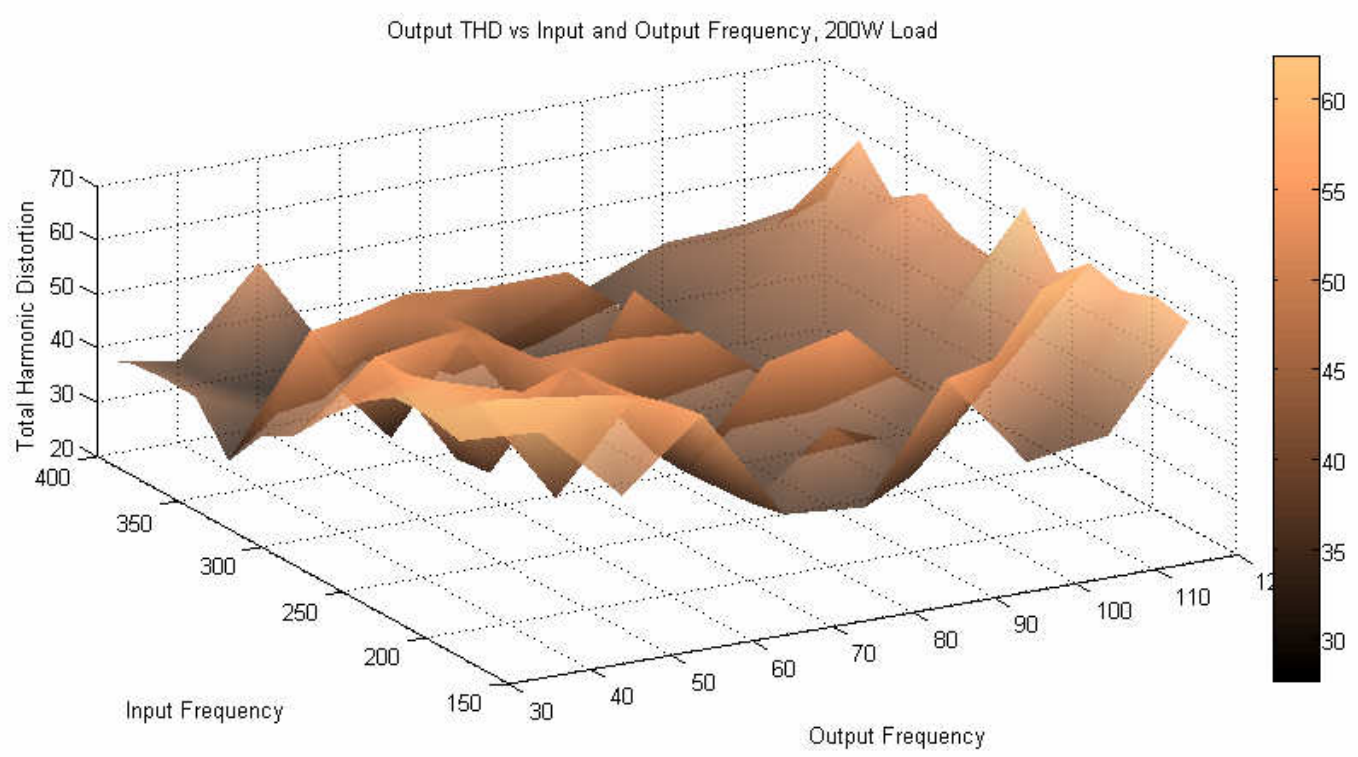

Figure 5-17. Experimental output total harmonic distortion at 122V/200W load 


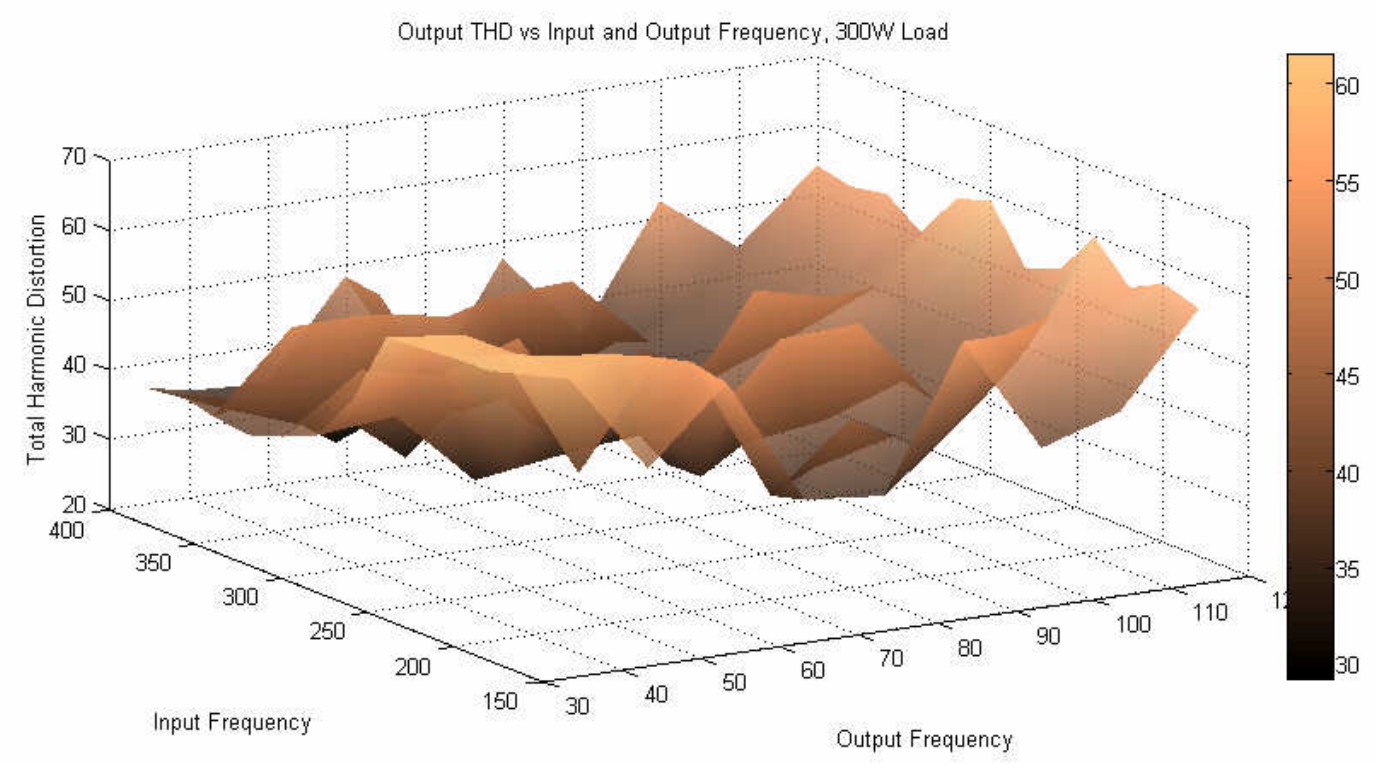

Figure 5-18. Experimental output total harmonic distortion at 122V/300W load

The last measurement is power efficiency. This is the only data set that correlates well with the simulation data. As seen in Figure 5-19 through Figure 5-21, efficiency is relatively constant with output frequency as switching loss is relatively constant.

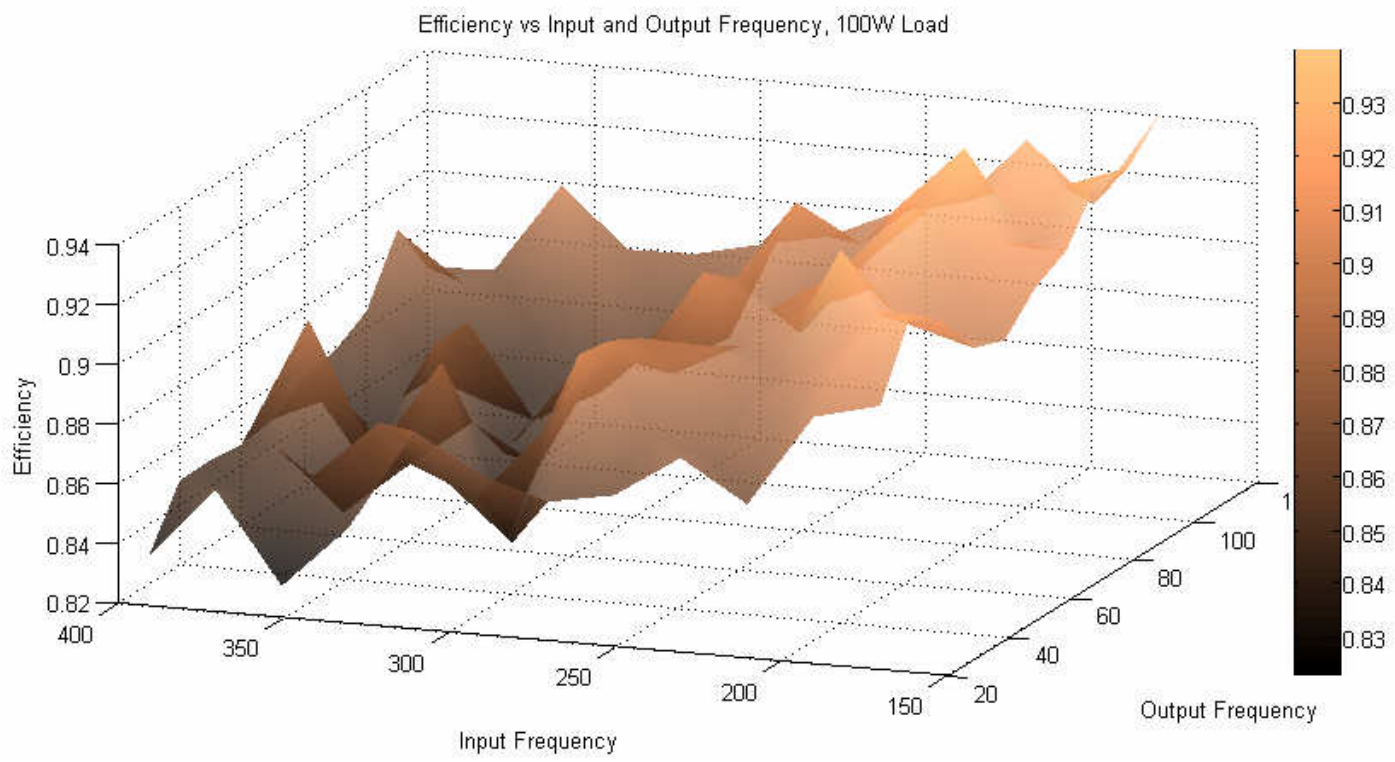

Figure 5-19. Experimental efficiency at $122 \mathrm{~V} / 100 \mathrm{~W}$ load 


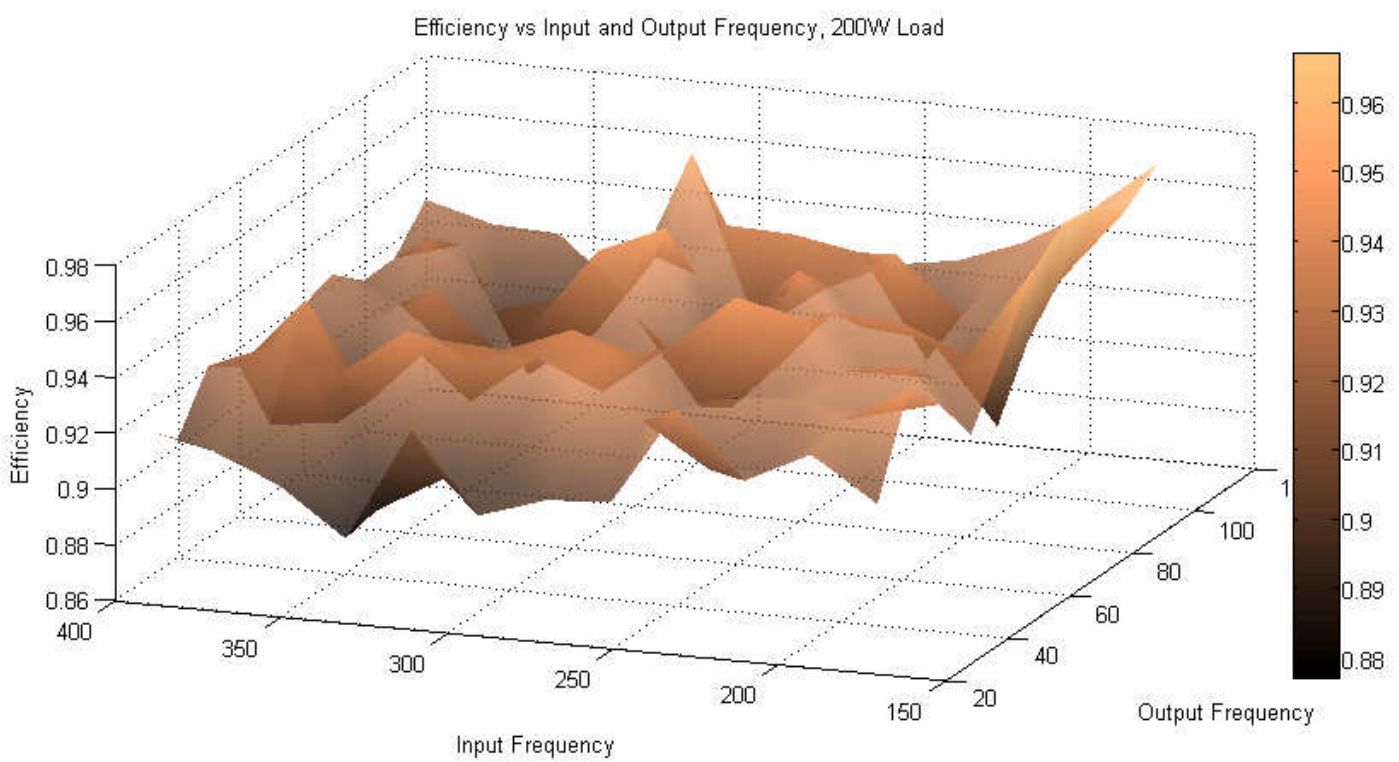

Figure 5-20. Experimental efficiency at 122V/200W load

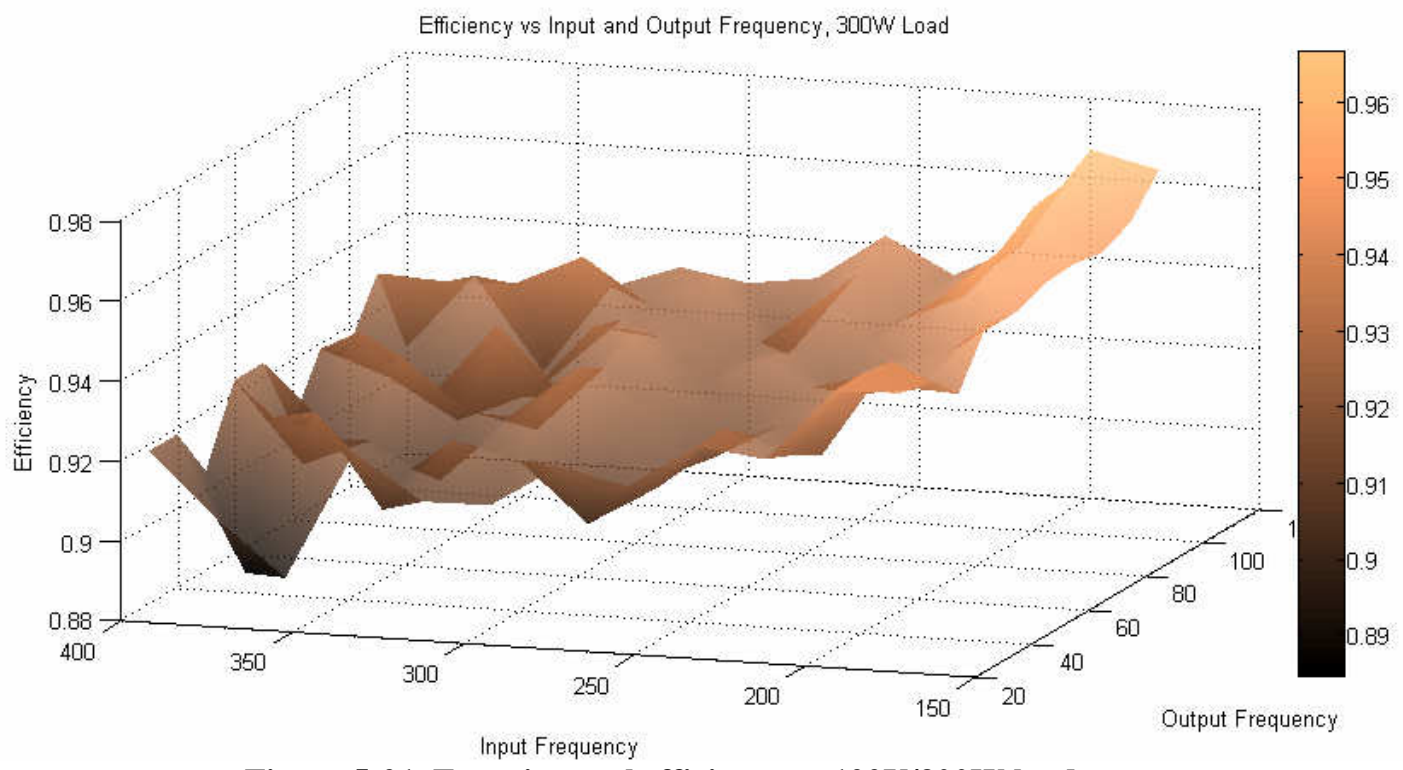

Figure 5-21. Experimental efficiency at 122V/300W load

Efficiency also decreases with increasing frequency due to more switching loss.

Efficiency decreases with increasing load due to the reduction of the switching loss to output power ratio. All of this is explained in greater detail in Section 4-4. The maximum deviation at any given point is approximately $4 \%$. 


\subsection{Analysis Case 1: Changing Output Frequency}

The three-dimensional plots from Section 5-3 and Section 4-4 mainly show raw data. It is not an easy task to correlate the different power quality parameters with varying frequencies and loads. The most straightforward way to understand the effect of different parameters is to take slices of the three-dimensional plots. In other words, either the input or output frequency, or load is fixed. Then one of the remaining variables is swept in intervals. The first case observes a nominal load of $200 \mathrm{~W}$. This case is representative of a cycloconverter being operated at a given load and the user having the choice of different output frequencies. One application is a variable speed drive.

Figure 5-22 shows the input power factor plot. Changing the output frequency makes little to no difference in power factor at any given input frequency. This plot emphasizes the 0.05 power factor deviation at lower input frequencies to the 0.2 power factor deviation at higher input frequencies. The reason behind these deviations is explained in Section 5-3.

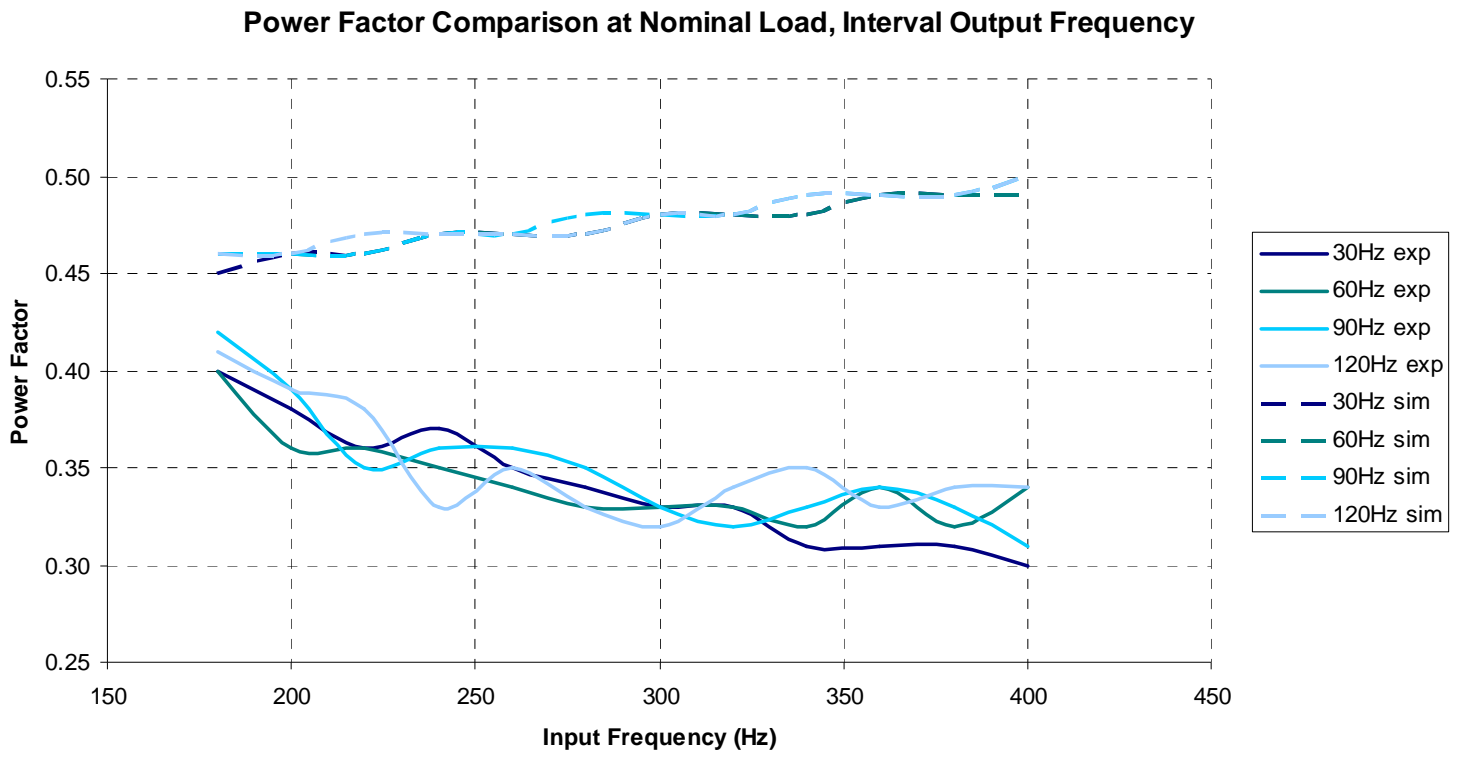

Figure 5-22. Input power factor comparison at 200W load, interval output frequency 
Figure 5-23 shows the input THD plot. The simulation curves show little deviation between different output frequencies. The experimental curves show slight variation. THD appears to peak when the input frequency is twice the output frequency. The main point to observe is that by operating the cycloconverter away from this peak, the expected THD is less than 55\%. The $70 \%$ range from simulation appears to be a worst-case scenario.

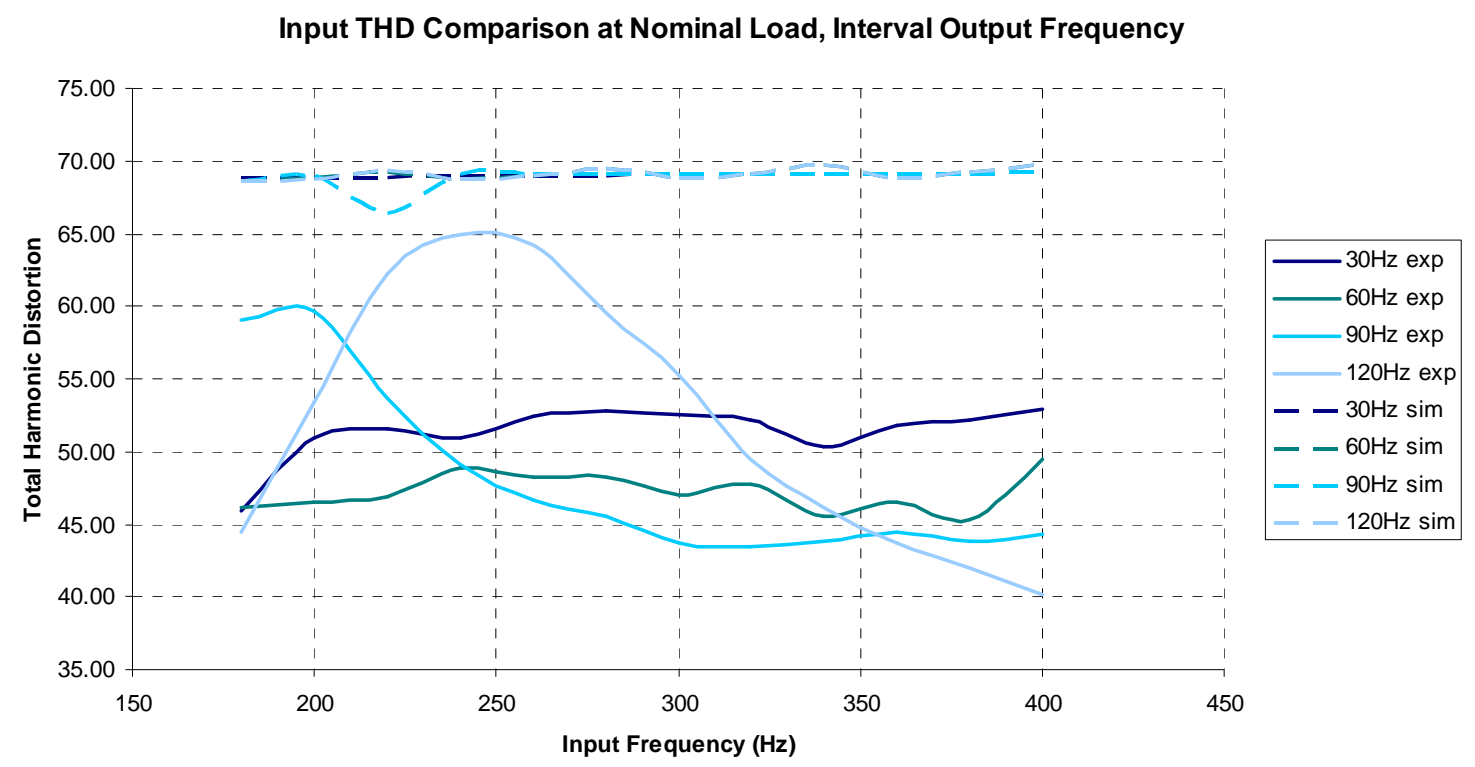

Figure 5-23. Input THD comparison at $200 \mathrm{~W}$ load, interval output frequency

The output THD plot is shown in Figure 5-24. Output frequency selection has little effect on the output THD. Although there is large experimental fluctuation, the average of the experimental output THD curves very closely matches the simulation curves. In this sense, it can be said that the expected output THD is about $45 \%$ on average. Depending on the particular input frequency, this THD can be instantaneously greater or lower. The THD can be improved by adding an LC filter on the output at the small expensive of efficiency. 


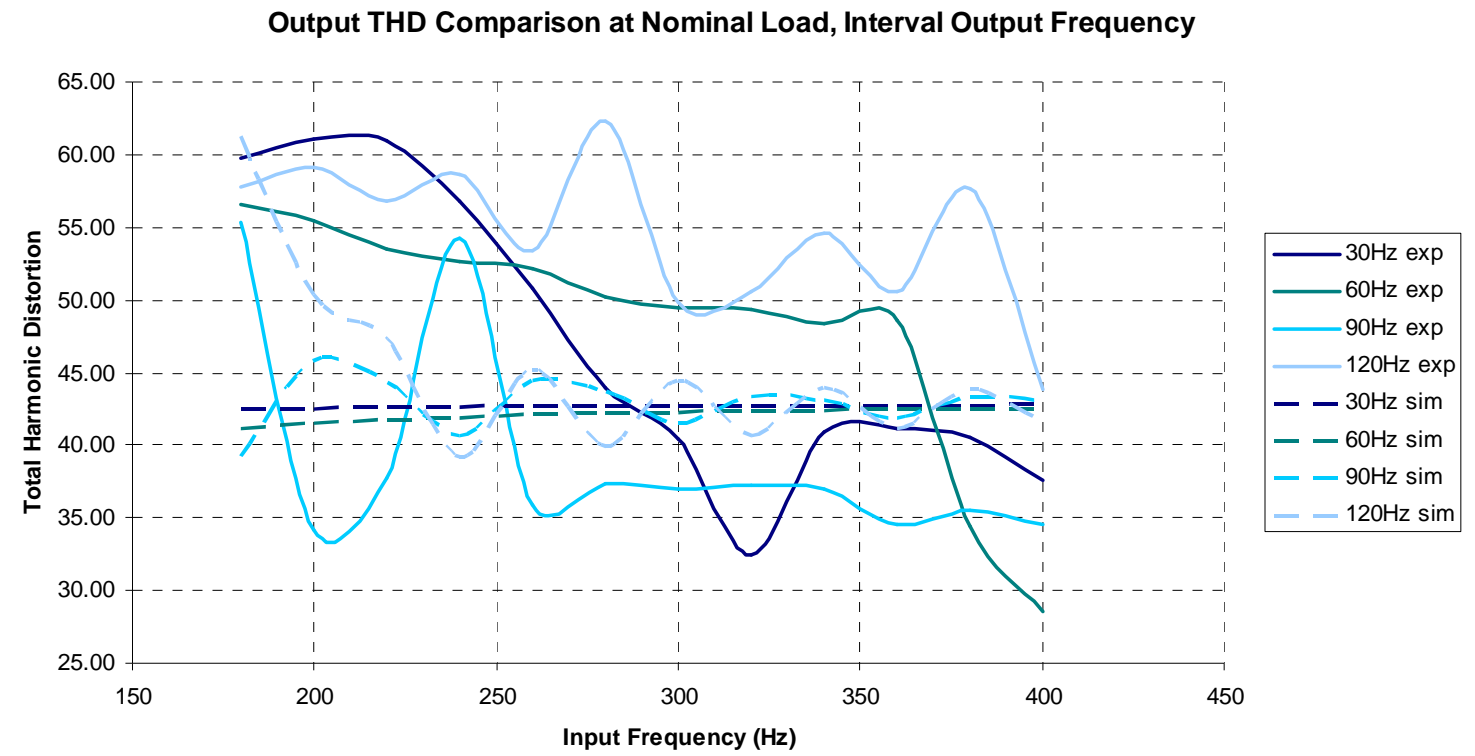

Figure 5-24. Output THD comparison at 200W load, interval output frequency

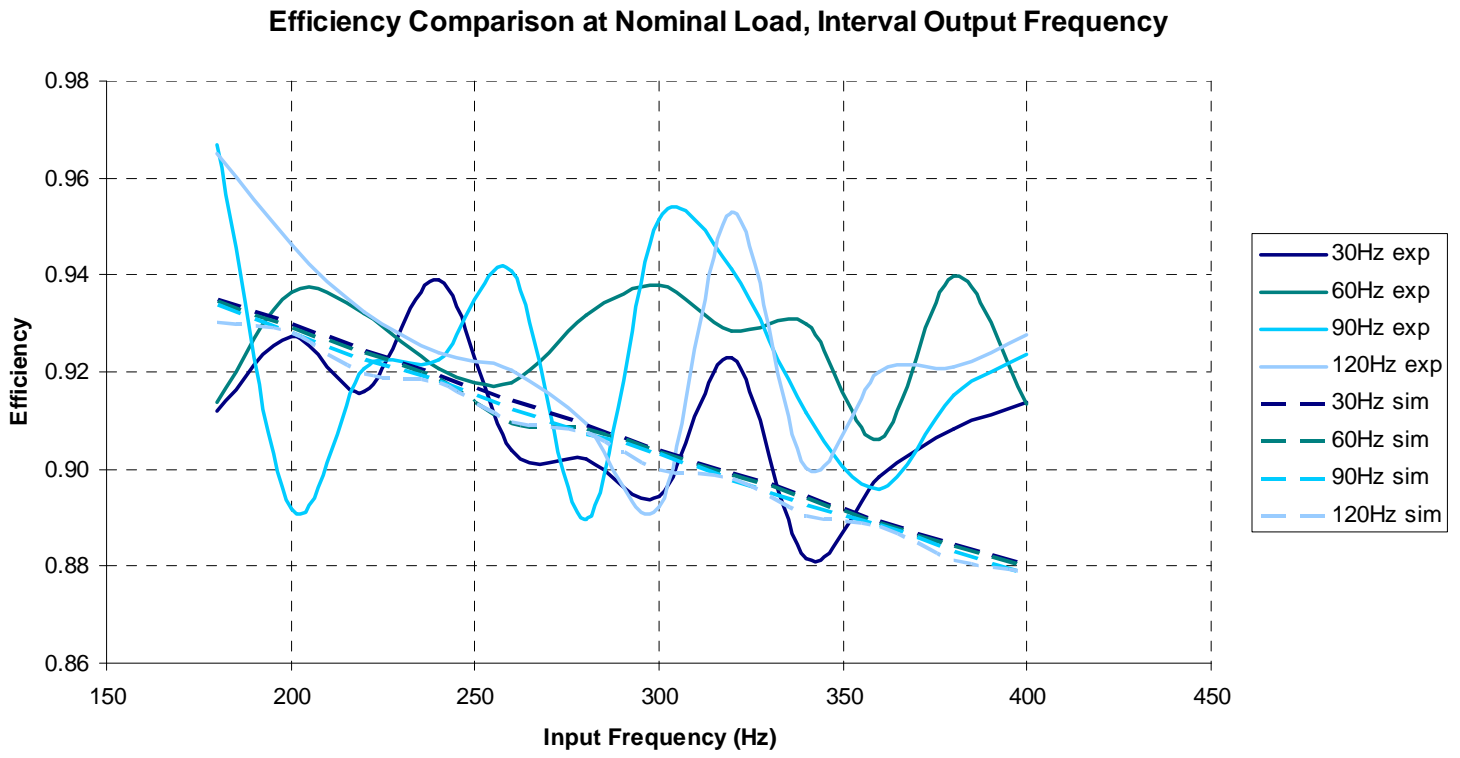

Figure 5-25. Efficiency comparison at 200W load, interval output frequency

One point to note is that the THD grows when there is low output frequency and high input frequency. This appears in both simulation and hardware.

Finally, the efficiency plot is shown in Figure 5-25. Changing the output frequency translates into little change in efficiency. Instantaneous experimental 
efficiency is within a few percent of the simulation efficiency at any input frequency. This is fully expected according to earlier analysis. Therefore, if the user has control over output frequency, there is little reason to select a higher frequency over a lower frequency or vice versa in regards to efficiency. This also applies for all of the other measurement parameters.

\subsection{Analysis Case 2: Changing Input Frequency}

The second case also observes a nominal load of $200 \mathrm{~W}$. This case is representative of a cycloconverter being operated at a constant load and the user having the choice of different input frequencies. Figure 5-26 shows the input power factor comparison plot. According to simulation, the input power factor slightly increases with increasing input frequency. The hardware tests show that the power factor slightly decreases with increasing input frequency. Overall, the power factor has a minimum value of 0.3 but should generally be higher.

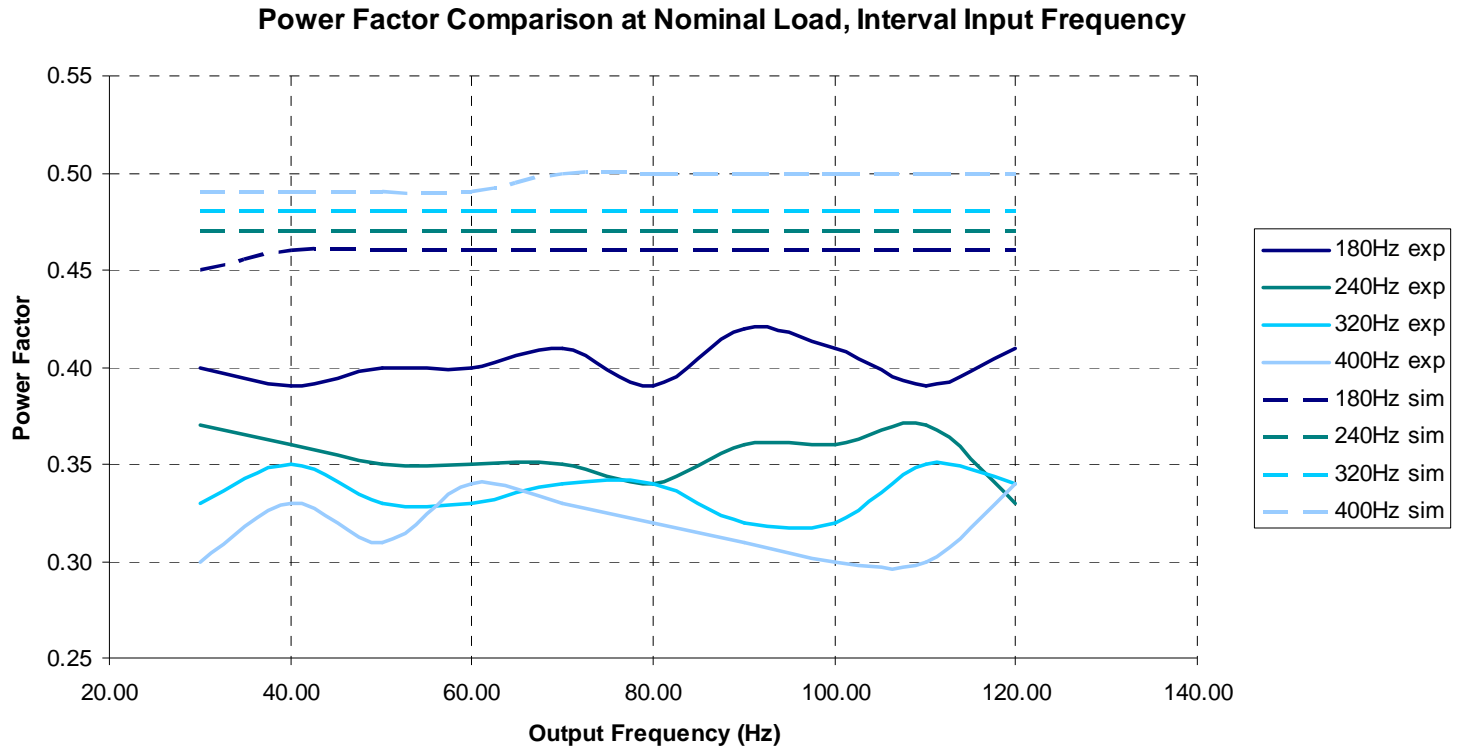

Figure 5-26. Input power factor comparison at $200 \mathrm{~W}$ load, interval input frequency 
Next is total harmonic distortion. Both THD trends are very similar to what was observed in Section 5.4. Input THD is plotted in Figure 5-27. When the output frequency is not close to half the input frequency, experimental THD was less than 55\%. Once again, the simulated input THD curves can be thought of as a worst-case scenario.

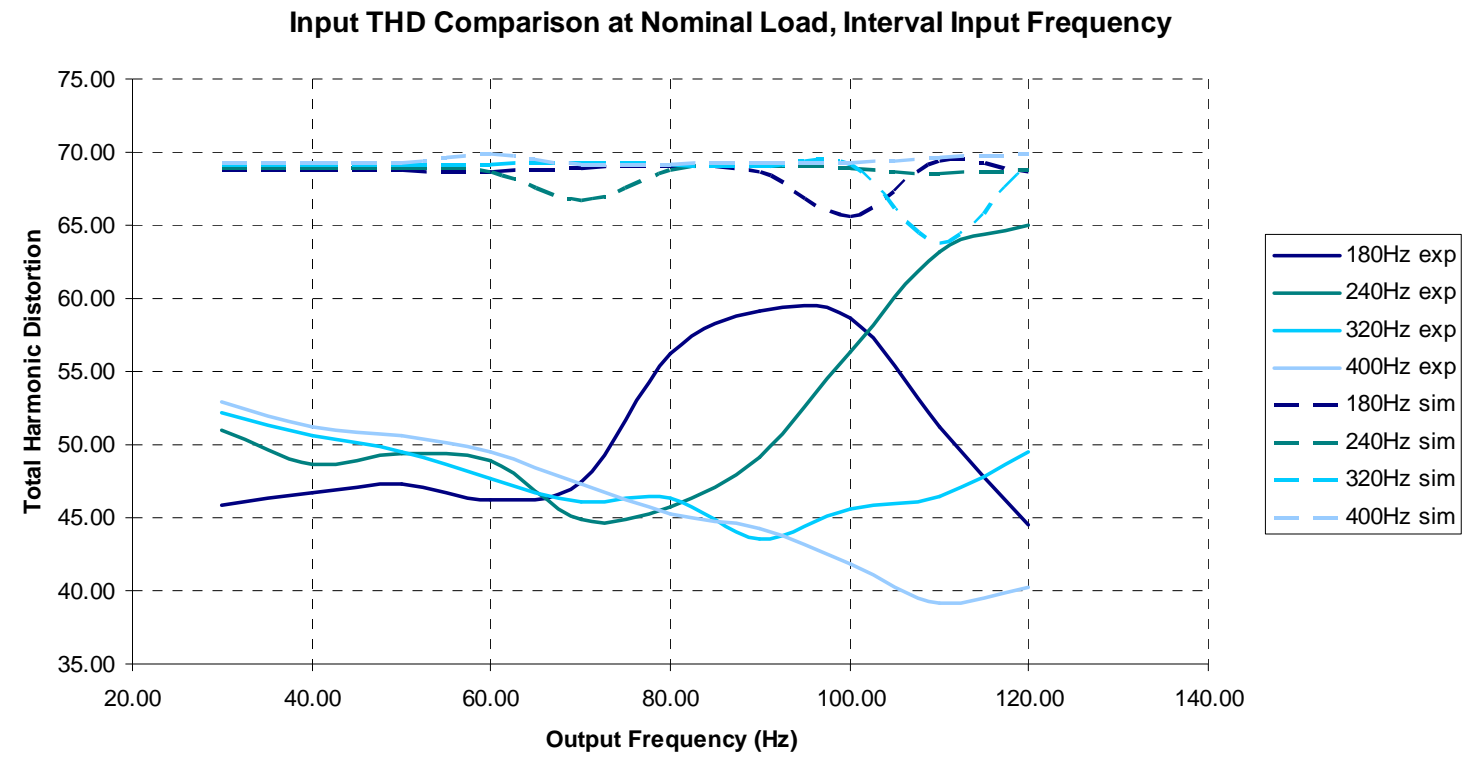

Figure 5-27. Input THD comparison at 200W load, interval input frequency

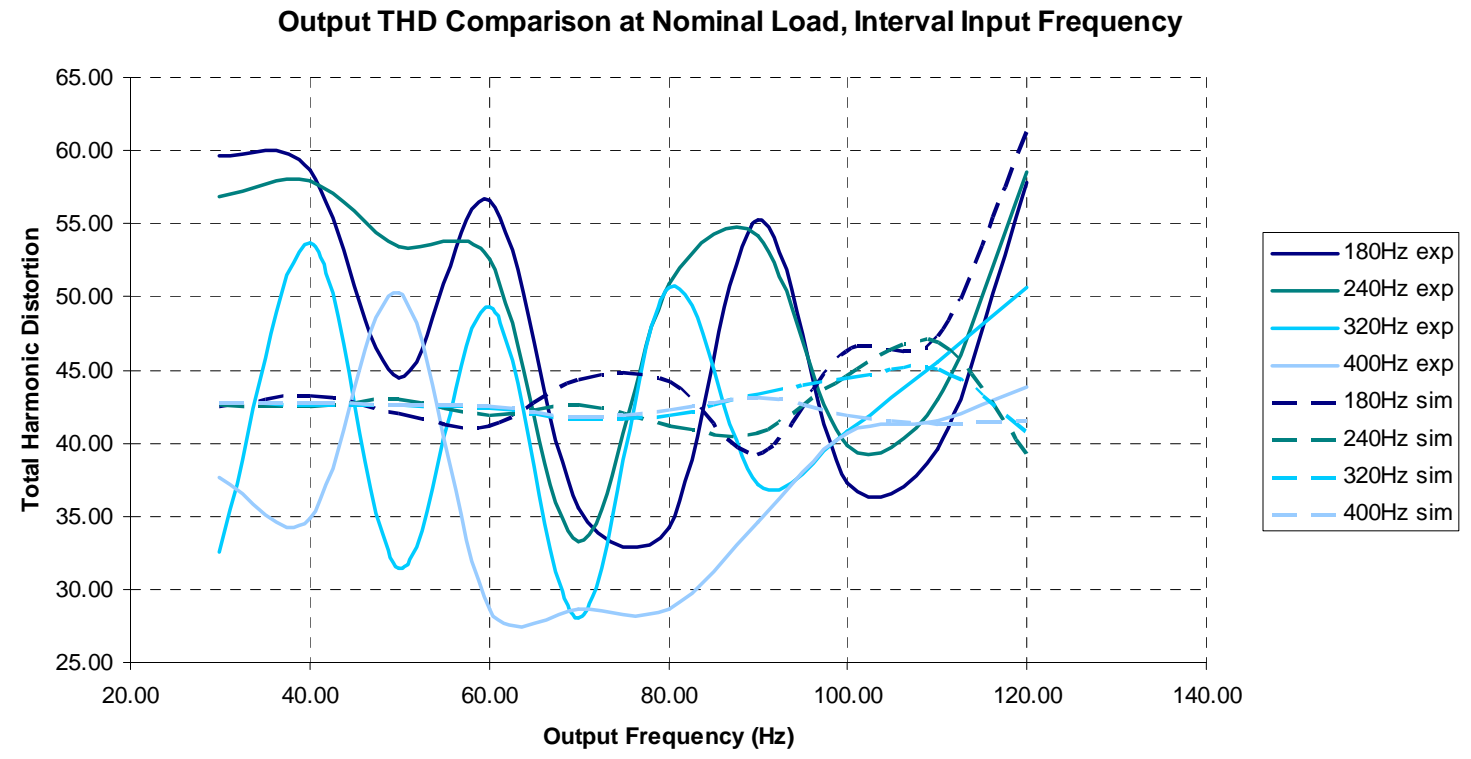

Figure 5-28. Output THD comparison at 200W load, interval input frequency 
Output THD is also identical to the previous case. This is shown in Figure 5-28. The THD increases significantly at both high input frequency and low output frequency. The best recommendation is to avoid this region of operation.

Efficiency is plotted in Figure 5-29. It is shown through both simulation and hardware that efficiency decreases with higher input frequency. There are experimental fluctuations on the order of a few percent of the simulation results. It can be concluded that if the user has control over input frequency, lower frequencies are desired to minimize the switching losses. The only foreseeable problem with low input frequencies is combining them with relatively high input frequencies. This can result in large input and output THD values.

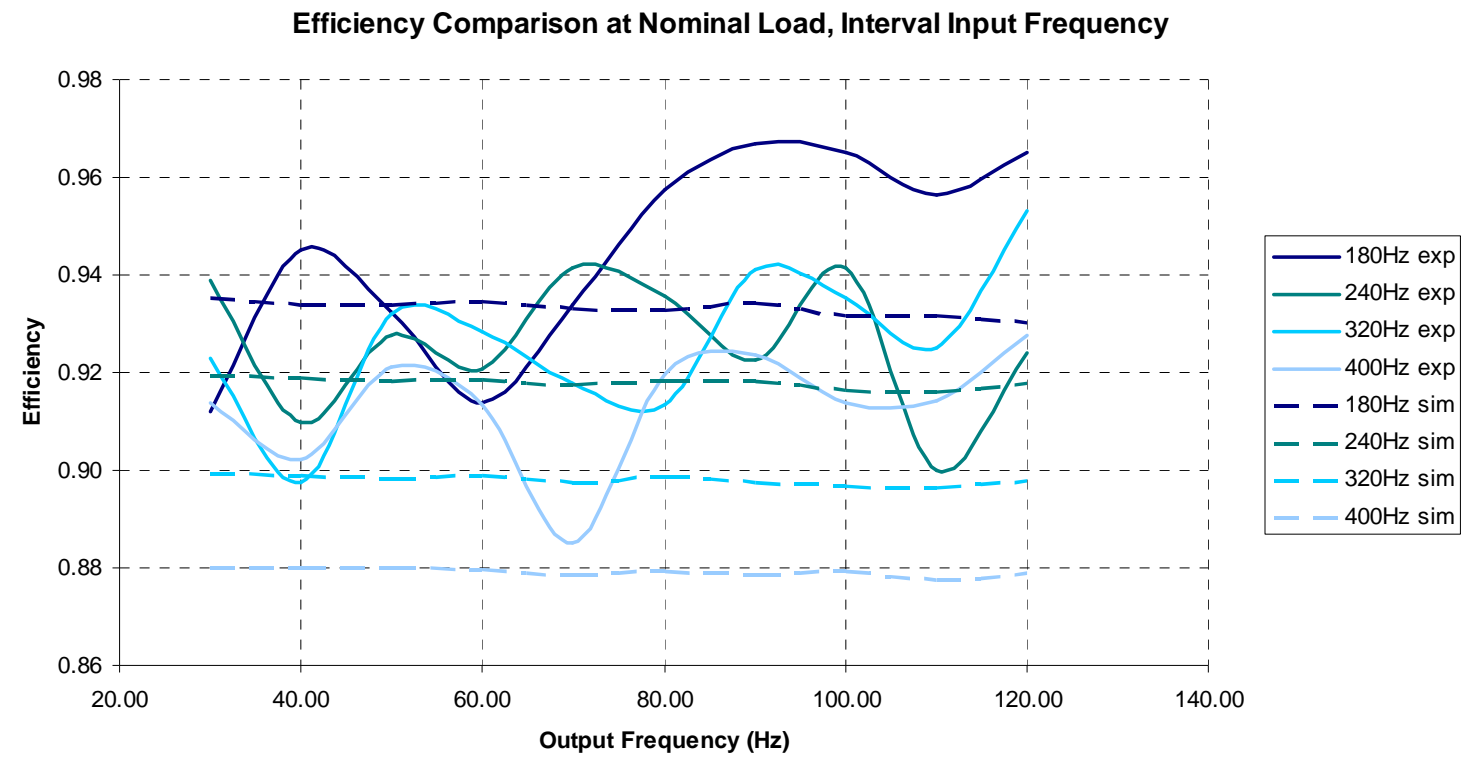

Figure 5-29. Efficiency comparison at $200 \mathrm{~W}$ load, interval input frequency 


\subsection{Analysis Case 3: Changing Load}

The last case deals with a fixed output frequency of $60 \mathrm{~Hz}$. The effect of varying output power will be observed. Figure 5-30 shows the effect of varying output power on input power factor. Increasing the load shows a decrease in power factor during simulation and an increase in power factor during the hardware test. Refer to Section 5-3 for the explanation for these discrepancies.

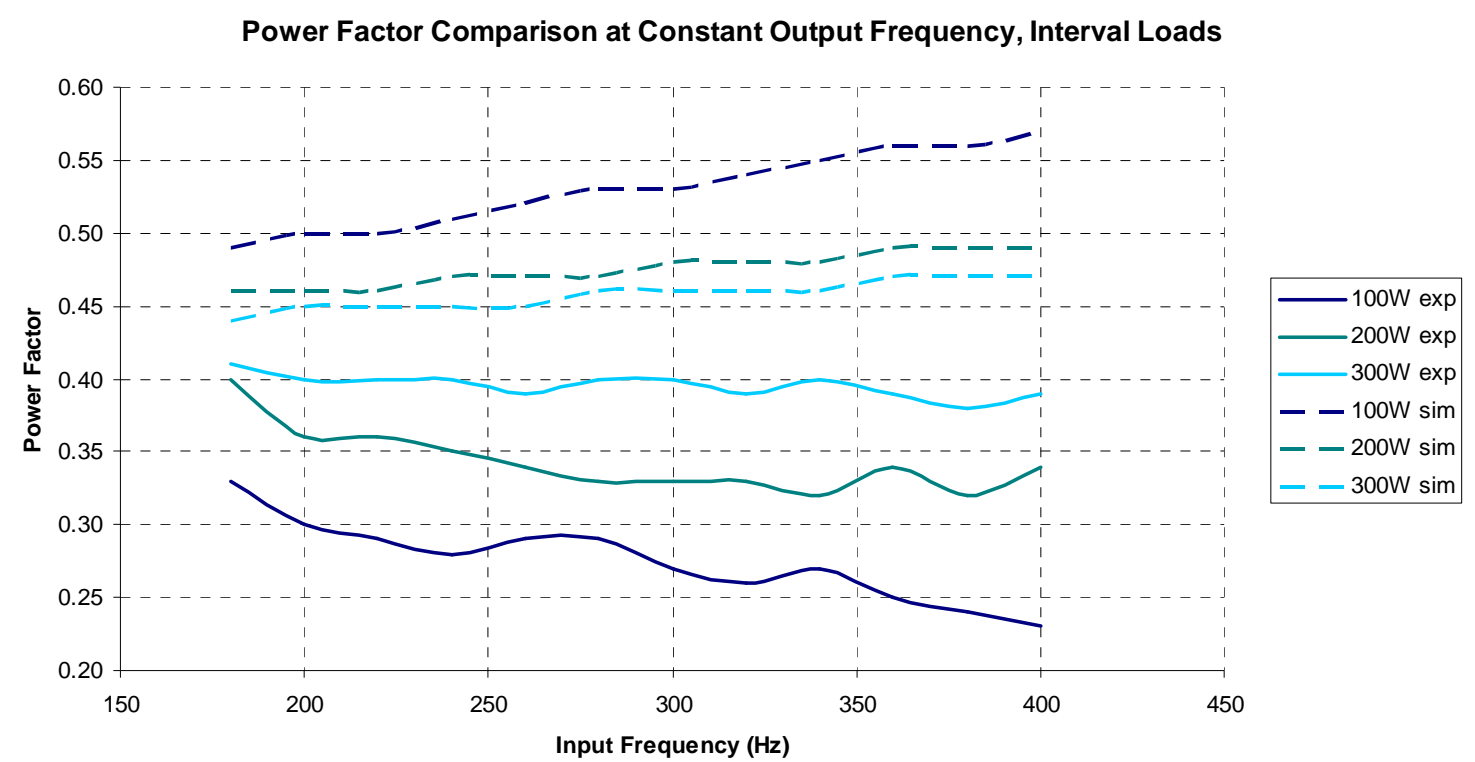

Figure 5-30. Input power factor comparison at $60 \mathrm{~Hz}$ output, interval loads

The following plots of input THD and output THD are shown in Figure 5-31 and

Figure 5-32 respectively. Input THD shows little variation with load changes. The only point to note is a $20 \%$ difference between simulation and experimental curves. Output THD shows large instantaneous fluctuations similar to the plots in Section 5-4 and Section 5-6. The average of these fluctuations is in line with the simulation output THD average of $43 \%$. 


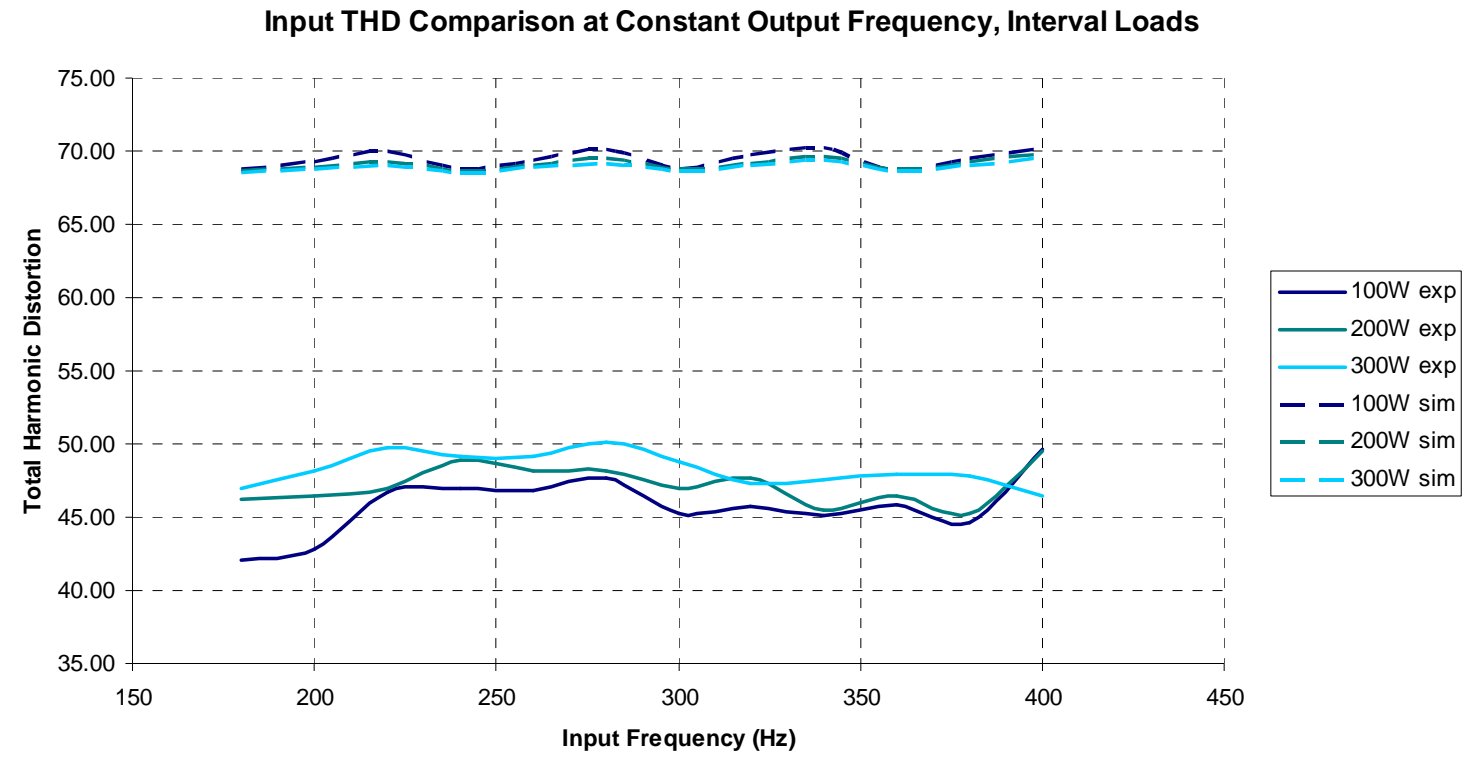

Figure 5-31. Input THD comparison at $60 \mathrm{~Hz}$ output, interval loads

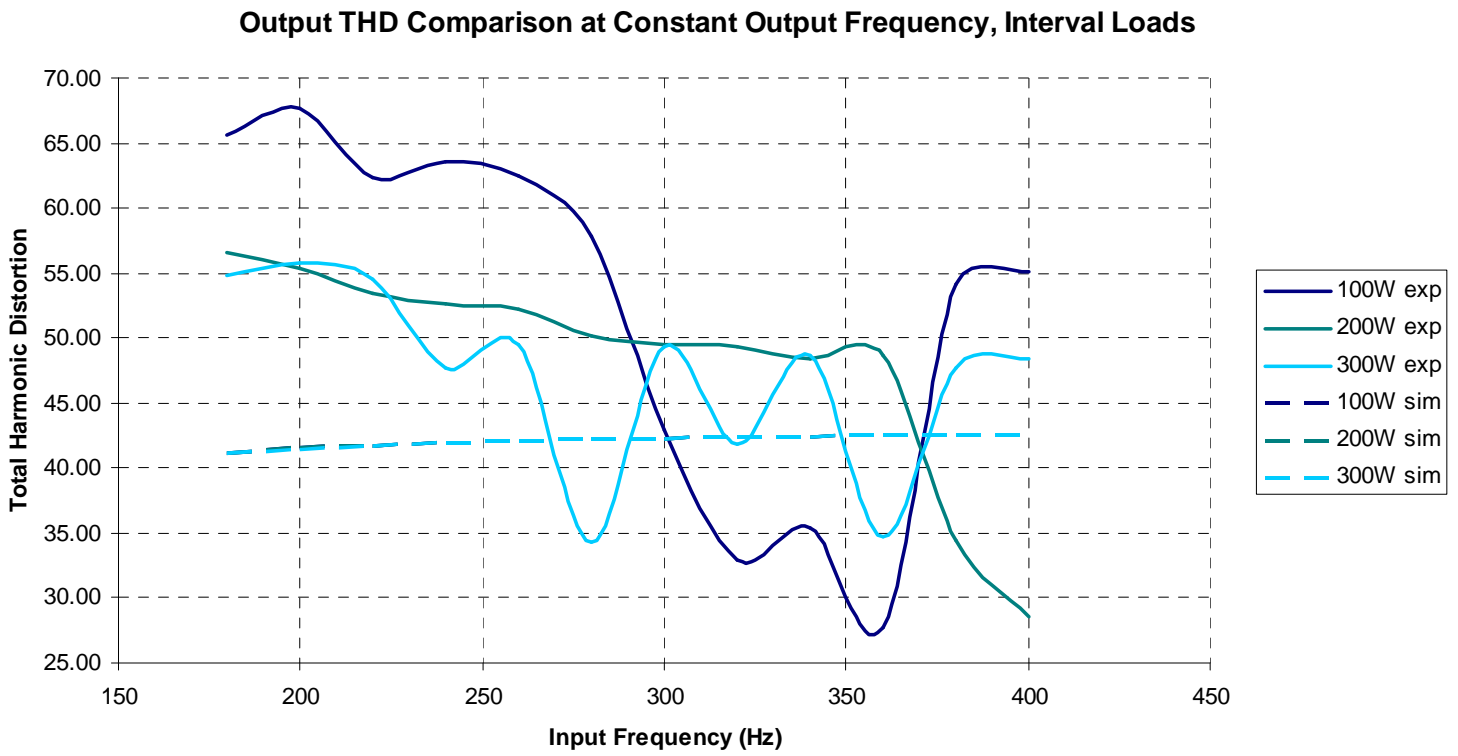

Figure 5-32. Output THD comparison at $60 \mathrm{~Hz}$ output, interval loads 


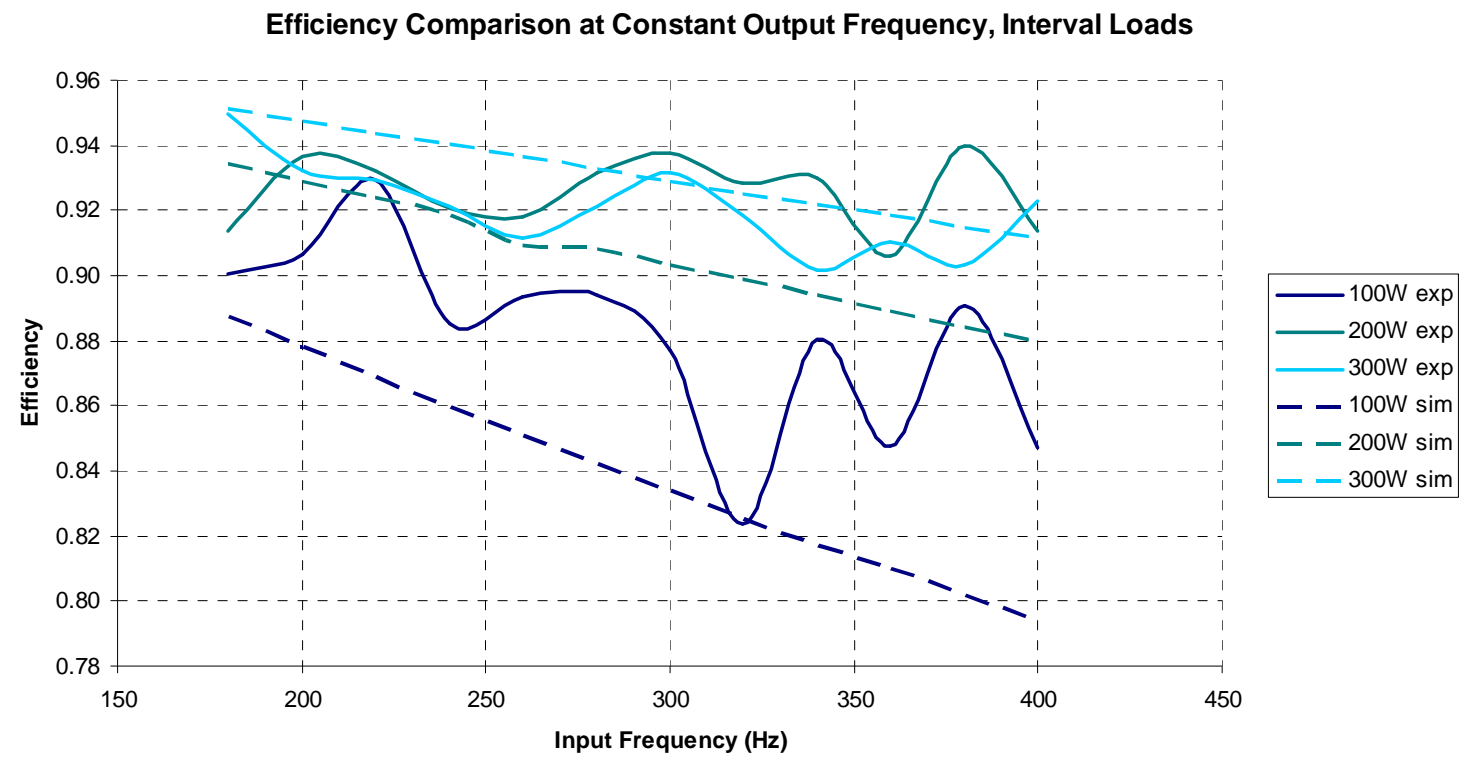

Figure 5-33. Efficiency comparison at $60 \mathrm{~Hz}$ output, interval loads

Figure 5-33 shows the effect on efficiency due to varying load. The results distinctly show that larger loads increase efficiency. Note that the change between each load is not linear. Increasing the load from $100 \mathrm{~W}$ to $200 \mathrm{~W}$ yields an efficiency improvement of $6 \%$ on average. Increasing the load from $200 \mathrm{~W}$ to $300 \mathrm{~W}$ yields an improvement of $3 \%$ on average. The main recommendation is to operate the cycloconverter with a load of at least $200 \mathrm{~W}$ in order to maintain efficiency above $90 \%$. Since cycloconverters tend to operate in the kilowatt to megawatt range, this should not be a problem. 


\section{Conclusion}

When people think of power electronics, power quality is one of the first things that come to mind. Parameters such as efficiency and total harmonic distortion are useful in determining the performance of a system. Power quality has been extensively studied for DC-DC converters, AC-DC converters, and DC-AC converters. Limited research has been performed on AC-AC converters. Two-step DC-link converters have not been extensively analyzed as a system, but they are composed of rectifiers and inverters that have been fully researched. This leaves the single-step cycloconverter with little in-depth power quality analysis. The cycloconverter has been widely used for many decades in mostly high power applications.

Power quality analysis of the cycloconverter is important because of different operating parameters. The two main parameters are input frequency and output frequency. For example, a user may want to design a cycloconverter to convert a constant frequency input to a constant frequency output. There are also cases in which the input frequency is not constant such as a wind turbine. Then there are cases in which the output frequency must be changeable such as a variable speed drive. In addition to frequency, the cycloconverter output load may also be variable. The main question is how these operating parameters correlate to the performance of the cycloconverter.

Based on simulation and experimental data, various trends can be observed. The power quality parameters of interest are power factor, total harmonic distortion, and efficiency. Varying the output frequency minimally affects the power quality parameters. The main reason is that output frequency only changes the conduction period of the 
positive and negative converter bridges. Since two switches are always conducting at six times the input frequency, it is understandable that there will be little change to performance. In terms of varying input frequency, there are more distinct trends. Power factor slightly changes with input frequency. Both input current THD and output voltage THD remain roughly constant. Efficiency decreases at higher input frequencies as a result of greater switching losses. Varying the load has a similar effect to varying the input frequency for power factor and total harmonic distortion. Efficiency tends to increase as the load increases, since the output power to switching loss ratio increases.

There are a few recommendations to be considered when designing a three-phase to single-phase cycloconverter. First, it is more beneficial to operate the cycloconverter at larger loads since there is higher efficiency with minimal adverse effects on power factor. In addition, it is not a good idea to have a very high input frequency. This results in lower efficiency due to greater switching losses. The next point is to maintain at least a 3:1 input frequency to output frequency ratio. The problem when the input frequency is approximately twice the output frequency is that the input current THD as well as the output voltage THD encounters an undesirable peak. In other words, coupling a high output frequency with a low input frequency should be avoided.

There are a few problems encountered while executing the hardware tests. The first is the measurement fluctuations of the PowerSight and Fluke power quality analyzers. A simple way to alleviate this is by taking an average of many readings, which increased the time necessary to record the data. Although the experimental data exhibits some of these fluctuations, the data on average correlates well with the simulation data. Another problem is that the Nexys board and Enerpro firing boards are 
not perfectly synchronized with each other. There is no feedback loop relaying the status of the firing boards back to the Nexys board, which greatly simplified the control system. The downside is a time-varying phase difference between the input and output waveforms that cannot be compensated for. This causes noticeable measurement fluctuations as the waveforms are never perfectly consistent. A better approach would be to integrate firing angle control and converter bridge control together. The converter bridge conduction intervals can then synchronize with the switching conduction intervals, reducing phase anomalies of the output waveform.

Although the results are satisfactory, there is room for additional research. The cycloconverter has been tested in its most straightforward form. It would be interesting to observe the power quality of a cycloconverter with at least a second order output filter. The total harmonic distortion at the output would definitely improve as a result of the filter, with possible increase in input power factor. It was shown in Chapter 2 that the cosine wave crossing method of determining firing angles can result in a cleaner frequency spectrum. It would also be interesting to observe power quality with this variation of the cycloconverter. However, a more advanced controls circuit will be needed. Overall, the results of this project serve as guidelines for designing a three-phase to single-phase cycloconverter in order to optimize power quality. 


\section{BIBLIOGRAPHY}

[1] Bose, B. K. Power Electronics and AC Drives. Englewood Cliffs: Prentice-Hall, 1986. Print.

[2] "Cycloconverters." Industrial Electronics Information for Manufacturing Applications. 29 Aug. 2008. Web. 28 May 2010. <http://www.industrialelectronics.com/Industrial_Power_Supplies_Inverters_and_Converter/25_Cycloc onverters.html>.

[3] "Harmonics in Polyphase Power Systems." All About Circuits. Web. 28 May 2010. <http://www.allaboutcircuits.com/vol_2/chpt_10/7.html>.

[4] Hunter, Gregory Peter. "Low Cost Cycloconverter Induction Motor Drives Using New Modulation Techniques." University of Technology, Sydney. 1997. Web. 28 May 2010. 〈http://services.eng.uts.edu.au/ gregh/thesis.pdf>.

[5] Kassakian, John G., Martin F. Schlecht, and George C. Verghese. Principles of Power Electronics. Reading: Addison-Wesley Publishing Company, 1991. Print.

[6] Krein, P. T., Xin Geng, and R. Balog. "High-Frequency Link Inverter Based on Multiple-Carrier PWM." University of Illinois at Urbana-Champaign. Web. 28 May 2010. <http://www.ece.tamu.edu/ rbalog/publications/APEC02_fnl.pdf>.

[7] McMurray, William. The Theory and Design of Cycloconverters. Cambridge: MIT Press, 1972. Print.

[8] Ozpineci, Burak, and Leon M. Tolbert. "Cycloconverters." University of Tennessee-Knoxville. Web. 28 May 2010. $\langle$ http://www.uv.es/emaset/descargas/cycloconvertertutorial.pdf $>$.

[9] Pelly, B. R. Thyristor Phase-Controlled Converters and Cycloconverters. New York: Wiley-Interscience, 1971. Print.

[10] "Power System Harmonics." Pacific Gas and Electric Company. Jan. 1993. Web. 28 May 2010.

$<$ http://www.pge.com/includes/docs/pdfs/mybusiness/customerservice/energystat us/powerquality/harmonics.pdf>.

[11] Ramaswamy, Venkat. "A Single SCR Circuit." University of Technology, Sydney. Web. 28 May 2010.

<http://services.eng.uts.edu.au/ venkat/pe_html/ch03s1/ch03s1p1.htm〉.

[12] Rashid, Muhammad H. Power Electronics: Circuits, Devices, and Applications. 3rd ed. Upper Saddle River: Pearson Prentice Hall, 2004. Print. 
[13] Rashid, Muhammad H. Power Electronics Handbook. N.p.: Academic Press, 2001. Google Books. Web. 28 May 2010.

<http://books.google.com/books?id=072rwRgFpcgC\&lpg=PA316\&ots=o6EkGO Qy7_\&dq=single\%20phase\%20ycloconverter\%20firing\%20angles\&pg=PA316\# $\mathrm{v}=$ onepage $\& \mathrm{q} \& \mathrm{f}=$ false $>$.

[14] "SCHEMATIC DIAGRAM: VARIABLE FREQUENCY 3-PHASE FIRING CIRCUIT." Enerpro, Inc. 8 Nov. 2007. Web. 28 May 2010.

$<$ http://www.enerpro-inc.com/pdfs/E445H\%20FCOVF6100\%20v.\%2011-0807.pdf $>$.

[15] "SKKT 92." Semikron. 3 Sept. 2004. Web. 28 May 2010. <http://www.semikron.com/internet/gecont/pdf/325.pdf>.

[16] "SPICE Models: Diodes and Rectifiers." All About Circuits. Web. 28 May 2010. <http://www.allaboutcircuits.com/vol_3/chpt_3/14.html>.

[17] Taufik. "Advanced Power Electronics." Lecture Notes. $3^{\text {rd }}$ revision, 2009.

[18] Taufik. "Introduction to Power Electronics." Lecture Notes. $6^{\text {th }}$ revision, 2008.

[19] "The Silicon-Controlled Rectifier (SCR)." All About Circuits. Web. 28 May 2010. <http://www.allaboutcircuits.com/vol_3/chpt_7/5.html>.

[20] "Variable Frequency Three Phase Thyristor Firing Board Model FCOVF6100." Enerpro, Inc. 4 Dec. 2006. Web. 29 May 2010. <http://www.enerproinc.com/pdfs/PD721\%20FCOVF6100ver12-04-06.pdf>. 